\title{
Padrões de Abundâncias entre Estrelas Muito Pobres em Metais no Halo da Galáxia
}

\section{Vinicius Moris PlacCO}

Orientadora: $\mathrm{PrOF}^{a}$. DR ${ }^{a}$. Silvia Rossi

Universidade de São Paulo

Instituto de Astronomia, Geofísica e Ciências Atmosféricas 

Padrões de Abundâncias entre Estrelas Muito Pobres em Metais no Halo da Galáxia 



\title{
Padrões de Abundâncias entre Estrelas Muito Pobres em Metais no Halo da Galáxia
}

\author{
Vinicius Moris PlacCO
}

Orientadora: $\mathrm{ProF}^{a} \cdot \mathrm{Dr}^{a}$. Silvia Rossi

Dissertação apresentada ao Departamento de Astronomia do Instituto de Astronomia, Geofísica e Ciências Atmosféricas da Universidade de São Paulo como parte dos requisitos para a obtenção do título de Mestre em Astronomia.

2007

Universidade de São Paulo

Instituto de Astronomia, Geofísica e Ciências Atmosféricas 




\section{AGRADECIMENTOS}

À minha família (Inez, Sylvio, Ju e Má), pelo imenso apoio e por acreditar que, desde o curso de Física, todo meu esforço não seria em vão;

À Carol, que nesses mais de quatro anos juntos nunca me deixou entristecer, e sempre esteve perto para me animar quando precisei;

À Silvia, que hoje considero como minha segunda mãe, pelos anos de trabalho, amizade, e por acreditar na minha capacidade;

Aos pesquisadores: Timothy Beers, por me receber em seu instituto, pelas orientações e pela grande ajuda com a análise dos dados; Sara Lucatello, por gentilmente ceder parte dos dados e sugestões para que o trabalho ficasse mais completo; Paul Barklem, por esclarecer algumas das minhas dúvidas quanto à análise;

À Professora Lúcia Pereira Barroso e à aluna Maísa Almeida de Mesquita, do Departamento de Estatística no Instituto de Matemática e Estatística da USP, pelo auxílio com as ferramentas estatísticas utilizadas neste trabalho;

Aos colegas: Alessandro Pereira Moisés, pela enorme ajuda com a revisão do texto; Rafael Kimura, por "encontrar" o computador que utilizei durante todo o mestrado;

Aos colegas da pós-graduação do IAG (Alan, Alessandro, Felipe, José Fernando, Márcia, Márcio Avellar, Márcio "Tiozinho” Barreto, Monique, Oscar, Patrícia, Rafael Kimura, Rodrigo Holanda, Rodrigo Vieira, Tiago Almeida, entre outros), pelas conversas descontraídas no "bandex" e nas "paradas para o café", que sempre renderam boas risadas;

Aos docentes do IAG, que através das disciplinas de pós-graduação do Departamento de Astronomia, contribuíram para minha formação acadêmica;

A todo o pessoal do IAG: secretaria (Marina, Walquiria, Conceição, Ana, Regina), informática (Marco, Ulisses, Luís, Patrícia), CPG, portaria, limpeza, gráfica, café, segurança e administração, que proporcionaram um excelente ambiente de trabalho e estudo durante todo o período; 
À FAPESP, pelo apoio financeiro, sob o projeto $n^{o}:$ 2005/01023-8;

Às Instituições: JINA (Joint Institute for Nuclear Astrophysics), CSCE (Center for the Study of Cosmic Evolution) e MSU (Michigan State University);

A todos aqueles que, por falha de memória, não foram citados, mas que de alguma forma contribuíram para que este trabalho fosse concluído;

Muito obrigado! 
"You create your own Universe as you go along"

Winston Churchill

"O verdadeiro lugar de nascimento é aquele em que, pela primeira vez, se lança um olhar inteligente sobre si mesmo"

Marguerite Yourcenar 


\section{RESUMO}

Um dos maiores desafios da Astrofísica é tentar compreender a complexidade da composição química das estrelas. Elementos com massas atômicas acima de A 60 são formados pelos chamados processos de captura de nêutrons (processo-s e processo-r). A presença destes em espectros de estrelas de baixa massa (longo período de vida) e com pouco conteúdo metálico sugere episódios de enriquecimento por estrelas massivas nos

primórdios da Galáxia. Portanto, o estudo das estrelas chamadas "pobres em metais" enriquecidas por elementos formados por captura de nêutrons pode reproduzir as condições físicas dominantes à época de sua formação.

O objetivo deste trabalho é explorar os padrões de abundâncias das estrelas muito pobres em metais observadas no survey HERES. Através deste estudo, é possível inferir correlações entre elementos químicos e restringir a operação dos processos de captura de nêutrons na Galáxia. Para tanto, utiliza-se técnicas estatísticas como a análise de conglomerados, que permite o estudo da formação de grupos naturais baseado na relação entre as abundâncias elementais.

Este estudo fornece uma análise compreensiva de uma amostra de 382 estrelas pobres em metais, além de introduzir duas novas subclasses para estrelas pobres em metais enriquecidas em elementos formados por captura de nêutrons. 


\begin{abstract}
One of the most challenging subjects of Astrophysics is trying to understand the complexity of the chemical composition of stellar objects. Spectroscopic observations are widely used nowadays in order to achieve these goals, as they provide the chemical composition of the atmosphere of the stars.

Elements with atomic masses above A 60 are formed by the so called neutron capture processes (r-process and s-process). Its presence on low-mass star spectra (which have long life-time) and low metal content suggests episodes of enrichment by high-mass stars that took place in the early times in the Galaxy formation. Then, the study of those "metal-poor" stars enriched by neutron-capture elements may help reproduce the physical conditions of the environment from where they were formed.

The main goal of this project is to explore the abundance patterns of the very metalpoor stars observed by the HERES survey. This study allows the analysis of the correlations between chemical elements and place some constraints on the operation of the neutron capture processes in the early Galaxy. This approach made use of statistical tools, such as agglomerative nesting, which can identify the formation of natural groups based on relations among elemental abundances.

In this context, this study provides a comprehensive analysis of a 382 metal-poor stars sample, and introduces two new subclasses for metal-poor stars with determined abundances of neutron-capture elements.
\end{abstract}




\section{SUMÁRIO}

1. Introdução . . . . . . . . . . . . . . . . . . . . . . . . 1

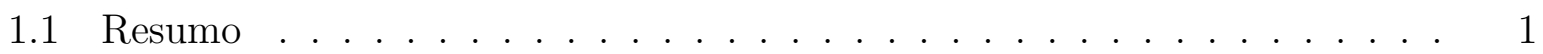

1.2 Estrelas pobres em metais . . . . . . . . . . . . . . . . . 3

1.2.1 Classificação . . . . . . . . . . . . . . . . . 4

1.2.2 Subclasses . . . . . . . . . . . . . . . . . . 4

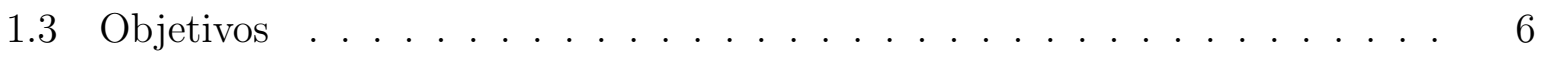

2. Processos de captura de nêutrons . . . . . . . . . . . . . . . . . . . . . . . . . . 7

2.1 Processo-s .................................. 7

2.1 .1 O processo lento . . . . . . . . . . . . . . 8

2.1.2 Distribuição exponencial e abundâncias no AGB . . . . . . . . . . . 11

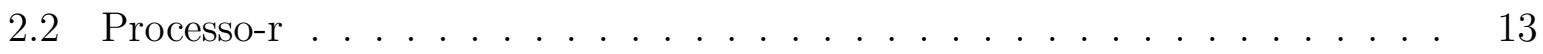

2.2 .1 Introdução . . . . . . . . . . . . . . . . . . . . . 14

2.2.2 O processo rápido . . . . . . . . . . . . . . . . 15

2.2.3 Waiting points e números mágicos . . . . . . . . . . . . . . . 16

3. Base de dados . . . . . . . . . . . . . . . . . . . . . . . . . . . . . . . . . . 19

3.1 O survey HERES . . . . . . . . . . . . . . . . . . . . . . . . . . 19

3.2 Caracterização da amostra . . . . . . . . . . . . . . . . 20

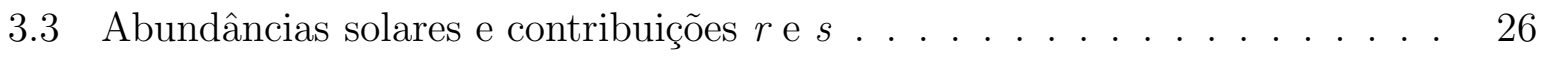

4. Análise . . . . . . . . . . . . . . . . . . . . . . . 31

4.1 Abundâncias elementais ...................... 33

4.2 Elementos formados por captura de nêutrons . . . . . . . . . . . . . . . . 38

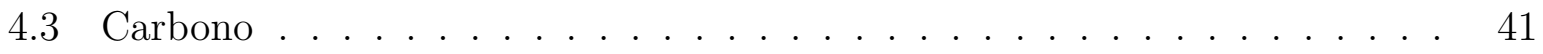

4.4 Enriquecimento químico . . . . . . . . . . . . . . . . . 45 
4.5 Análise de conglomerados . . . . . . . . . . . . . . . 51

4.5.1 $[\mathrm{Eu} / \mathrm{Fe}][\mathrm{Ba} / \mathrm{Fe}] \ldots \ldots \ldots . \ldots \ldots$

$4.5 .2[\mathrm{Eu} / \mathrm{Fe}][\mathrm{Ba} / \mathrm{Fe}][\mathrm{C} / \mathrm{Fe}][\mathrm{Sr} / \mathrm{Fe}] \ldots \ldots \ldots \ldots \ldots$

5. Padrões de abundâncias . . . . . . . . . . . . . . . . . . . . . . . . . 61

5.1 Estrelas $s \ldots \ldots \ldots \ldots$. . . . . . . . . . . . . . . . 62

5.1 .1 Objetos s-II . . . . . . . . . . . . . . 62

5.1 .2 Objetos s-I . . . . . . . . . . . . . . . . . 64

5.2 Estrelas $r / s \ldots \ldots \ldots \ldots \ldots$. . . . . . . . . . . . . . . . . . . . . .

5.3 Estrelas $r \ldots \ldots \ldots$. . . . . . . . . . . . . . . . 67

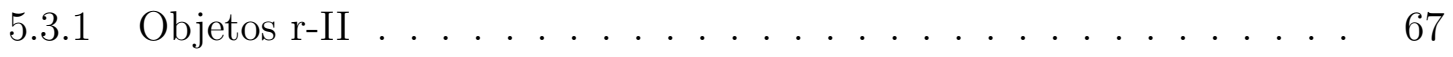

5.3 .2 Objetos $\mathrm{r}-\mathrm{I} \ldots \ldots \ldots \ldots \ldots$

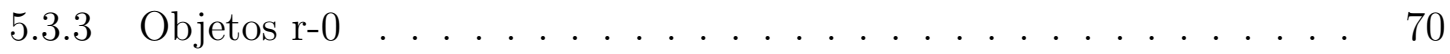

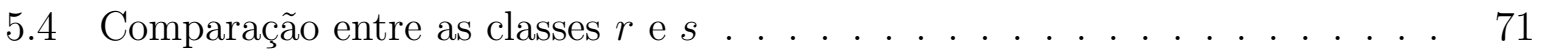

6. Conclusões e perspectivas . . . . . . . . . . . . . . . . . . . . 77

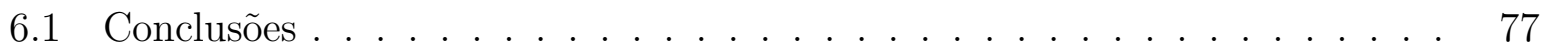

6.2 Perspectivas . . . . . . . . . . . . . . . . . . . . 79

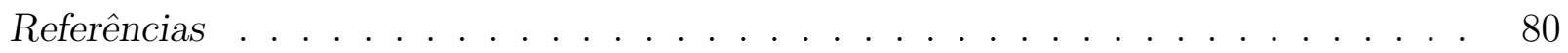

$\begin{array}{ll}\text { Apêndice } & 87\end{array}$

A. Ferramentas estatísticas . . . . . . . . . . . . . . . . . 89

A.1 Agrupamento hierárquico . . . . . . . . . . . . . . . . . . . . 89

A.1.1 Introdução . . . . . . . . . . . . . . . . . 89

A.1.2 Critério de parecença e método de Ward . . . . . . . . . . . . . . 90

A.2 Probabilidades e correlações . . . . . . . . . . . . . . . . . 92

A.2.1 Coeficiente de correlação . . . . . . . . . . . . . . 92

A.2.2 Valor $p . \ldots \ldots \ldots . \ldots \ldots 5$ 


\section{LISTA DE FIGURAS}

2.1 Abundâncias dos elementos químicos no Sistema Solar (segundo Grevesse \& Sauval 1998), indicando a faixa de ocorrência dos diferentes processos de nucleossíntese nas estrelas. Os elementos em vermelho são sintetizados por processo-r e os em azul por processo-s (fração maior que 50\% segundo Arlandini et al. 1999). . . . . . . . . . . . . . . . . . . 8

2.2 Produto da abundância pela seção de choque de captura em função do número de massa. A linha mais espessa representa a componente principal do processo-s e a linha mais fina a componente fraca. Figura adaptada de Kappeler et al. (1989). . . . . . . . . . . . . . . . . . . . . 10

2.3 Esquema da ocorrência dos pulsos térmicos. Os pulsos aparecem como linhas verticais devido à sua curta duração ( 300 anos) comparada com o período interpulsos ( $10^{4}$ à $10^{5}$ anos) - Pagel (1997). Figura adaptada de Wasserburg et al. (1994). . . . . . . . . . . . . . . . .

2.4 Plano prótons x nêutrons, mostrando a drip line dos nêutrons, onde a captura de nêutrons termina e tem início o decaimento $\beta$. Figura adaptada de http://www.pas.rochester.edu/ ${ }^{\sim}$ cline/Research/sciencehome.htm. . . . . . .

2.5 Plano prótons x nêutrons. Podemos notar que o r-process path muda seu comportamento quando se encontra nos locais de números mágicos de nêutrons. Figura retirada de http://www.europhysicsnews.com/. . . . . . . . . . . 18

3.1 Diagrama de identificação de estrelas $r$ e $s$ da amostra. Também são separadas as diferentes faixas de metalicidade dos objetos. . . . . . . . . . . 23

3.2 Distribuição de metalicidade da amostra. . . . . . . . . . . . . . . . . 25

3.3 Diagrama de Kiel: $T_{\text {eff }}$ vs. $\log (g)$. Nota-se que as estrelas com menor quantidade de carbono se concentram na parte superior (mais fria) do gráfico. 26 
3.4 Abundância solar para elementos com $\mathrm{Z}>30$. A linha verde representa a componente $r$ e a azul a componente $s$. As frações utilizadas foram retiradas de Arlandini et al. (1999). . . . . . . . . . . . . . . . . . .

3.5 Diferenças percentuais entre os trabalhos de Asplund et al. (2005) $\left(\log \left(\epsilon_{A}\right)\right)$ e Grevesse et al. (1998) $\left(\log \left(\epsilon_{G}\right)\right)$ para os elementos da amostra. . . . . . . 28

3.6 Comparação entre as contribuições do processo-r para alguns elementos cujas diferenças são maiores que $5 \%$ e para os elementos da amostra. A linha verde representa a distância entre os valores de Burris et al. (2000) e Arlandini et al. (1999). . . . . . . . . . . . . . . . . .

4.1 Diagrama de pares para os elementos químicos estudados neste trabalho. .

4.2 Abundâncias elementais para os elementos com número atômico $6<\mathrm{Z}<25$ presentes na amostra. Os círculos pretos indicam $[\mathrm{C} / \mathrm{Fe}] \geq+1.0$ e os triângulos indicam $[\mathrm{C} / \mathrm{Fe}]<+1.0 . \ldots \ldots \ldots \ldots$

4.3 Abundâncias elementais para os elementos com número atômico $27<\mathrm{Z}<63$ presentes na amostra. Os círculos pretos indicam $[\mathrm{C} / \mathrm{Fe}] \geq+1.0$ e os triângulos indicam $[\mathrm{C} / \mathrm{Fe}]<+1.0 . \ldots \ldots \ldots \ldots \ldots$

4.4 Abundâncias elementais para alguns elementos da amostra e comparação com objetos de outros estudos. As setas indicam limites superiores/inferiores para as abundâncias de alguns elementos. Os símbolos referem-se aos obje-

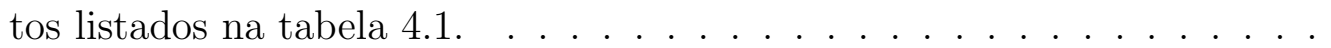

4.5 Comportamento das abundâncias em função da metalicidade para os elementos $\mathrm{Sr}$ e $\mathrm{Ba}(s)$ e $\mathrm{Eu}(r) \ldots \ldots \ldots \ldots$

4.6 Comportamento dos elementos formados por captura de nêutrons em relação à abundância de carbono. As linhas vermelhas representam a abundância solar para as razões e a linha pontilhada denota o limite para as estrelas $\operatorname{CEMP}([\mathrm{C} / \mathrm{Fe}]>+1.0$ - tabela 1.3$) . \ldots \ldots \ldots$

4.7 Comportamento das abundâncias de bário e carbono em relação à metalicidade. Também é mostrado, nos paineis da direita, o comportamento das subclasses $r$ e $s$ para os mesmo parâmetros. . . . . . . . . . . . . 
4.8 Razões entre elementos $s$ (primeiro e segundo picos) e $r(\mathrm{Eu})$ em função da abundância de carbono. A linha verde representa a componente do processos e a linha vermelha representa a componente do processo-r para as razões de elementos mostradas na parte inferior direita de cada gráfico. . . . . . .

4.9 Razões de abundâncias entre elementos $r$ e $s$. A linha verde (tracejada) representa o valor solar para o processo-s puro e a linha vermelha (cheia) o processo-r puro. Os diferentes símbolos discriminam intervalos de abundância do Eu (lado esquerdo) e as subclasses $r$ e $s$ (lado direito). . . . . . . . . .

4.10 Comparação entre o comportamento dos elementos do primeiro e segundo picos do processo-s com o Eu em relação à metalicidade. Os asteriscos denotam $[\mathrm{Ba} / \mathrm{Eu}]>0.0$ e os triângulos $[\mathrm{Ba} / \mathrm{Eu}] \leq 0.0$. A linha verde (tracejada) representa o padrão solar para o processo-s e a linha vermelha (cheia) o processo-r. . . . . . . . . . . . . . . . . . .

4.11 Comportamento das razões $[l s / h s]$ com a abundância de bário $[\mathrm{Ba} / \mathrm{H}]$, em relação às classes $r$ e $s$, e à abundância de carbono. . . . . . . . . . . . .

4.12 Comportamento de cada componente da razão $[h s / l s]$ com a metalicidade e comparação com a média dos elementos. Foram omitidas as dispersões relativas ao $\mathrm{Nd}$ pois seguem a mesma tendência do elemento La. . . . . . . 50

4.13 Dendrograma para o agrupamento das variáveis [Eu/Fe] e [Ba/Fe]. As linhas verticais representam os limites dos grupos formados e a linha horizontal representa o número de grupos encontrado segundo o critério da figura 4.14. 52

4.14 Curva de decaimento de grupos para o agrupamento de $[\mathrm{Eu} / \mathrm{Fe}]$ e $[\mathrm{Ba} / \mathrm{Fe}] . \quad 53$

4.15 Gráfico de pares para as variáveis do agrupamento da figura 4.13. . . . . . 54

4.16 Dendrograma para o agrupamento das variáveis [Eu/Fe], [Ba/Fe], [C/Fe] e $[\mathrm{Sr} / \mathrm{Fe}]$. As linhas verticais representam os limites dos grupos formados e a linha horizontal representa o número de grupos encontrado segundo o

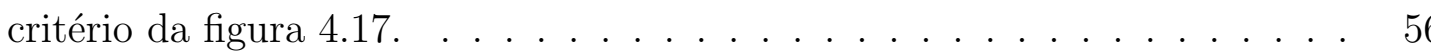

4.17 Curva de decaimento de grupos para o agrupamento de [Eu/Fe], [Ba/Fe], $[\mathrm{C} / \mathrm{Fe}]$ e $[\mathrm{Sr} / \mathrm{Fe}] \ldots \ldots \ldots \ldots \ldots \ldots \ldots$

4.18 Gráfico de pares para as variáveis do agrupamento da figura 4.16. . . . . 58 
4.19 Diagrama semelhante à figura 3.1, para os grupos formados no agrupamento da seção 4.5.2. . . . . . . . . . . . . . . . . . . . . .

5.1 Abundâncias de estrelas s-II da amostra. A linha vermelha (cheia) representa o padrão solar do processo-r normalizado pelo Eu e a linha verde (tracejada) o padrão solar do processo-s normalizado pelo Ba. As frações utilizadas foram retiradas de Arlandini et al. (1999). . . . . . . . . . . . .

5.2 Abundâncias de estrelas s-I da amostra. A linha vermelha (cheia) representa o padrão solar do processo-r normalizado pelo Eu e a linha verde (tracejada) o padrão solar do processo-s normalizado pelo Ba. As frações utilizadas foram retiradas de Arlandini et al. (1999). . . . . . . . . . . . . . . . .

5.3 Abundâncias de estrelas $r / s$ da amostra. A linha vermelha (cheia) representa o padrão solar do processo-r normalizado pelo Eu e a linha verde (tracejada) o padrão solar do processo-s normalizado pelo Ba. As frações utilizadas foram retiradas de Arlandini et al. (1999). . . . . . . . . . . .

5.4 Abundâncias de estrelas r-II da amostra. A linha vermelha (cheia) representa o padrão solar do processo-r normalizado pelo Eu e a linha verde (tracejada) o padrão solar do processo-s normalizado pelo Ba. As frações utilizadas foram retiradas de Arlandini et al. (1999). . . . . . . . . . . .

5.5 Abundâncias de estrelas r-I da amostra. A linha vermelha (cheia) representa o padrão solar do processo-r normalizado pelo Eu e a linha verde (tracejada) o padrão solar do processo-s normalizado pelo Ba. As frações utilizadas foram retiradas de Arlandini et al. (1999). . . . . . . . . . . . . . . .

5.6 Abundâncias de estrelas r-0 da amostra. A linha vermelha (cheia) representa o padrão solar do processo-r normalizado pelo Eu e a linha verde (tracejada) o padrão solar do processo-s normalizado pelo Ba. As frações utilizadas foram retiradas de Arlandini et al. (1999). . . . . . . . . . . . . . . . . 71

5.7 Comportamento das abundâncias (em relação ao ferro) entre as subclasses $r$ e $s$ em função do número atômico.

5.8 Comportamento das abundâncias normalizadas entre as subclasses $r$ e $s$ sem levar em conta a abundância de ferro. . . . . . . . . . . . . . 
5.9 Comparação entre os objetos localizados nos extremos da figura 4.19. A linha vermelha (cheia) representa o padrão solar do processo-r normalizado pelo Eu e a linha verde (tracejada) o padrão solar do processo-s normalizado pelo Ba. As frações utilizadas foram retiradas de Arlandini et al. (1999). 75

A.1 Exemplo de agrupamento hierárquico em duas dimensões. A figura do lado esquerdo mostra a dispersão dos dados e do lado direito é mostrado o dendrograma do agrupamento. Figura adaptada de http://en.wikipedia.org/. .

A.2 Quatro conjuntos de dados distintos podem fornecer os mesmos valores médios, ajustes lineares $(y=3.0+0.5 \mathrm{x})$ e coeficientes de correlação $(0.82)$ (Anscombe 1973). . . . . . . . . . . . . . . . . . . . . 93 


\section{LISTA DE TABELAS}

1.1 Nomenclatura para metalicidade (Beers \& Christlieb 2005). . . . . . . . . 4

1.2 Subclasses de estrelas pobres em metais. . . . . . . . . . . . . . . 5

1.3 Subclasses de estrelas enriquecidas em carbono. . . . . . . . . . . . . . 5

3.1 Subclasses propostas neste trabalho para estrelas pobres em metais enriquecidas em elementos formados por captura de nêutrons. . . . . . . . . . . 21

3.2 Distribuição da amostra segundo as tabelas 1.1, 1.3 e 3.1. . . . . . . . . . . 21

3.3 Contribuições dos processos $r$ e $s$ para a abundância total dos elementos da amostra, segundo as frações de Arlandini et al. (1999) e Burris et al. (2000). 29

4.1 Objetos utilizados na figura 4.4 para comparação com os dados do HERES. Os objetos CS31082-001 (Hill et al. 2002), CS22892-052 (Sneden et al. 1996 e 2003) e HD221170 (Burris et al. 2000 e Ivans et al. 2006) já fazem parte da amostra e não foram destacados na figura. A coluna classe foi preenchida de acordo com os critérios da tabela 3.1. Os valores em vermelho representam limites superiores/inferiores para as abundâncias. . . . . . . . . . . . . 37

4.2 Componentes $r$ e $s$ para as razões de elementos químicos utilizadas nesta

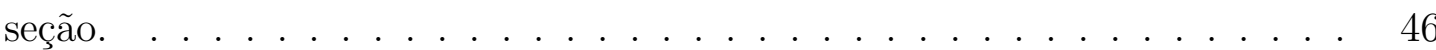

4.3 Sumário das abundâncias elementais para os diferentes grupos formados no agrupamento da seção 4.5.2. . . . . . . . . . . . . . . . . . . . . . . . 59

5.1 Abundâncias de Sr, Ba e Eu e metalicidades para as estrelas da figura 5.9. 76

A.1 Matriz de Correlação para as abundâncias elementais. O esquema de cores refere-se aos seguintes intervalos: $|r| \geq 0.8,0.6 \leq|r|<0.8,0.5 \leq|r|<0.6$ e $|r|<0.5 \ldots \ldots \ldots \ldots \ldots$

A.2 Esquema de símbolos para o valor-p dos coeficientes de correlação. . . . . . 95 


\section{INTRODUÇÃO}

\subsection{Resumo}

As atmosferas estelares contêm informações importantes acerca das condições e processos físicos que ocorreram na época de formação das estrelas. Sabe-se que o tempo de vida de uma estrela será tão extenso quanto menor for sua massa, fato decisivo na escolha de objetos para o estudo das primeiras gerações estelares e da nucleossíntese primordial (ver, por exemplo, Kippenhahn \& Weigert 1994). Além disso, através do estudo destes objetos pode-se inferir a presença de uma primeiríssima geração estelar, chamada "População III", cujos elementos químicos, produtos da evolução, possivelmente são observados hoje em estrelas muito velhas. Estes primeiros objetos, se observados, não deveriam mostrar presença de metal em sua composição, devido à época de sua formação. Assim, o fato de não se observar objetos nestas condições dá espaço para hipóteses de que estas estrelas tenham sido massivas e tenham vivido apenas alguns milhões de anos.

Abundâncias elementais estelares são essenciais para identificação de populações estelares, caracterização da história química da Galáxia e para impor alguns limites na formação da Via Láctea. Os processos de captura de nêutrons (processo-r e o processo-s) são os responsáveis pela síntese da maior parte dos elementos pesados na região de massa $\mathrm{A} \geq 60$. A teoria de nucleossíntese identifica locais astrofísicos bastante diferentes para operabilidade desses dois processos. Núcleos formados por processo-r são produtos primários de nucleossíntese, formados em um meio associado com a evolução de estrelas massivas $\left(\mathrm{M} \geq 10 M_{\odot}\right)$, como por exemplo em explosões de supernovas tipo-II (SNII) e outros eventos astrofísicos onde haja um fluxo intenso de nêutrons livres e temperaturas elevadas ${ }^{1}$ (ver, por exemplo, Qian \& Wasserburg 2003). Já os núcleos originados via processo-s são vistos como produtos de captura de nêutrons sobre núcleos pré-existentes de silício-ferro, ocorrendo ambos no

\footnotetext{
${ }^{1}$ Mais detalhes sobre as condições necessárias para a ocorrência dos processos de captura de nêutrons são mostrados no capítulo 2 .
} 
centro de estrelas de massa intermediária $\left(1.8 \leq M_{\odot} \leq 10\right.$ - Herwig 2005) durante a queima de He e, particularmente, nas camadas de He que apresentam pulsos térmicos no ramo assimptótico das gigantes (AGB). Neste cenário, espera-se que os primeiros elementos pesados $(A \geq 60)$ a serem introduzidos na componente gasosa interestelar da Galáxia tenham sido núcleos formados por processo-r em associação com estrelas massivas, em escalas de tempo inferiores a $10^{8}$ anos (Truran 1981). Já os elementos formados por processo-s devem ter sido formados posteriormente, como resultado da evolução de estrelas de massas mais baixas, com escalas de tempo superiores a $10^{9}$ anos, tendo, portanto, um importante papel no enriquecimento químico das regiões onde se encontram.

Dois grandes surveys de prisma-objetivo expandiram enormemente os números de membros estelares de populações do halo e disco espesso da Galáxia: o survey HK de Beers e colaboradores (Beers et al. 1985 e 1992) e o survey Hamburg/ESO de Christlieb e colegas (HES: Christlieb 2003). Estes surveys têm revelado a possível existência de um "limite inferior" de metalicidade estelar na Galáxia (em $[\mathrm{Fe} / \mathrm{H}]^{2} \sim-6.0$ ), a existência de uma classe de estrelas pobres em metais enriquecidas em elementos formados por processo-r e processo-s, a provável operabilidade de processos envolvendo aumento de carbono na evolução das estrelas das primeiras gerações, entre outras evidências. Além disso, têm também fornecido identificação de um número suficientemente grande de estrelas com metalicidades muito baixas $([\mathrm{Fe} / \mathrm{H}]<-2.0)$, as quais propiciam estudos espectroscópicos em alta resolução da evolução das abundâncias elementais nos primórdios da Galáxia. A descoberta recente de HE 0107-5240, uma estrela gigante do halo enriquecida em carbono com $[\mathrm{Fe} / \mathrm{H}]=-5.3$ (Christlieb et al. 2002), é um exemplo de um retorno não antecipado de tais surveys.

Estudos recentes (por exemplo Ballero et al. 2006) mostram o efeito de uma População III essencialmente massiva na evolução química da Galáxia. Se a primeira geração estelar fosse composta por estrelas massivas, estas terminariam suas vidas explodindo como SNII, enriquecendo o meio com os produtos da nucleossíntese explosiva. Sendo assim, as estrelas pobres em metais seriam uma segunda geração estelar formada a partir de um meio interestelar já poluído por elementos pesados. Então, à medida em que se remonta a épocas iniciais da formação da Galáxia, espera-se um meio cada vez menos homogêneo (Barbuy

\footnotetext{
${ }^{2}[\mathrm{~A} / \mathrm{B}]=\log \left(N_{A} / N_{B}\right)_{\star}-\log \left(N_{A} / N_{B}\right)_{\odot}$, onde $N$ refere-se às abundâncias por número de átomos de um dado elemento e os índices referem-se à estrela $(\star)$ e ao Sol $(\odot)$.
} 
et al. 2005), já que as explosões de supernova tipo II geram um enriquecimento químico e aumento de densidade em regiões próximas aos restos de $\mathrm{SN}$, onde novos objetos serão formados.

Nesse ínterim, essa primeira geração estelar supermassiva teria sido reponsável pela formação de uma grande parte dos elementos químicos estáveis da tabela periódica, bem como seus isótopos instáveis e menos abundantes. Um estudo detalhado do comportamento de alguns destes elementos de acordo com o ambiente em que se encontram (por exemplo estrelas de baixa massa ou em sistemas binários) pode contribuir para o entendimento dos diferentes processos físicos evolutivos que resultaram no cenário atual.

Por outro lado, algumas tentativas de explicar o comportamento de certos núcleos em função da metalicidade (por exemplo, Cescutti et al. 2006) não conseguem reproduzir o espalhamento observado para baixas metalicidades, o que pode sugerir que outros mecanismos ainda desconhecidos possam ter operado na formação da Galáxia.

\subsection{Estrelas pobres em metais}

Pode-se encontrar no Universo um sem-número de galáxias que contém, cada uma, milhões de estrelas em sua constituição. Pode-se dizer também que, na nossa Galáxia por exemplo, nem todas as estrelas têm a mesma composição química. Este fato sugere épocas, locais e condições físicas distintas para uma dada classe de objetos. Em particular, têm-se estrelas cujas abundâncias atmosféricas de elementos pesados (principalmente o ferro) são substancialmente menores que seu equivalente solar.

Estes objetos são chamados pobres em metal $(M P)$, e podem fornecer importantes evidências sobre os primórdios da Galáxia, bem como do Universo. Também é possível, através do estudo da abundância de ferro e de outros elementos ao longo de diferentes gerações estelares, inferir as propriedades da Função de Massa Primordial $(F M P)$ e da Função de Distribuição de Metalicidade (FDM - Beers \& Christlieb 2005).

Porém, o termo "pobre em metal" não necessariamente reflete o conteúdo metálico total da estrela, e sim a abundância do elemento químico ferro (metalicidade). A notação mais utilizada para metalicidade é $[\mathrm{Fe} / \mathrm{H}]$. As estrelas $M P$ são objetos de população II, ou seja, de baixa massa e com idade comparável à idade da Galáxia. Elas se localizam, em sua maioria, no halo da Galáxia, e o estudo de sua cinemática pode indicar se o objeto foi 
formado neste ambiente ou se trata de um objeto extragalático, adicionado ao halo como resultado de processos de interação com outras galáxias e aglomerados.

\subsubsection{Classificação}

As estrelas pobres em metal são classificadas segundo a nomenclatura proposta por Beers \& Christlieb (2005), de acordo com sua metalicidade (tabela 1.1).

Os valores de abundância de ferro, bem como a classificação que indica quão pobre em metal é uma estrela, são feitos em comparação com os valores solares, visto que o Sol é considerado uma estrela de seqüência principal de baixa massa típica, e tem suas abundâncias elementais muito bem determinadas (ver, por exemplo, Grevesse \& Sauval 1998; Asplund et al. 2005).

\begin{tabular}{ccc}
\hline \hline$[\mathrm{Fe} / \mathrm{H}]$ & Termo & Sigla \\
\hline$\sim 0.0$ & Solar & - \\
$<-1.0$ & Metal-Poor & $\mathrm{MP}$ \\
$<-2.0$ & Very Metal-Poor & VMP \\
$<-3.0$ & Extremely Metal-Poor & EMP \\
$<-4.0$ & Ultra Metal-Poor & $\mathrm{UMP}$ \\
$<-5.0$ & Hyper Metal-Poor & HMP \\
$<-6.0$ & Mega Metal-Poor & MMP \\
\hline
\end{tabular}

Tab. 1.1 Nomenclatura para metalicidade (Beers \& Christlieb 2005).

Então, com as medidas de referência do Sol bem determinadas, as abundâncias são obtidas ajustando-se espectros sintéticos ou medindo-se larguras equivalentes nos espectros observados e fazendo-se comparações entre os perfis das linhas de interesse.

\subsubsection{Subclasses}

Como dito anteriormente, a metalicidade de uma estrela não reflete seu conteúdo metálico total. Desta forma, foram criadas subclasses que descrevem as sobre-abundâncias de determinados elementos nas estrelas pobres em metal. Uma das subclasses de objetos refere-se ao excesso de elementos formados por processo de captura de nêutrons em relação 
à abundância solar. A tabela 1.2 mostra as subclasses propostas em Beers \& Christlieb (2005) para tais objetos.

\begin{tabular}{cccc}
\hline \hline Sigla & \multicolumn{3}{c}{ Critério de Classificação } \\
\hline r-I & $0.3 \leq[\mathrm{Eu} / \mathrm{Fe}] \leq+1.0$ e & {$[\mathrm{Ba} / \mathrm{Eu}]<0.0$} \\
r-II & {$[\mathrm{Eu} / \mathrm{Fe}]>+1.0$} & e & {$[\mathrm{Ba} / \mathrm{Eu}]<0.0$} \\
s & {$[\mathrm{Ba} / \mathrm{Fe}]>+1.0$} & e & {$[\mathrm{Ba} / \mathrm{Eu}]>+0.5$} \\
$\mathrm{r} / \mathrm{s}$ & \multicolumn{3}{c}{$0.0 \leq[\mathrm{Ba} / \mathrm{Eu}] \leq+0.5$} \\
\hline
\end{tabular}

Tab. 1.2 Subclasses de estrelas pobres em metais.

Nos objetos $r$-I acredita-se que ocorra o chamado processo-r "fraco", enquanto nos $r$-II ocorre o processo-r "forte". Os objetos $s$ possuem predominância em elementos formados por processo-s e os $r / s$ possuem elementos formados por ambos os processos, com abundâncias equivalente de $[\mathrm{Ba} / \mathrm{Fe}]$ e $[\mathrm{Eu} / \mathrm{Fe}]$.

O Eu é utilizado como referência de elemento produzido por captura rápida de nêutrons porque sua abundância é bem determinada em espectros ópticos. Todavia, a condição $\left[\mathrm{Ba}^{3} / \mathrm{Eu}\right]<0.0$ deve ser imposta, visto existir uma fração de $\mathrm{Eu}$ ( $6 \%$, segundo Arlandini et al. (1999)) formada por processo-s.

Além da subclassificação de acordo com o enriquecimento por elementos formados por captura de nêutrons, Beers \& Christlieb (2005) também propõe subclasses relacionadas com a sobre-abundância de carbono, discriminadas na tabela 1.3.

\begin{tabular}{cccc}
\hline \hline Sigla & \multicolumn{2}{c}{ Critério de Classificação } \\
\hline CEMP & {$[\mathrm{C} / \mathrm{Fe}]>+1.0$} & & \\
CEMP-r & {$[\mathrm{C} / \mathrm{Fe}]>+1.0$} & e & {$[\mathrm{Eu} / \mathrm{Fe}]>0.0$} \\
CEMP-s & {$[\mathrm{C} / \mathrm{Fe}]>+1.0-[\mathrm{Ba} / \mathrm{Fe}]>+1.0$} & e & {$[\mathrm{Ba} / \mathrm{Eu}]>+0.5$} \\
CEMP-r $/ \mathrm{s}$ & {$[\mathrm{C} / \mathrm{Fe}]>+1.0$} & e & $0.0 \leq[\mathrm{Ba} / \mathrm{Eu}] \leq+0.5$ \\
CEMP-no & {$[\mathrm{C} / \mathrm{Fe}]>+1.0$} & e & {$[\mathrm{Ba} / \mathrm{Fe}]<0.0$} \\
\hline
\end{tabular}

Tab. 1.3 Subclasses de estrelas enriquecidas em carbono.

O fenômeno de enriquecimento em carbono foi observado também na amostra de estrelas muito pobres em metal de Beers et al. (1992). Além disso, nota-se que no intervalo

\footnotetext{
${ }^{3} \mathrm{O}$ Ba é um elemento formado principalmente por processo-s (ver tabela 3.3).
} 
$-4.0<[\mathrm{Fe} / \mathrm{H}]<-2.0$, existe uma tendência de crescimento da abundância de carbono com a diminuição da metalicidade (Rossi et al. 2005). Este excesso de carbono pode ser atribuído a fontes intrínsecas ou extrínsecas que operaram nos primórdios da Galáxia, cujos resultados podem ser vistos nas atmosferas das estrelas mais antigas.

\subsection{Objetivos}

O objetivo deste trabalho, baseado em análise automatizada de abundâncias de uma grande base de dados espectrais gerada durante o HERES (Christlieb et al. 2004 - seção 3.1), é explorar os padrões de abundâncias elementais produzidos pelas primeiras gerações de estrelas na Galáxia. Utilizando uma amostra de 382 estrelas gigantes com $[\mathrm{Fe} / \mathrm{H}]<-1.0$, pretende-se identificar o comportamento geral dos padrões de abundância em função da metalicidade, fornecer medidas de espalhamento e especificar a frequiência de diferentes classes de objetos com padrões de abundância similares. Assim, com o estudo desta amostra de estrelas de baixa metalicidade, espera-se identificar e quantificar a freqüência de "grupos naturais" de padrões de abundância, dado fundamental para se compreender as origens astrofísicas destes objetos. Para tanto, são utilizadas diferentes ferramentas estatísticas. Entre elas, destaca-se o agrupamento hierárquico (ver Jain 1999 e apêndice A.1) que separa as estrelas em subgrupos baseados nas abundâncias elementais (seção 4.5).

Através do estudo do comportamento de certos elementos (como o carbono e os formados por captura de nêutrons) em função da metalicidade, pode-se inferir características da geração estelar anterior ou primordial, que deu origem a estes objetos. Este estudo é importante para se determinar os tipos de objetos que fizeram parte da "População III", e como esta população evoluiu para que o cenário observado atualmente pudesse ocorrer.

De forma resumida, no capítulo 2 são mostradas as principais características dos processos de captura de nêutrons dominantes na formação dos elementos químicos estudados neste trabalho. No capítulo 3, segue a descrição do survey HERES e da base de dados, bem como uma discussão sobre as abundâncias elementais e contribuições referentes aos processos $s$ e $r$.

Os capítulos 4 e 5 prestam-se, respectivamente, à análise da amostra como um todo e à análise individual de estrelas selecionadas segundo critérios discutidos no texto. Por fim, no capítulo 6 são colocadas as conclusões e perspectivas deste trabalho. 


\section{PROCESSOS DE CAPTURA DE NÊUTRONS}

Sabe-se que os elementos químicos com massas acima dos elementos do pico do ferro (A 60) não são formados por processos de fusão (reações entre partículas carregadas) e sim por sucessivas capturas de nêutrons a partir de uma "semente" de ferro". Alguns elementos também podem ser formados pelo processo de captura de prótons (processo-p), porém as características deste processo são pouco entendidas e sua ocorrência é menos freqüente. A figura 2.1 mostra as faixas de ocorrência dos diferentes processos de formação de elementos químicos.

Em geral, os processos de captura de nêutrons são divididos em dois tipos principais: o processo-s (lento), onde os nêutrons são capturados em escalas de tempo longas quando comparadas com o decaimento $\beta^{-}$; e o processo-r (rápido), que ocorre em condições extremas de densidade e temperatura, onde uma série de capturas ocorre antes do decaimento. Uma descrição detalhada de ambos os processos pode ser vista no trabalho pioneiro de Burbidge et al. (1957). Neste trabalho são tratados apenas alguns aspectos de cada processo, bem como suas conexões com ambientes astrofísicos, que servem de base para a análise mostrada nos capítulos seguintes.

\subsection{Processo-S}

Como resultado de uma reação $(n, \gamma)$, um núcleo $(Z, A)$ é transformado em seu isótopo mais pesado $(Z, A+1)$. Dependendo da estabilidade dos isótopos, pode-se ter sucessivas capturas de nêutrons antes de se atingir um isótopo instável que sofra decaimento $\beta^{-}$. Para os isótopos instáveis, o processo-s ocorrerá quando o tempo de captura for muito maior que a escala de tempo de decaimento. Isso faz com que os elementos formados pelo processo-s sigam uma linha próxima ao vale de estabilidade no plano prótons vs. nêutrons

\footnotetext{
${ }^{1}$ Outros elementos do pico do ferro como Mn, Co e Ni também agem como sementes, porém com frações muito baixas.
} 


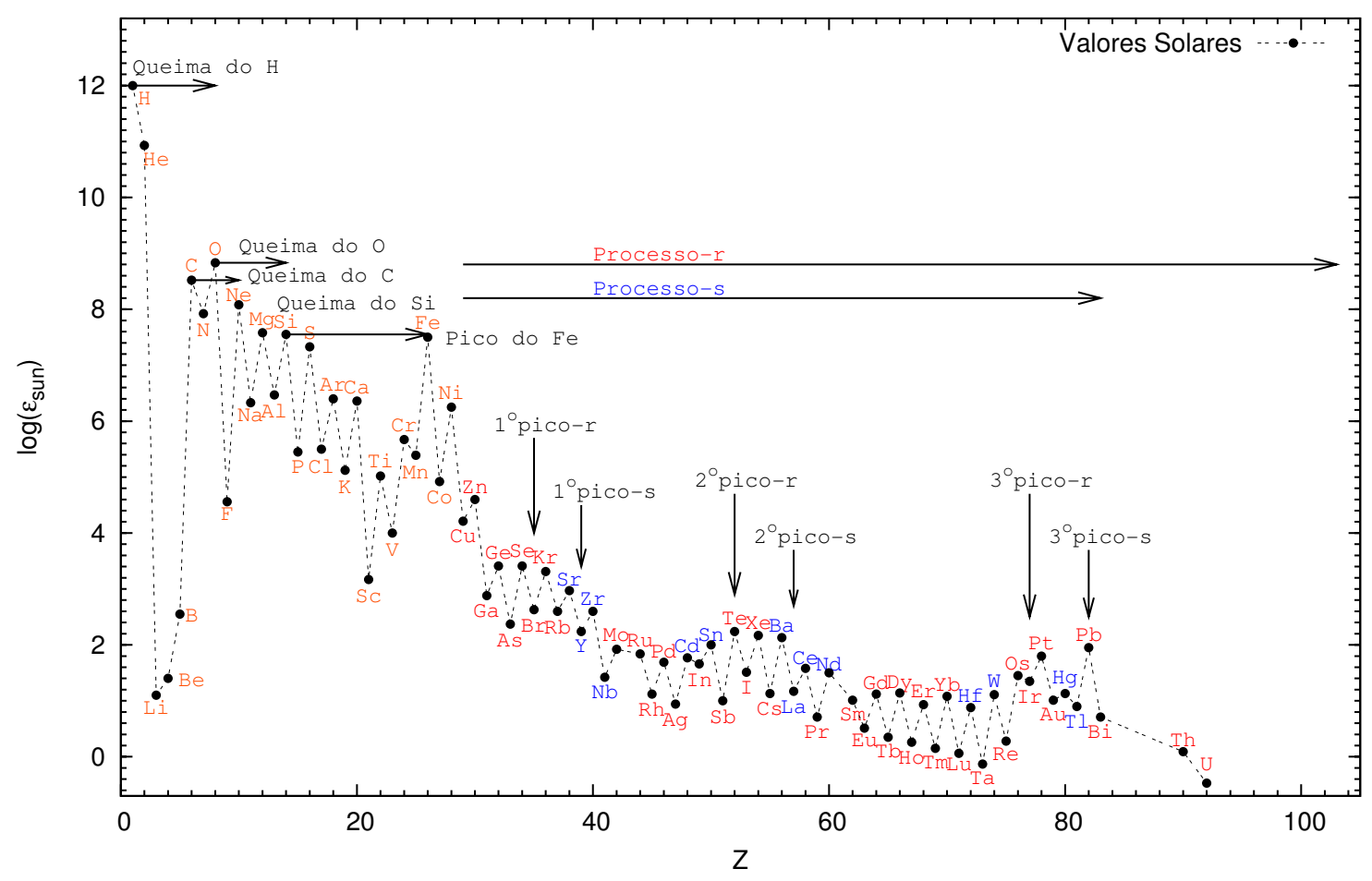

Fig. 2.1 Abundâncias dos elementos químicos no Sistema Solar (segundo Grevesse \& Sauval 1998), indicando a faixa de ocorrência dos diferentes processos de nucleossíntese nas estrelas. Os elementos em vermelho são sintetizados por processo-r e os em azul por processo-s (fração maior que 50\% segundo Arlandini et al. 1999).

(ver figuras 2.4 e 2.5), ou seja, para um dado elemento (caracterizado pela massa $A$ e número atômico $Z$ ), o processo-s ocorrerá próximo aos isótopos mais estáveis.

\subsubsection{O processo lento}

A captura lenta de nêutrons pode sintetizar elementos até o ${ }^{209} \mathrm{Bi}$ a partir de uma semente de ${ }^{56} \mathrm{Fe}$. Acima deste limite, ocorrem sucessivos decaimentos $\alpha$ que, nas condições de temperatura e densidade do processo-s, não permitem a formação de elementos mais pesados, que por sua vez serão formados em ambientes com condições distintas (processor). Para um isótopo formado somente por processo-s, a dependência temporal de sua abundância $\left(N_{A}\right)$ é dada por:

$$
\frac{d N_{A}(t)}{d t}=N_{n}(t) N_{A-1}(t)<\sigma v>_{A-1}-N_{n}(t) N_{A}(t)<\sigma v>_{A}-\lambda_{\beta}(t) N_{A}(t)
$$


onde $N_{n}(t)$ é a densidade de nêutrons no tempo $t$ e $\lambda_{\beta}=1 / \tau_{\beta}(t)=\ln 2 / T_{\frac{1}{2}}$ fornece a taxa de decaimento $\beta$ no tempo $t$ se o isótopo $A$ for radioativo. Pode-se notar a dependência temporal de todos os termos da equação, visto existir uma correlação entre as abundâncias e a temperatura do meio (que não permanece constante). Assim, o primeiro termo da equação 2.1 descreve a produção do isótopo $A$ a partir de $(A-1)$; o segundo termo mostra a diminuição da abundância pela captura de nêutrons e o último termo a diminuição pelo decaimento $\beta$. Pelo fato da equação 2.1 não poder ser resolvida para o caso geral, são feitas algumas aproximações ${ }^{2}$ (como considerar a temperatura na estrela constante) que fornecem a seguinte relação:

$$
\frac{d N_{A}(t)}{d t}=v_{T} N_{n}(t)\left(\sigma_{A-1} N_{A-1}-\sigma_{A} N_{A}\right)
$$

onde $v_{T}$ é a velocidade térmica das partículas no meio. Vale lembrar que o processo-s ocorre para uma dada faixa de temperatura e densidade de nêutrons, porém a aproximação de temperatura constante é válida pois, durante uma dada exposição de nêutrons no meio, estes parâmetros não variam significativamente.

Sendo o fluxo de nêutrons dado por $\phi(t)=v_{T} \cdot N_{n}(t)$ (nêutrons $\cdot \mathrm{cm}^{-2} \mathrm{~s}^{-1}$ ), pode-se introduzir o fluxo de nêutrons integrado no tempo, dado por:

$$
\tau=\int_{0}^{t} \phi(t) d t=v_{T} \int_{0}^{t} N_{n}(t) d t .
$$

A equação 2.3 fornece uma medida da exposição total de nêutrons (em nêutrons $\mathrm{cm}^{-2}$ ). Assim, a equação 2.2 pode ser reescrita em termos da nova quantidade $\tau$ :

$$
\frac{d N_{A}}{d \tau}=\sigma_{A-1} N_{A-1}-\sigma_{A} N_{A} \rightarrow 56 \leq A \leq 209
$$

ou seja, a abundância de um determinado isótopo depende, além das seções de choque, da abundância do isótopo "vizinho" e da quantidade de nêutrons disponíveis no meio. As condições iniciais para a equação 2.4 são: $N_{56}(0)=1$ e $N_{A \neq 56}(0)=0$

Assim, considerando-se um estado estacionário (isto é, $\frac{d N_{A}}{d \tau}=0$ ), tem-se $\sigma N$ constante, que é válido para alguns intervalos de massa e pode ser usado como uma aproximação local, perdendo a validade próximo às regiões de massa $A \sim 84,138$ e 208, que correspondem aos

\footnotetext{
2 maiores detalhes podem ser vistos em Rolfs \& Rodney (1988).
} 
números mágicos de nêutrons $N=50,82$ e 126. A figura 2.2 mostra o comportamento de $\sigma N$ para nuclídeos s-only no Sistema Solar. Este estado estacionário é atingido quando a taxa de formação é igual à taxa de destruição de um determinado elemento. Isto implica que um núcleo com uma seção de choque pequena (grande) deve ter uma abundância grande (pequena) para manter a continuidade no caminho do processo-s.

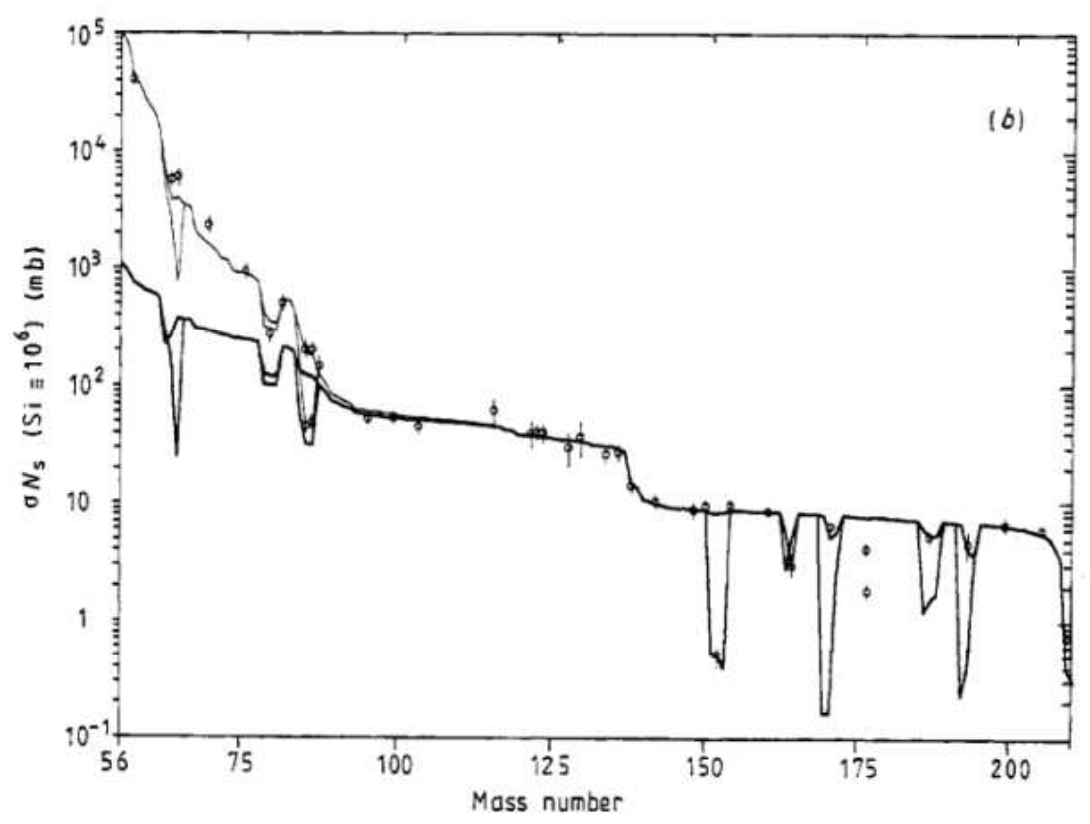

Fig. 2.2 Produto da abundância pela seção de choque de captura em função do número de massa. A linha mais espessa representa a componente principal do processo-s e a linha mais fina a componente fraca. Figura adaptada de Kappeler et al. (1989).

A solução geral para a equação 2.4 é dada por:

$$
N_{k}(\tau)=\sum_{i=56}^{k} C_{k i} e^{-\sigma_{i} \tau} \rightarrow C_{k i}=\prod_{j=56}^{k}\left(\frac{\sigma_{j}}{\sigma_{j}-\sigma_{i}}\right) ; j \neq i
$$

que apresenta uma forte dependência $\operatorname{com} \sigma_{j}-\sigma_{i}$, fazendo com que pequenas incertezas na determinação dessas grandezas levem a grandes desvios no cálculo de $N_{k}$. No entanto, se a distribuição de exposições for exponencial, dada por uma função densidade de probabilidade da forma $p(\tau) d \tau=e^{-\tau / t a u_{0}} d \tau / \tau_{0}$, as abundâncias são dadas por:

$$
\tilde{N}\left(\tau_{0}\right)=\int_{0}^{\infty} N(\tau) p(\tau) d \tau
$$


que é a transformada de Laplace da solução para uma única exposição. Fazendo as devidas substituições e integrando os resultados, ${ }^{3}$ obtêm-se:

$$
\sigma_{A} N_{A}=\frac{1}{\tau_{0}} \prod_{i=56}^{A}\left(1+\frac{1}{\tau_{0} \sigma i}\right)^{-1} .
$$

Assim, enquanto $\tau_{0} \sigma_{i}$ for grande, $\sigma N$ irá decrescer vagarosamente com o aumento da massa atômica. Porém, próximo aos números mágicos, $\sigma$ diminui rapidamente, fazendo com que $\sigma N$ tenha uma queda repentina (ver figura 2.2). A distribuição exponencial sugerida acima é conhecida como a componente principal do processo-s e sua interpretação física será discutida na seção seguinte. Apesar de sua formulação simples, a equação 2.7 fornece bons ajustes para massas com $A<80$ no Sistema Solar, com $\tau_{0} \sim 0.3 m b^{-1}$. Para massas menores, é necessário inserir uma componente adicional, conhecida como componente fraca do processo-s, caracterizada por uma exposição única $\left(\tau \sim 4.0 m b^{-1}\right)$ ou uma distribuição exponencial com valor de $\tau_{0}$ distinto da componente principal $\left(\tau_{0} \sim 16 m b^{-1}\right)$.

Outro parâmetro importante para descrever o processo-s é o número médio de nêutrons capturados por uma "semente" de ferro, dado por:

$$
n_{c}=\frac{\sum_{57}^{209}(A-56) N(A)}{N(56)}=\frac{1}{\tau_{0}} \sum_{57}^{209} \frac{A-56}{\sigma_{A}} \prod_{i=56}^{A}\left(1+\frac{1}{\tau_{0} \sigma_{i}}\right)^{-1} .
$$

Para um dado valor de $\tau_{0}$, tem-se informação sobre a quantidade de nêutrons capturados por cada núcleo-semente, que é um vínculo de suma importância, uma vez que a disponibilidade de nêutrons em um determinado ambiente físico está diretamente relacionada com a temperatura, que por sua vez varia com o estágio evolutivo da estrela.

\subsubsection{Distribuição exponencial e abundâncias no $A G B$}

Como visto acima, a exposição total de nêutrons pode ser escrita na forma exponencial, onde é definido um valor de $\tau_{0}\left(m b^{-1}\right)$ para diferentes faixas de massa. Porém, além da definição matemática fornecer aproximações locais coerentes, existe também uma interpretação física para este tipo de exposição.

Para estrelas com massas no intervalo $1.0 \leq \mathrm{M}\left(M_{\odot}\right) \leq 4.0$, o processo-s ocorre quando esta se encontra no estágio evolutivo AGB (Asymptotic Giant Branch - Herwig 2005). Nesta

\footnotetext{
${ }^{3} \mathrm{O}$ desenvolvimento das equações pode ser visto, por exemplo, em Pagel (1997).
} 
fase, para estrelas isoladas, ocorrem sucessivos pulsos térmicos e episódios de mistura do material da superfície com as camadas mais internas. Durante um período entre pulsos, o núcleo de hélio tem sua massa aumentada em $\Delta M_{\alpha}$ devido à queima do hidrogênio em hélio na camada logo acima. Praticamente toda esta massa se mistura na região entre as camadas (convectivas) de massa, $M_{i s c}$, gerada pelo próximo pulso e é exposta a um fluxo de nêutrons lentos $\Delta \tau$. Assim, a fração $\Delta M_{\alpha} / M_{i s c} \equiv 1-r$ recebe este fluxo pela primeira vez, enquanto a fração restante $r$ se sobrepõe ao próximo pulso e receberá um fluxo $2 \tau_{0}$. A fração $r^{2}$ seguinte irá se sobrepor aos dois pulsos anteriores e assim sucessivamente. Quando o estado estacionário for atingido, após um número suficiente $n$ de pulsos, tem-se que a probabilidade de ocorrer uma exposição $n \Delta \tau$ será:

$$
(1-r) r^{n-1}=\frac{1-r}{r} r^{\frac{\tau}{\Delta \tau}} \propto e^{-\frac{\tau}{\tau_{0}}} \rightarrow \tau_{0}=\frac{\Delta \tau}{\ln \left(\frac{1}{r}\right)}
$$

A figura 2.3 mostra um esquema dos pulsos térmicos que ocorrem na fase AGB. Também é mostrado o mecanismo pelo qual pode-se introduzir ${ }^{13} C$ na zona convectiva entre camadas, para o intervalo de massas descrito acima, além de possíveis sítios para a produção dos elementos formados por processo-s.

As linhas superior e inferior da figura 2.3 mostram, respectivamente, a evolução da massa de $H e$ e $C$ ao longo do tempo. No início, temos o aumento da massa de $H e$ produzido pela queima de $H$. Este $H e$ sintetizado se acumula em torno do núcleo inerte de ${ }^{12} C$ da estrela até atingir a massa crítica, que dita o início da conversão de $H e$ em $C$. Com isso, a abundância de $H e$ começa a diminuir enquanto a abundância de $C$ aumenta, como pode ser visto na figura 2.3, até que o $H e$ disponível para queima termine e novamente se inicie a conversão de $H$ em $H e$. A este processo de expansão e esfriamento do envelope, (que ocorre no início da queima de $H e$ e provoca a parada da queima de $H$ ) concomitante com a contração gravitacional do envelope (devido ao término da queima de $H e$ e que dá início novamente à queima de $H$ ), dá-se o nome de pulsos térmicos.

O número de pulsos térmicos e a intensidade dos mesmos estão relacionados com a massa da estrela no AGB (ver, por exemplo, a revisão feita por Herwig 2005), e quando ocorrem, geram fortes movimentos convectivos que causam uma mistura instantânea ${ }^{4}$ na camada de He, trazendo para a superfície material recém formado pela queima de $H$ e

\footnotetext{
${ }^{4}$ quando comparada com as escalas de tempo de queima
} 


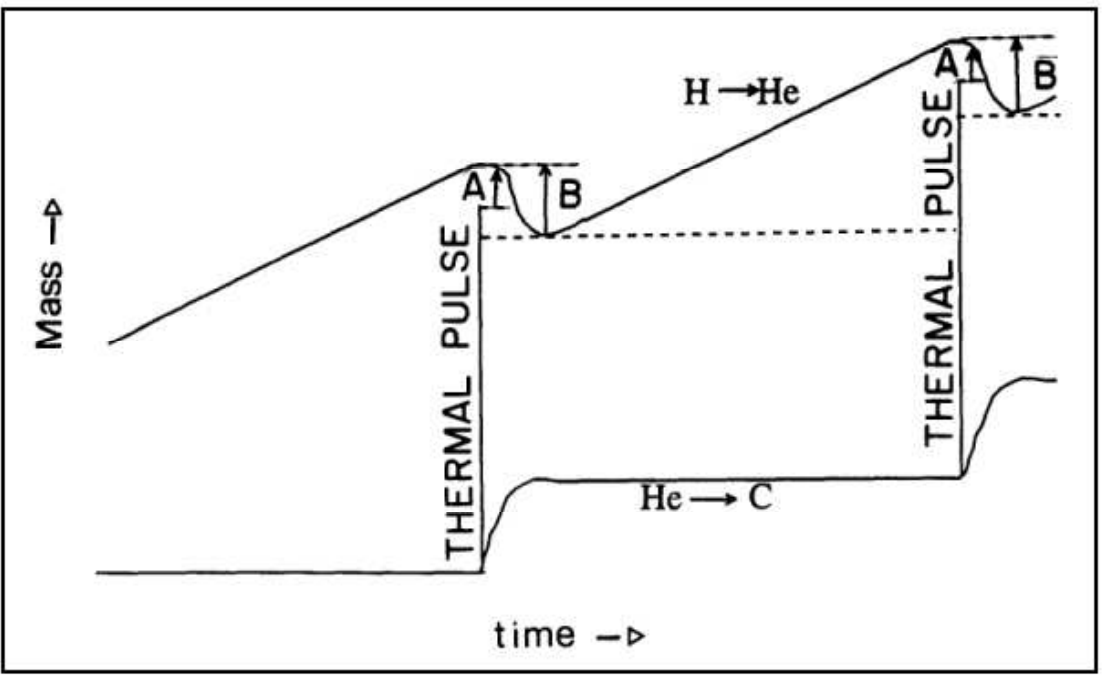

Fig. 2.3 Esquema da ocorrência dos pulsos térmicos. Os pulsos aparecem como linhas verticais devido à sua curta duração ( 300 anos) comparada com o período interpulsos ( 104 à $10^{5}$ anos) - Pagel (1997). Figura adaptada de Wasserburg et al. (1994).

He. Após uma série de pulsos, o envelope convectivo torna-se profundo o bastante para "dragar" elementos formados por processo-s e carbono das camadas mais interiores da estrela ( $3^{a}$ dragagem) para a superfície.

Esses elementos recém trazidos à superfície podem, nos estágios finais de evolução da estrela, enriquecer a atmosfera de uma companheira menos massiva num sistema binário. Tal transferência de matéria pode ser uma explicação para o padrão de abundância de elementos-s encontrados em alguns objetos (ver seção 5.1) e o excesso de carbono observado em estrelas de baixa metalicidade.

\subsection{Processo-r}

A seção 2.1 mostra a associação entre a componente lenta (processo-s $\rightarrow$ slow process) da captura de nêutrons e estrelas principalmente na fase de gigante vermelha, com fluxo de nêutrons livres de $\sim 10^{5} \mathrm{~cm}^{-2} \mathrm{~s}^{-1}$. Em contrapartida, temos a componente rápida (processo-r $\rightarrow$ rapid process) que ocorre com fluxos de nêutrons na faixa de $\sim 10^{22}-10^{26}$ $\mathrm{cm}^{-2} \mathrm{~s}^{-1}$.

Um grande número de estudos (entre eles Burbidge et al. 1957, Cowan \& Sneden 2003, 
Qian \& Wasserburg 2003, Rolfs \& Rodney 1988 e Wasserburg 1996) mostra que tais valores intensos de fluxo de nêutrons livres podem ser encontrados em explosões de supernovas de tipo II (SNII), estrelas de nêutrons ou eventos AIC (Accretion Induced Collapse). A seguir, são mostradas as principais características do processo rápido de captura de nêutrons e suas conexões com esses ambientes astrofísicos que geram temperaturas e densidades de nêutrons tão extremas.

\subsubsection{Introdução}

O processo de captura de nêutrons é dito rápido (r) quando se dá em um intervalo de tempo menor do que o do decaimento $\beta$. Isto ocorre em uma certa configuração de densidade de nêutrons $\left(N_{n}\right)$, temperatura $(T)$ e energia de ligação dos nêutrons $\left(Q_{n}\right)$. De todos os elementos da tabela periódica, 27 são produzidos apenas por processo-r. Alguns deles são: ${ }^{110} \mathrm{Pd},{ }^{116} \mathrm{Cd},{ }^{122,124} \mathrm{Sn},{ }^{128,130} \mathrm{Te},{ }^{134,136} \mathrm{Xe},{ }^{142} \mathrm{Ce},{ }^{148} \mathrm{Nd},{ }^{232} \mathrm{Th},{ }^{235,238} \mathrm{U}$. A tabela 3.3 mostra a contribuição de alguns elementos tanto no processo-r quanto no processo-s, para o sistema solar. Os outros elementos acima do ${ }^{56} \mathrm{Fe}$ podem ser produzidos por processo-p (prótons), processo-s (lento) ou pelos processos $r$ e $s$ misturados, dependendo das condições do meio.

Uma das formas de se estimar a abundância de um certo elemento formado por processor $\left(N_{r}\right)$ é pela diferença entre a abundância solar $\left(N_{\odot}\right)$ e a abundância por processo-s $\left(N_{s}\right)$ (Rolfs \& Rodney 1988):

$$
N_{r} \simeq N_{\odot}-N_{s}=N_{\odot}-\frac{f(A)}{\sigma(A)}
$$

onde $\sigma(A)$ é a seção de choque de captura de um núcleo de massa $A$ e $f(A)$ é uma função que depende da massa (ver seção 2.1). Para que a equação 2.10 forneça boas estimativas de $N_{r}$, deve-se ter valores cada vez mais precisos de seções de choque $\sigma(A)$. Estudos recentes (por exemplo Winckler et al. 2006) utilizam técnicas cada vez mais aprimoradas de física nuclear experimental para determinar as seções de choque dos elementos de interesse para o estudo dos processos de captura de nêutrons. No trabalho de Winckler et al., as diferenças calculadas para as contribuições do lantânio no processo-s chegam à 7\%, em comparação com trabalhos anteriores, fato que, segundo a equação 2.10, acarreta numa diferença similar para a contribuição do processo-r. 


\subsubsection{O processo rápido}

Para que o processo-r ocorra é necessário que se tenha uma densidade elevada de nêutrons, fazendo com que as taxas de captura sejam maiores que as do decaimento $\beta$ $\left(\tau_{n \gamma} \ll \tau_{\beta}\right)$.

O processo-r ocorre quando um núcleo captura um nêutron e libera um fóton, como pode ser visto a seguir:

$$
(Z, A) \stackrel{(n, \gamma)}{\longrightarrow}(Z, A+i)
$$

onde $i$ é o número total de nêutrons capturados. Por exemplo, para um tempo de captura $\tau_{n \gamma} \leq 1 \mathrm{~ms}$, devemos ter $N_{n} \geq 10^{19} \mathrm{~cm}^{-3}$.

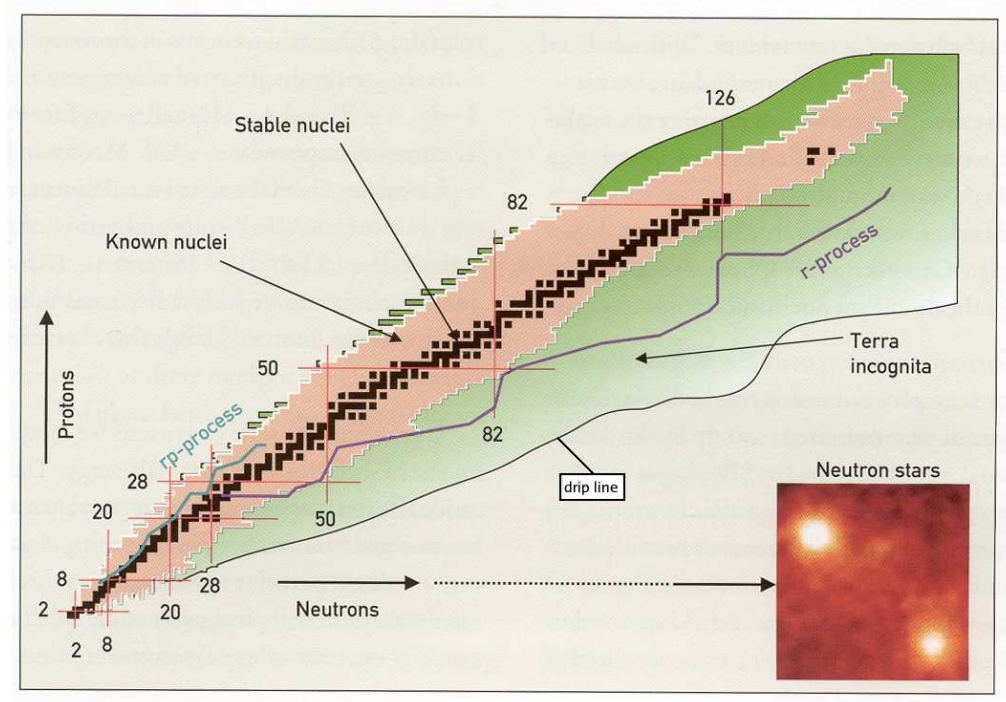

Fig. 2.4 Plano prótons $\mathrm{x}$ nêutrons, mostrando a drip line dos nêutrons, onde a captura de nêutrons termina e tem início o decaimento $\beta$. Figura adaptada de http://www.pas.rochester.edu/ cline/Research/sciencehome.htm.

Com o aumento do número de nêutrons ocorre a diminuição da energia de ligação $Q_{n}$. A adição de nêutrons ao núcleo termina quando $Q_{n} \rightarrow 0 . \operatorname{Em} Q_{n}=0$ encontra-se a $d r i p$ line. Isto ocorre quando a taxa de fotodesintegração $(\gamma, n)$ se iguala à taxa de captura $(n, \gamma)$, ou seja:

$$
\lambda_{\gamma n} \propto \frac{T^{\frac{3}{2}}}{N_{n}} e^{-\frac{Q n}{k T}} \lambda_{n \gamma}
$$


onde $\lambda=\frac{1}{\tau}$ são as taxas de decaimento dos núcleos.

Assim, na situação $(\gamma, n) \approx(n, \gamma)$, a cadeia de captura de nêutrons termina e o núcleo "espera" o decaimento $\beta$ ocorrer, e então:

$$
(Z, A+i) \rightarrow(Z+1, A+i)+\beta^{-}+\bar{\nu}
$$

O novo núcleo formado $(Z+1, A+i)$ começa novamente a capturar nêutrons até que as condições acima sejam novamente satisfeitas, e o equilíbrio seja atingido em $(Z+1, A+$ $i+k)$. O processo continua enquanto as condições de densidade, temperatura e $Q_{n}$ forem satisfeitas.

A condição para $Q_{n}$ pode ser calculada fazendo-se o balanço de energia da reação de captura de um nêutron por um núcleo $X(A, Z)$,

$$
X(A, Z)+n \rightleftharpoons X(A+1, Z)+\gamma+Q_{n}(A, Z)
$$

A energia de ligação $Q_{n}$ para o núcleo $X(A, Z)$ pode ser escrita como:

$$
\begin{aligned}
& Q_{n}(A, Z)=B_{n}(A+1, Z)=\ldots \\
& \quad \ldots=c^{2}\left[M(A, Z)+M_{n}-M(A+1, Z)\right] .
\end{aligned}
$$

Neste caso, $B_{n}$ é a energia de ligação no núcleo $(A+1, Z)$. Efetuando-se as devidas substituições (Burbidge et al. 1957), pode-se dizer que nêutrons serão adicionados enquanto a condição

$$
Q_{n} \geq \frac{T_{9}}{5.04}\left(34.07+\frac{3}{2} \log T_{9}-\log N_{n}\right)
$$

for satisfeita.

\subsubsection{Waiting points e números mágicos}

Quando a captura de nêutrons é interrompida, temos o chamado Waiting Point (ponto de espera), que é o ponto onde o decaimento $\beta$ deve ocorrer antes que mais nêutrons sejam adicionados. Para cada $Z$ existe um waiting point distinto, que por sua vez também depende de $T$ e $N_{n}$. 
A dependência temporal das abundâncias é dada por:

$$
\frac{d N_{Z}(t)}{d t}=\lambda_{Z-1}(t) N_{Z-1}(t)-\lambda_{Z}(t) N_{Z}(t)
$$

onde novamente $\lambda_{Z}$ refere-se à taxa de decaimento de um núcleo com abundância $N_{Z}$.

O processo-r leva os núcleos para o lado rico em nêutrons, aproximadamente $10-20$ nêutrons em excesso em relação aos vizinhos isóbaros. Se o "caminho" atinge um núcleo com número mágico de nêutrons $\left(N_{n}=50,82,126\right)$, o próximo isótopo mais pesado com $N_{m}+1$ nêutrons (ver equação 2.17) terá um $Q_{n}$ muito pequeno e uma meia vida longa (pois o núcleo anterior $N_{m}$ levará mais tempo para capturar outro neutron, pois tem uma camada fechada). A isto se deve a existência dos picos, tanto para o processo-r $\mathrm{r}^{5}$ quanto para o processo-s, mostrados da figura 2.1, já que, com camadas de nêutrons fechadas, esses núcleos possuem maiores abundâncias que os demais na mesma região de massa. Então, esses núcleos com camadas fechadas de nêutrons representam importantes waiting points no caminho do processo-r. Isto pode ser ilustrado como:

$$
\left(Z, N_{m}\right) \stackrel{\beta^{-}}{\longrightarrow}\left(Z+1, N_{m}\right) \ldots\left(Z+k, N_{m}\right)
$$

Este processo aumenta a carga do núcleo. Após várias capturas e decaimentos, o núcleo $\left(Z, N_{m}\right)$ se torna $\left(Z+k, N_{m}\right)$, como podemos ver na figura 2.5 como linhas de número de nêutrons constante no r-process path. Quando o núcleo resultante está próximo o suficiente da linha de estabilidade $Q_{n}$ aumenta, "quebra" o "gargalo mágico" de nêutrons e recomeça a seqüência de captura.

Quando o processo-r termina, o núcleo rico em nêutrons sofre decaimento $\beta$ até atingir o isóbaro mais estável (A constante). Pode-se dizer que, a partir da equação 2.17:

$$
\lambda_{A-1}(t) N_{A-1}(t) \approx \lambda_{A}(t) N_{A}(t) \rightarrow \frac{d N_{A}(t)}{d t} \approx 0
$$

isto é, a abundância do núcleo "r-processado" dividido pelo tempo de decaimento $\beta$ do progenitor é aproximadamente constante ${ }^{6}$.

\footnotetext{
${ }^{5}$ A contribuição do processo-r é, em sua maior parte, devida a elementos mais afastados da linha de estabilidade, ou seja, com maior número de nêutrons.

${ }^{6}$ Núcleos com números mágicos possuem maiores escalas de tempo de decaimento $\beta$, portanto são mais abundantes.
} 


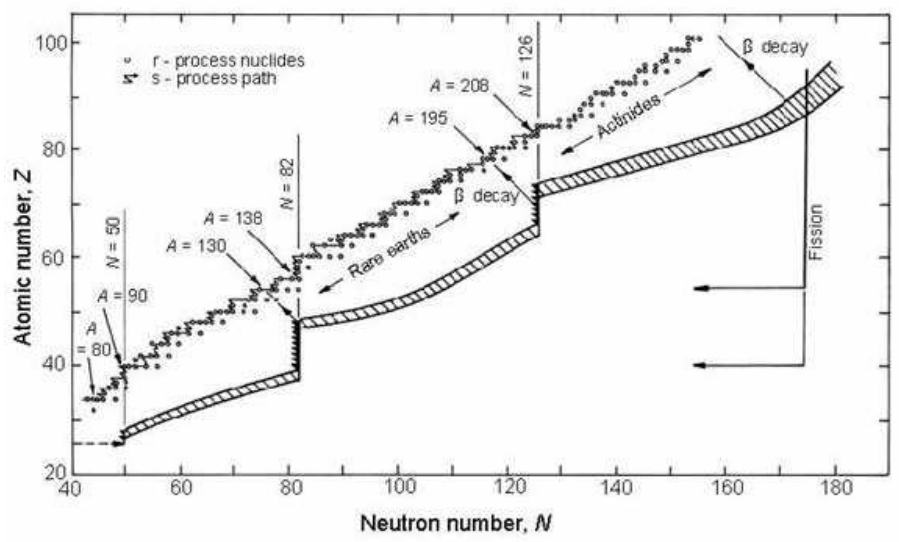

Fig. 2.5 Plano prótons x nêutrons. Podemos notar que o r-process path muda seu comportamento quando se encontra nos locais de números mágicos de nêutrons. Figura retirada de http://www.europhysicsnews.com/.

Não existe correlação óbvia entre as propriedades nucleares dos progenitores e as dos núcleos formados após os decaimentos $\beta$. O processo-r ultrapassa os núcleos $\alpha$-radioativos (onde termina o processo-s) e só termina com a fissão induzida por nêutrons ou por fissão " $\beta$-delayed" em $A_{\max } \sim 270$ (ver figura 2.5), sendo o único responsável pela produção dos elementos mais pesados que o bismuto. Assim, os novos núcleos terão $A=\frac{A_{\max }}{2}$, e o processo cíclico continua enquanto houver suprimento de nêutrons.

Os waiting points no plano $Z v s . N$ dependem dos valores de $N_{n}, T$ e $Q_{n}$, os quais ditam a quantidade de cada elemento que é formado. Para maiores valores de $N_{n}$, os waiting points se deslocam para a matéria mais rica em nêutrons (como pode ser visto na equação 2.12). A captura termina quando a fissão é mais rápida que o decaimento $\beta$.

Vale lembrar, porém, que os waiting points são aproximações feitas para obtenção de estimativas das escalas de tempo de decaimento, pois não levam em conta as seções de choque envolvidas. Com o desenvolvimento atual da capacidade dos computadores, estas estimativas estão sendo substituídas por cálculos dinâmicos que levam em conta as seções de choque. Uma dificuldade encontrada é a medição destes parâmetros para os núcleos muito distantes da linha de estabilidade, pois, à medida em que se "caminha" em direção à matéria mais rica em nêutrons (próximo a drip line), os isótopos tornam-se cada vez menos estáveis e abundantes. 


\section{BASE DE DADOS}

\subsection{O survey HERES}

O survey HERES (Hamburg ESO R-process Enhanced Star survey - Christlieb et al. 2004), que é parte do projeto HES (Hamburg ESO Survey - Reimers 1990; Wisotzki et al. 1996, 2000), tem como principal objetivo a busca por estrelas pobres em metais com sobre-abundância de elementos formados por processo rápido de captura de nêutrons. Estas estrelas são muito importantes pois permitem, além de estudar a natureza do processo-r, a possível identificação dos locais astrofísicos onde ocorreu a nucleossíntese destes elementos. Também é possível fazer determinações de idade a partir do estudo de elementos radioativos como o ${ }^{232} \mathrm{Th}$ (meia-vida de $14.05 \cdot 10^{9}$ anos) ou o ${ }^{238} \mathrm{U}$ (4.468.10 anos). Através de comparações entre cálculos teóricos e valores observados para as razões de abundâncias destes elementos (relativas aos seus isótopos estáveis), pode-se derivar quando ocorreu o evento que os originou (por exemplo uma explosão de SNII ou evento AIC).

Espectroscopia "snapshot" de alta resolução para uma amostra de 382 candidatas com $[\mathrm{Fe} / \mathrm{H}]<-1.0$, selecionadas a partir dos surveys HK e HES, foi obtida com o VLT/UVES. Estes espectros, com razão sinal-ruído moderada (S/N 40/1), apresentam qualidade suficiente para detecção da linha $4129 \AA$ do Eu, um conhecido indicador de operacionalidade de processos de captura de nêutrons. Além disso, os espectros foram utilizados para obtenção de medidas de abundâncias elementais para até 22 espécies por estrela, incluindo os elementos alfa, os elementos do pico do $\mathrm{Fe}$ e os elementos formados por captura de nêutrons, utilizando-se técnicas automatizadas de análise. Os objetos identificados como sendo os mais interessantes (por exemplo, aqueles com provável deteç̧ão de elementos formados por processo-s e processo-r) foram então re-observados em resoluções mais altas e com uma razão $\mathrm{S} / \mathrm{N}$ muito maior.

Estes dados fornecem a melhor amostra possível para estudo: 1) da freqüência de estrelas com elementos formados por processos de captura de nêutrons altamente (ou mo- 
deradamente) enriquecidos em função de [Fe/H], um dado fundamental para compreensão de suas origens; 2) da distribuição do nível de enriquecimento entre estas estrelas; 3) da dispersão nos padrões observados destes processos e; 4) o padrão geral e dispersões das abundâncias elementais para as estrelas com metalicidades bem baixas, com base em toda a amostra.

\subsection{Caracterização da amostra}

A base de dados do HERES completa contêm um total de 382 objetos, para os quais foram determinados $\mathrm{T}_{\text {eff }}, \log (g),[\mathrm{Fe} / \mathrm{H}]$ e $[\mathrm{C} / \mathrm{Fe}]$ (fornecido por Timothy Beers - comunicação particular). Os objetos que possuem abundâncias calculadas para os demais elementos químicos (descritos abaixo) perfazem um total de 326 objetos, sendo que 253 foram retirados de Barklem et al. (2005) e os demais fornecidos por comunicação particular (Sara Lucatello - 33 objetos; Timothy Beers - 40 objetos). Dentro desta sub-amostra (326 objetos), os objetos com abundâncias calculadas de Ba e Eu foram separados através dos parâmetros listados nas tabelas 1.1, 1.2 e 1.3. No entanto, para as subclasses relacionadas aos processos de captura de nêutrons, foi utilizada a tabela 3.1, com as novas subclasses propostas por este trabalho. A distribuição dos objetos segundo estas subclasses está mostrada na tabela 3.2 .

Como se pode observar, a tabela 3.1 possui um número de subclasses maior do que o proposto originalmente por Beers \& Christlieb (2005). Foram introduzidas duas novas subclasses, s-II (de acordo com Barklem et al. 2005) e r-0 (subclasse introduzida neste trabalho), com o intuito de separar melhor objetos com características distintas. Estas subclasses são exploradas nas seções 5.1 e 5.3 .

Todos os objetos da amostra são objetos pobres em metais $([\mathrm{Fe} / \mathrm{H}]<-1.0)$ com exceção de dois objetos, que possuem $[\mathrm{Fe} / \mathrm{H}] \sim-0.5$. Para cada um deles temos ${ }^{1}$ : nome (ou código relacionado à tomada de dados), ascensão reta e declinação (em coordenadas J2000), temperatura efetiva $\left(T_{\text {eff }}\right)$, gravidade superficial $(\log (g))$, velocidade radial $\left(v_{\text {rad }}\right)$, razão sinal ruído $(\mathrm{S} / \mathrm{N})$, velocidade de microturbulência $(\xi)$ e abundâncias elementais $(\log \epsilon)$, $\operatorname{com}$ seus respectivos erros associados. As abundâncias foram determinadas para os seguintes elementos: $C, M g, A l, C a, S c, T i, V, C r, M n, F e, C o, N i, Z n, S r, Y, Z r, B a, L a$,

\footnotetext{
${ }^{1}$ Detalhes sobre os cálculos das grandezas citadas podem ser encontrados em Barklem et al. (2005).
} 


\begin{tabular}{cccc}
\hline \hline Sigla & Critério de Classificação \\
\hline r-0 & {$[\mathrm{Eu} / \mathrm{Fe}]<+0.3$} & e & {$[\mathrm{Ba} / \mathrm{Eu}]<0.0$} \\
r-I & $0.3 \leq[\mathrm{Eu} / \mathrm{Fe}] \leq+1.0$ & e & {$[\mathrm{Ba} / \mathrm{Eu}]<0.0$} \\
r-II & {$[\mathrm{Eu} / \mathrm{Fe}]>+1.0$} & e & {$[\mathrm{Ba} / \mathrm{Eu}]<0.0$} \\
s-I & {$[\mathrm{Ba} / \mathrm{Fe}]>+1.0-[\mathrm{Eu} / \mathrm{Fe}]<+1.0$} & e & {$[\mathrm{Ba} / \mathrm{Eu}]>+0.5$} \\
s-II & {$[\mathrm{Ba} / \mathrm{Fe}] \geq+1.0-[\mathrm{Eu} / \mathrm{Fe}] \geq+1.0$} & e & {$[\mathrm{Ba} / \mathrm{Eu}]>+0.5$} \\
r $/ \mathrm{s}$ & $0.0 \leq[\mathrm{Ba} / \mathrm{Eu}] \leq+0.5$ \\
\hline
\end{tabular}

Tab. 3.1 Subclasses propostas neste trabalho para estrelas pobres em metais enriquecidas em elementos formados por captura de nêutrons.

$C e, N d, S m, E u$. Além disso, também foram calculadas distâncias, posições $(R, x, y, z)$ e velocidades ( $\left.U, V, W, V_{\phi}, V_{R}\right)$ para uma grande parte da amostra (312 objetos), fornecidas por Daniela Carollo (comunicação particular).

\begin{tabular}{|c|c|c|c|c|c|c|c|c|}
\hline Classe & & $\#$ & Classe & & $\#$ & Classe & & $\#$ \\
\hline EMP & $\rightarrow$ & 46 & $r-0$ & $\rightarrow$ & 14 & CEMP & $\rightarrow$ & 83 \\
\hline VMP & $\rightarrow$ & 201 & r-I & $\rightarrow$ & 37 & CEMP-r & $\rightarrow$ & 11 \\
\hline $\mathrm{MP}$ & $\rightarrow$ & 77 & r-II & $\rightarrow$ & 10 & CEMP-s & $\rightarrow$ & 12 \\
\hline \multirow[t]{3}{*}{ SOLAR } & $\rightarrow$ & 2 & s-I & $\rightarrow$ & 6 & CEMP-r/s & $\rightarrow$ & 4 \\
\hline & & & S-II & $\rightarrow$ & 7 & CEMP-no & $\rightarrow$ & 3 \\
\hline & & & $\mathrm{r} / \mathrm{s}$ & $\rightarrow$ & 4 & & & \\
\hline Total & $\rightarrow$ & 326 & & & & & & \\
\hline
\end{tabular}

Tab. 3.2 Distribuição da amostra segundo as tabelas 1.1, 1.3 e 3.1.

Pode-se notar na tabela 3.2 que a amostra contém 61 objetos pertencentes à classe $r$ $([\mathrm{Ba} / \mathrm{Eu}]<0.0), 7$ altamente enriquecidos em elementos $s([\mathrm{Ba} / \mathrm{Fe}]>1.0$ e $[\mathrm{Ba} / \mathrm{Eu}]>0.5)$ e 4 objetos enriquecidos tanto pelo processo $s$ quanto pelo $r(0.0 \leq[\mathrm{Ba} / \mathrm{Eu}] \leq 0.5)$. A análise detalhada de cada uma destas subclasses é feita no capítulo 5 .

No decorrer deste trabalho, foram utilizadas diferentes formulações para apresentar o comportamento das abundâncias elementais dos objetos, de acordo com o tipo de análise realizada. Pode-se usar uma definição onde o fator de normalização é a abundância solar para uma dada razão de elementos: 


$$
\left[\frac{A}{B}\right] \equiv \log \left(\frac{N_{A}}{N_{B}}\right)_{\star}-\log \left(\frac{N_{A}}{N_{B}}\right)_{\odot},
$$

ou ainda usar o valor da abundância normalizado para a quantidade de hidrogênio no objeto, que é definido como (ver, por exemplo, Grevesse \& Sauval 1998):

$$
\log \epsilon_{X}=\log \left(\frac{N_{X}}{N_{H}}\right)+12 .
$$

Para se fazer uma análise das abundâncias de um único objeto e compará-la, por exemplo, com os padrões solares para os processos $s$ e $r$ (como será visto nas seções 5.1, 5.2 e 5.3), é mais conveniente usar os valores calculados pela equação 3.2. Já a notação de colchetes se mostra útil para comparar objetos entre si, pois fornece a sobre(sub)abundância do elemento em relação ao valor solar. Usando a definição dada pela equação 3.1 é possível escrever:

$$
\left[\frac{X}{F e}\right]=\left[\frac{X}{H}\right]-\left[\frac{F e}{H}\right]
$$

ou seja, além da normalização pelo valor solar, esta razão também leva em conta a metalicidade (quantidade de ferro) do objeto. Isto é importante, visto que objetos com mesmo valor de $\log \epsilon$, para determinado elemento, não necessariamente possuem o mesmo comportamento. A dependência com a metalicidade introduz uma escala de "tempo", no sentido de que objetos com mesma abundância, mas com metalicidades diferentes, sofreram episódios de enriquecimento distintos e, portanto, possuem padrões de abundância diferentes. A substituição da equação 3.1 na equação 3.3 resulta em:

$$
\left[\frac{X}{F e}\right]=\log \left(\frac{N_{X}}{N_{H}}\right)_{\star}-\log \left(\frac{N_{F e}}{N_{H}}\right)_{\star}-\log \left(\frac{N_{X}}{N_{H}}\right)_{\odot}+\log \left(\frac{N_{F e}}{N_{H}}\right)_{\odot}
$$

e, com a equação 3.2 obtém-se:

$$
\left[\frac{X}{F e}\right]=\log \epsilon_{X_{\star}}-12-\log \epsilon_{F e_{\star}}+12-\log \epsilon_{X_{\odot}}+12+\log \epsilon_{F e_{\odot}}-12
$$

$\mathrm{e}$

$$
\left[\frac{X}{F e}\right]=\log \epsilon_{X_{\star}}-\log \epsilon_{X_{\odot}}-\left[\frac{F e}{H}\right]
$$


A equação 3.6 mostra que, além da dependência com a metalicidade, a razão [X/Fe] depende também do valor da abundância do elemento $X$ no Sol $\left(\log \epsilon_{X_{\odot}}\right)$. Sendo assim, pode-se notar que esta dependência implica, por exemplo, que um diagrama semelhante ao da figura 3.1, utilizando as variáveis $\log \epsilon$, não forneça uma distribuição que permita a separação dos objetos como foi feita acima.

A figura 3.1 mostra a distribuição dos dados utilizando-se as abundâncias dos elementos európio e bário e os critérios de separação dados na tabela 3.1. Note-se que duas estrelas encontram-se muito próximas do limite para as estrelas r/s. Ao utilizar as incertezas associadas às abundâncias pode haver uma classificação dupla para estes objetos. Porém, como será visto a seguir, a análise detalhada das abundâncias elementais destes objetos não depende de sua classificação, e naturalmente mostra suas diferenças em relação aos demais.

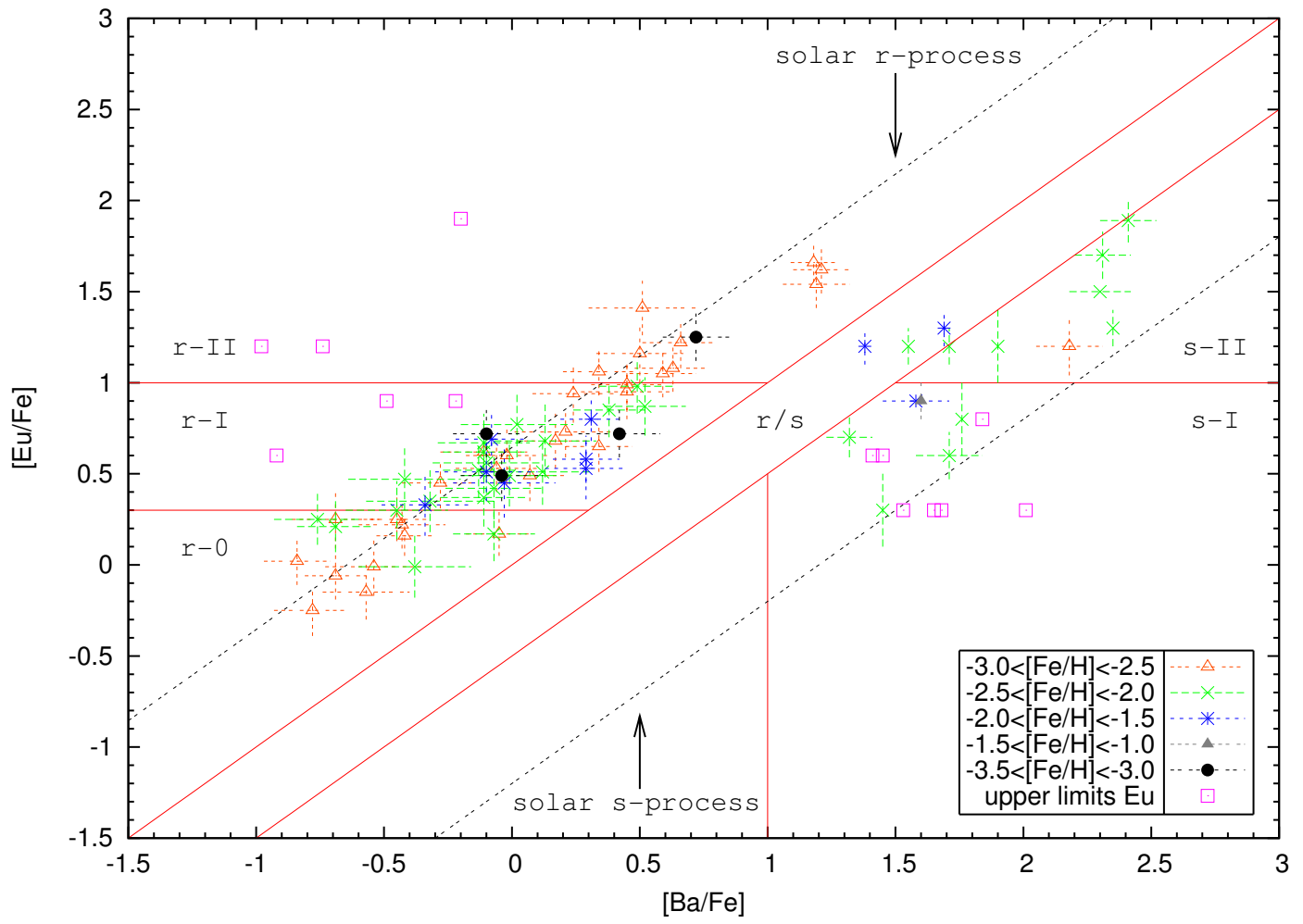

Fig. 3.1 Diagrama de identificação de estrelas $r$ e $s$ da amostra. Também são separadas as diferentes faixas de metalicidade dos objetos.

As classificações propostas têm como principal objetivo fornecer informações sobre as abundâncias elementais desses objetos e eventualmente atribuir um caráter evolutivo, re- 
lacionado aos ambientes de formação estelar, bem como fornecer um limite para o início da operação dos processos de captura de nêutrons. Entretanto, o caráter evolutivo deve ser entendido como estando somente relacionado às subclasses, e não englobando um cenário onde, por exemplo, uma estrela $r$ "evolua" para uma estrela $s$.

As linhas diagonais seccionadas da figura 3.1 representam as contribuições dos processos $s$ e $r$ para o valor solar da razão $[\mathrm{Ba} / \mathrm{Eu}]$. Ao longo do trabalho são feitos cálculos destas contribuições para uma série de razões de elementos químicos diferentes, sendo que, para uma razão genérica entre elementos $A$ e $B([\mathrm{~A} / \mathrm{B}])$, e utilizando-se as equações 3.1 e 3.2, tem-se que:

$$
\left[\frac{A}{B}\right]_{r, s}=\left(\log \epsilon_{A_{r, s}}-\log \epsilon_{B_{r, s}}\right)-\left(\log \epsilon_{A}-\log \epsilon_{B}\right)
$$

$\mathrm{e}$

$$
\begin{gathered}
\log \epsilon_{A_{r, s}}=\log \left(f_{A_{r, s}} \cdot \epsilon_{A_{m}}\right) \\
\log \epsilon_{B_{r, s}}=\log \left(f_{B_{r, s}} \cdot \epsilon_{B_{m}}\right),
\end{gathered}
$$

onde $\log \epsilon_{A}$ and $\log \epsilon_{B}$ são os valores solares fotosféricos (retirados de Grevesse \& Sauval 1998), $f_{A_{r, s}}$ e $f_{B_{r, s}}$ são as frações $r$ ou $s$ dos elementos $A$ e $B$ (retiradas de Arlandini et al. 1999 ou Burris et al. 2000), e $\log \epsilon_{A_{m}}$ e $\log \epsilon_{B_{m}}$ são as abundâncias meteoríticas dos elementos $A$ e $B$, também retiradas de Grevesse \& Sauval (1998). O uso das abundâncias meteoríticas no cálculos faz-se necessário pois, como estes são medidos in situ, possuem valores mais precisos. Porém, para fornecer os valores de comparação das contribuições $r$ e $s$ é necessário também utilizar os valores fotosféricos, visto que as abundâncias elementais remontam às características das atmosferas das estrelas observadas. A quantidade $\left(\log \epsilon_{A_{r, s}}\right.$ - $\left.\log \epsilon_{B_{r, s}}\right)$ pode então ser escrita utilizando-se as equações 3.8, como:

$$
\left(\log \epsilon_{A_{r, s}}-\log \epsilon_{B_{r, s}}\right)=\left(\log f_{A_{r, s}}+\log \epsilon_{A_{m}}\right)-\left(\log f_{B_{r, s}}+\log \epsilon_{B_{m}}\right) .
$$

Assim, substituindo a equação 3.9 na equação 3.7 tem-se:

$\underline{F r a c ̧ a ̃ o r ~}$

$$
\left[\frac{A}{B}\right]_{r}=\underbrace{\left(\log f_{A_{r}}-\log f_{B_{r}}\right)}_{\text {Arlandini1999 }}+\underbrace{\left(\log \epsilon_{A_{m}}-\log \epsilon_{B_{m}}\right)-\left(\log \epsilon_{A}-\log \epsilon_{B}\right)}_{\text {Grevesse } 1998}
$$


Fraçãos

$$
\left[\frac{A}{B}\right]_{s}=\underbrace{\left(\log f_{A_{s}}-\log f_{B_{s}}\right)}_{\text {Arlandini1999 }}+\underbrace{\left(\log \epsilon_{A_{m}}-\log \epsilon_{B_{m}}\right)-\left(\log \epsilon_{A}-\log \epsilon_{B}\right)}_{\text {Grevesse1998 }}
$$

As frações calculadas via equações 3.10 e 3.11 são utilizadas ao longo do trabalho para comparar os valores das razões de elementos $r$ e $s$ com os valores solares. Assim, pode-se concluir da figura 3.1 que tanto as estrelas $s$ quanto as estrelas $r$ seguem os padrões solares para os processos de captura de nêutrons, exceto para os objetos onde estão disponíveis apenas os limites superiores para as abundâncias de Eu.

A figura 3.2 mostra a distribuição de metalicidade dos 382 objetos da amostra. As metalicidades destes objetos encontram-se no intervalo $-3.50 \leq[\mathrm{Fe} / \mathrm{H}] \leq-0.6$, e o valor médio desta distribuição é $[\mathrm{Fe} / \mathrm{H}]=-2.43$.

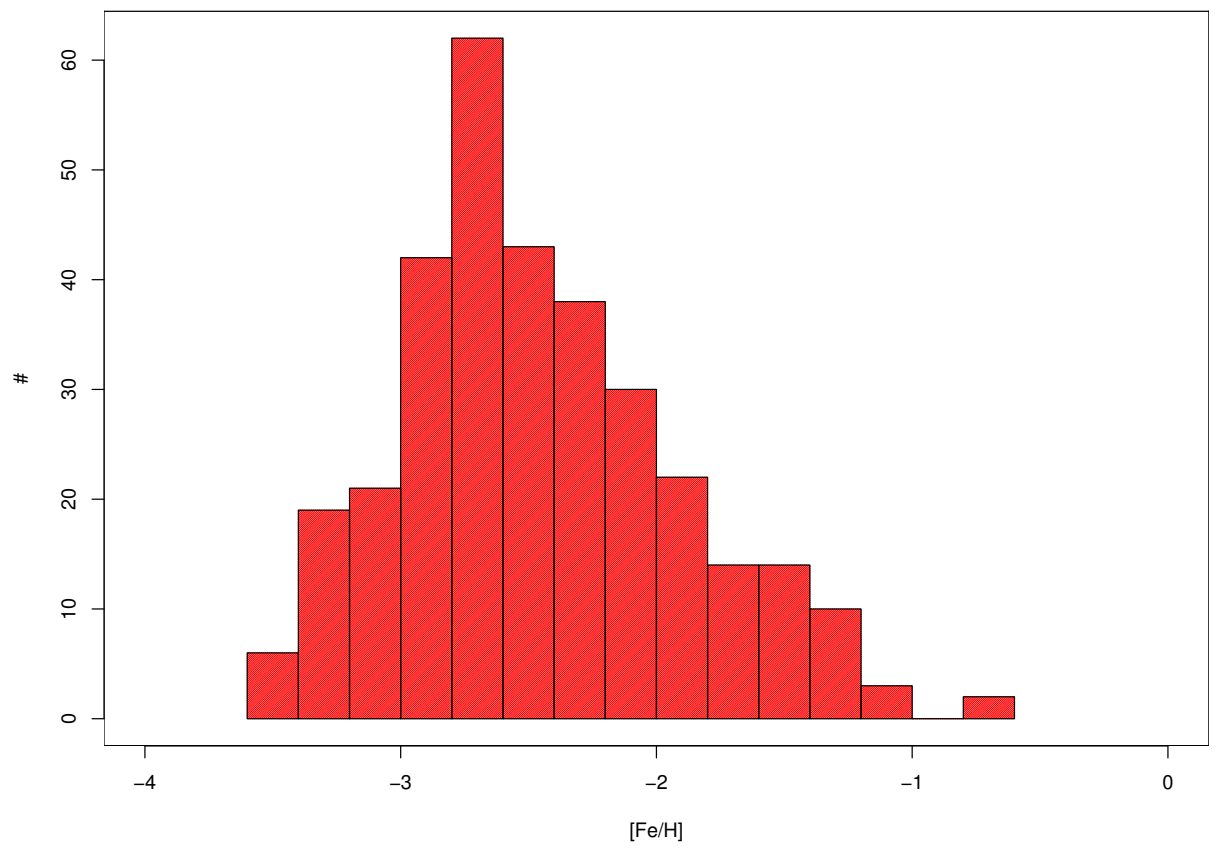

Fig. 3.2 Distribuição de metalicidade da amostra.

Outros parâmetros importantes relacionados aos objetos são a temperatura efetiva e a gravidade superficial. As temperaturas podem ser determinadas através de métodos fotométricos como medições de magnitudes e índices de cor em diversas bandas. Os intervalos de $T_{\text {eff }}$ e $\log (g)$ para a amostra são, respectivamente: $4149 \leq T_{\text {eff }}(\mathrm{K}) \leq 6884$ e $0.13 \leq \log (g)(\mathrm{cm} / \mathrm{s}) \leq 6.31$. 


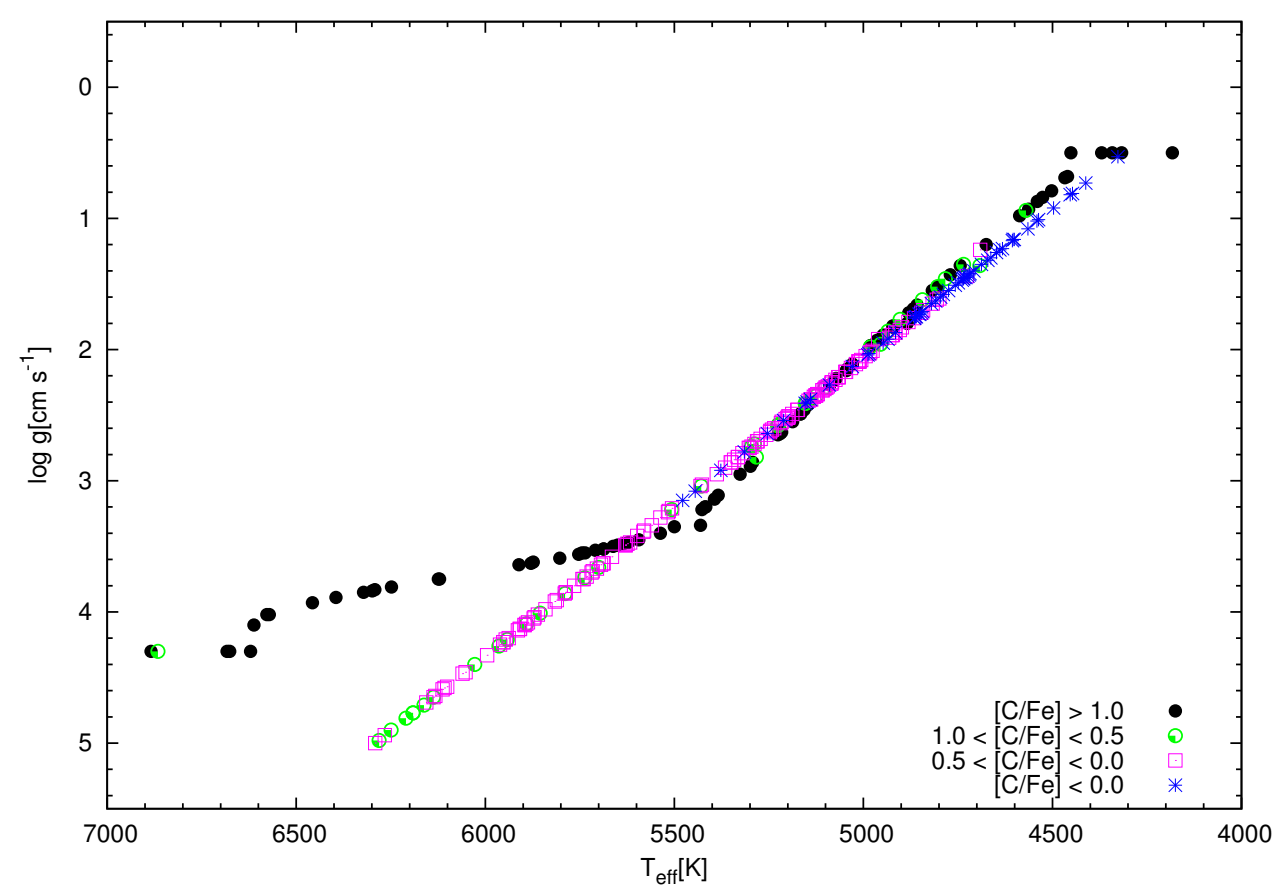

Fig. 3.3 Diagrama de Kiel: $T_{\text {eff }}$ vs. $\log (g)$. Nota-se que as estrelas com menor quantidade de carbono se concentram na parte superior (mais fria) do gráfico.

A figura 3.3 (Diagrama de Kiel) mostra o comportamento destas duas grandezas para todos os objetos da amostra. O comportamento da distribuição para os objetos com $[\mathrm{C} / \mathrm{Fe}]<+1.0$ se deve à relação de calibração utilizada para o cálculo de $\log (g)$ a partir de $T_{\text {eff }}$. Esta relação é diferente da utilizada para os objetos com $[\mathrm{C} / \mathrm{Fe}] \geq+1.0$, principalmente para temperaturas mais altas, onde a influência da banda G do $\mathrm{CH}(\sim 4300 \AA)$ se torna mais acentuada, dificultando a identificação do contínuo "real" no espectro do objeto.

\subsection{Abundâncias solares e contribuições $r$ e $s$}

Sabe-se (ver, por exemplo, Burbidge et al. 1957, Pagel 1997, Rolfs \& Rodney 1988) que a formação de elementos químicos com $\mathrm{A} \geq 60$ se dá por reações endotérmicas. Os processos que governam a nucleossíntese para estes elementos são conhecidos como $s, r$ e $p$. Os processos $r$ e $s$ estão associados à captura de nêutrons (como visto no capítulo 2), e agem em condições distintas no interior estelar. Já no processo $p$ ocorre a captura de prótons, sendo este processo bem menos freqüente do que os acima citados e seus 
mecanismos de ocorrência ainda pouco conhecidos.

Como visto nas seções 2.1 e 2.2, existem condições particulares para que os processos $r$ e $s$ ocorram. Além disso, também sabe-se que os elementos químicos possuem contribuições de ambos os processos (Arlandini et al. 1999, Burris et al. 2000), mais ou menos intensas dependendo de cada elemento. A figura 3.4 mostra o padrão de abundância solar segundo as abundâncias fotosféricas determinadas por Asplund et al. (2005). Também estão mostradas na figura as contribuições dos processos $s$ e $r$, segundo as frações de Arlandini et al. (1999).

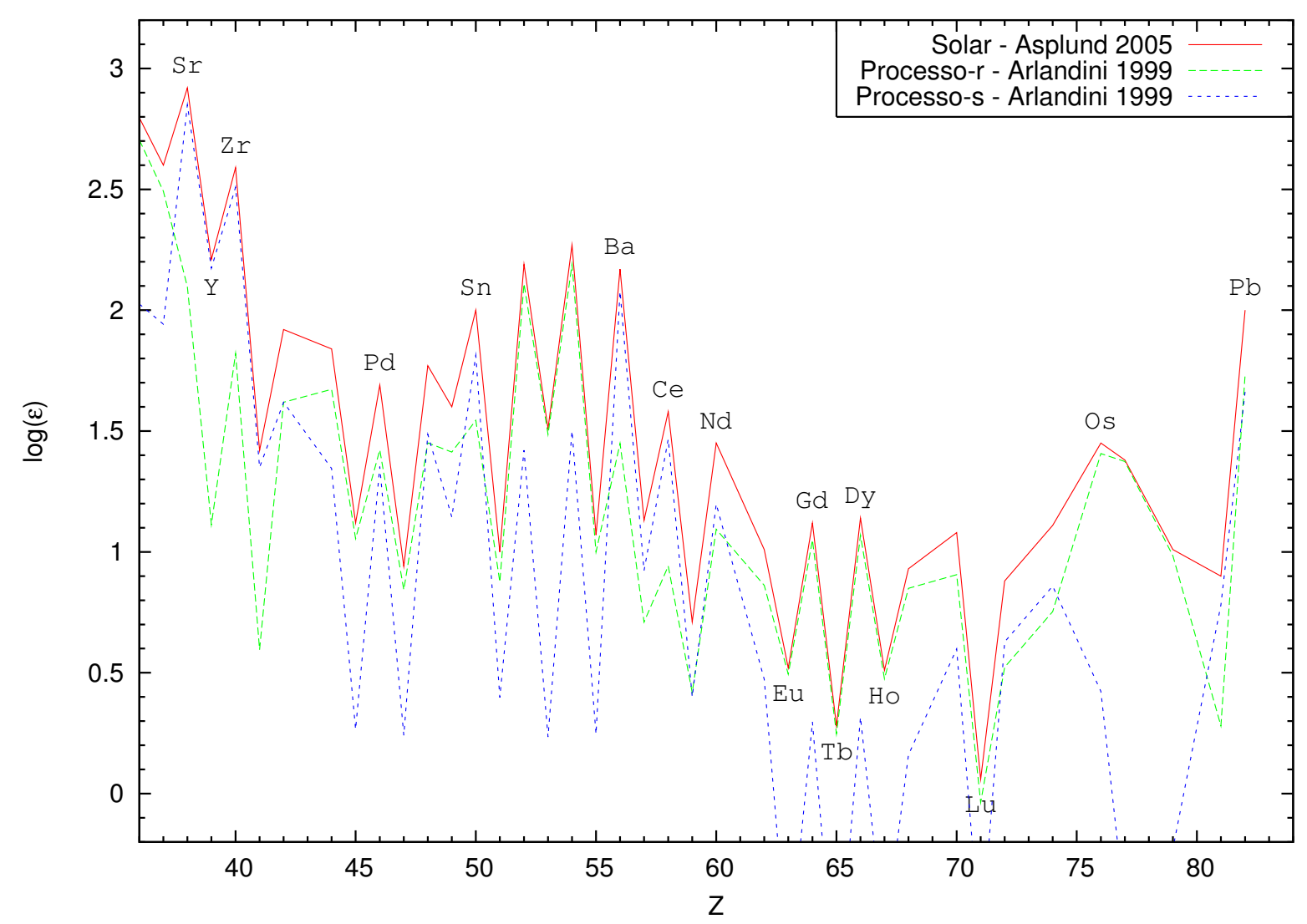

Fig. 3.4 Abundância solar para elementos com Z>30. A linha verde representa a componente $r$ e a azul a componente $s$. As frações utilizadas foram retiradas de Arlandini et al. (1999).

É muito importante obter valores cada vez mais precisos das abundâncias solares, pois elas fornecem uma base para que se entenda o interior do Sol e do sistema solar, e também funcionam como uma forma de se entender a composição química de outras estrelas. Se- 
gundo Asplund et al. (2005), a precisão das abundâncias fotosféricas é da ordem de 10\% e depende essencialmente de quão bom seja o modelo de atmosferas utilizado.

As abundâncias solares fotosféricas em Asplund et al. (2005) foram determinadas utilizando-se um modelo hidrodinâmico $3 D$ dependente do tempo, enquanto de Grevesse \& Sauval (1998) trabalham com um modelo $1 D$ para a atmosfera solar. Estas diferenças de modelagem geram diferenças nas determinações das abundâncias e suas incertezas, que por sua vez alteram os valores de $[\mathrm{A} / \mathrm{B}]$ e de $\log (\epsilon)$. A figura 3.5 mostra as diferenças percentuais entre as abundâncias determinadas pelos dois trabalhos, para os elementos citados na seção 3.2 .

As maiores diferenças entre as abundâncias solares presentes na figura 3.5 são encontradas para os elementos $S c$, $L a$ e $N d$, que ficam entre 2.5 e 4\%. Para todos os outros elementos as diferenças não são maiores que 2.5\%, e para 6 deles não existe diferença entre os valores. Neste trabalho são utilizados os valores solares (meteoríticos e atmosféricos) de Grevesse \& Sauval 1998, visto serem os mesmos usados nas análises feitas por Barklem et al. (2005) e por Sara Lucatello (comunicação particular).

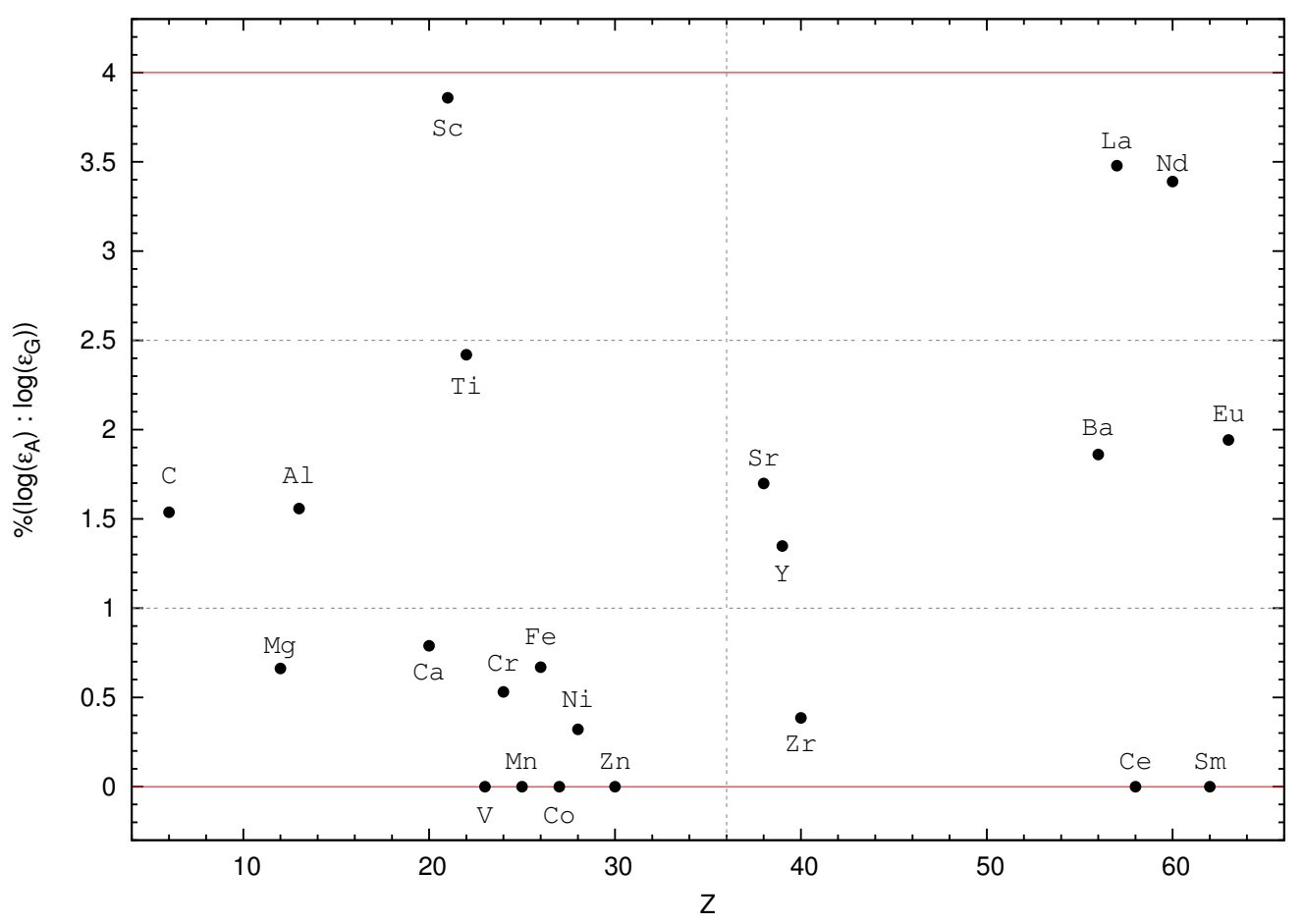

Fig. 3.5 Diferenças percentuais entre os trabalhos de Asplund et al. (2005) $\left(\log \left(\epsilon_{A}\right)\right)$ e Grevesse et al. (1998) $\left(\log \left(\epsilon_{G}\right)\right)$ para os elementos da amostra. 
Como visto anteriormente na seção 3.2, este trabalho utiliza abundâncias elementais de uma série de elementos químicos. Dos 22 elementos citados, 10 ( $Z n$, Sr, $Y, Z r, B a, L a$, $C e, N d, S m$ e $E u$ ) são formados por processo de captura de nêutrons. A tabela 3.3 mostra as contribuições $r$ e $s$ dos 10 elementos listados acima, segundo dois trabalhos distintos: Arlandini et al. (1999) e Burris et al. (2000).

Para alguns dos elementos da tabela 3.3, nota-se uma grande diferença nas contribuições $r$ e $s$, o que pode acarretar em valores diferentes no cálculo dos padrões solares dos elementos para comparação.

\begin{tabular}{cccccc}
\hline Elemento & $\mathrm{Z}$ & Burris $(r)$ & Burris $(s)$ & Arlandini $(r)$ & Arlandini $(s)$ \\
\hline $\mathrm{Zn}$ & 30 & 0.66 & 0.34 & 0.991 & 0.009 \\
\hline $\mathrm{5r}$ & 38 & 0.11 & 0.89 & 0.150 & 0.850 \\
$\mathrm{Y}$ & 39 & 0.28 & 0.72 & 0.080 & 0.920 \\
$\mathrm{Zr}$ & 40 & 0.19 & 0.81 & 0.170 & 0.830 \\
\hline & & & $2^{\circ}$ pico do processo-s & \\
$\mathrm{Ba}$ & 56 & 0.15 & 0.85 & 0.190 & 0.810 \\
$\mathrm{La}$ & 57 & 0.25 & 0.75 & 0.380 & 0.620 \\
$\mathrm{Ce}$ & 58 & 0.19 & 0.81 & 0.230 & 0.770 \\
$\mathrm{Nd}$ & 60 & 0.53 & 0.47 & 0.440 & 0.560 \\
\hline $\mathrm{Sm}$ & 62 & 0.66 & 0.34 & 0.710 & 0.290 \\
$\mathrm{Eu}$ & 63 & 0.97 & 0.03 & 0.942 & 0.058 \\
\hline
\end{tabular}

Tab. 3.3 Contribuições dos processos $r$ e $s$ para a abundância total dos elementos da amostra, segundo as frações de Arlandini et al. (1999) e Burris et al. (2000).

A figura 3.6 mostra mais claramente estas diferenças. Note que, para os elementos presentes na amostra, a maior discrepância se dá para o $Z n(\sim 0.33)$, seguido do $Y(\sim 0.20)$ e do La ( 0.13). Para os outros elementos ainda existem diferenças, porém menores, mas que também devem ser levadas em conta.

Durante a análise das abundâncias dos objetos, foram utilizadas as frações de ambos os trabalhos para fins comparativos. O trabalho de Burris et al. (2000) utiliza o chamado approach clássico (Cowan \& Sneden 2003) para calcular as contribuições $r$ e $s$ dos elementos. 


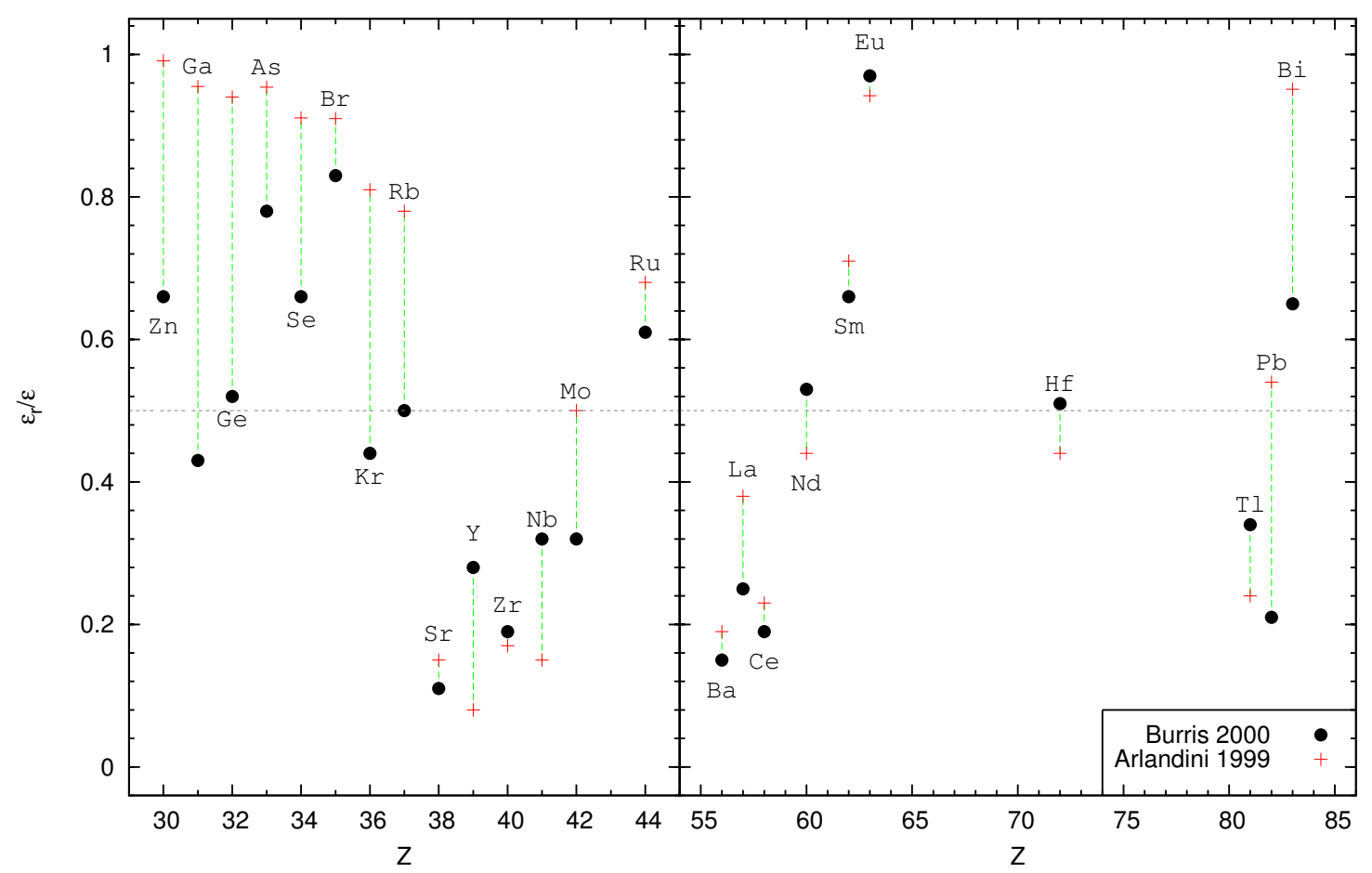

Fig. 3.6 Comparação entre as contribuições do processo-r para alguns elementos cujas diferenças são maiores que $5 \%$ e para os elementos da amostra. A linha verde representa a distância entre os valores de Burris et al. (2000) e Arlandini et al. (1999).

Este cálculo é feito com base na curva $\sigma N$ vs. $Z$ (ou seja, o produto da seção de choque de captura com a abundância do processo-s), semelhante à figura 2.2. Vale lembrar que esta determinação é empírica, e também fornece a fração do processo-r segundo a equação 2.10. Já o trabalho de Arlandini et al. (1999) é baseado num modelo de nucleossíntese do processo-s em estrelas de baixa massa no AGB.

As frações de Arlandini et al. (1999) mostraram-se mais adequadas para ajustar os padrões solares $r$ e $s$ para os objetos, sendo que o fator principal das diferenças (para os elementos formados por captura de nêutrons utilizados na análise) reside no elemento $Y$. 


\section{ANÁLISE}

Neste trabalho, os elementos formados por captura de nêutrons $(S r, Y, Z r, B a, L a$, $C e, N d, S m$ e $E u$ ) e o carbono, são estudados com detalhe via dispersões das abundâncias com a metalicidade, razões de abundâncias e análise de agrupamento hierárquico.

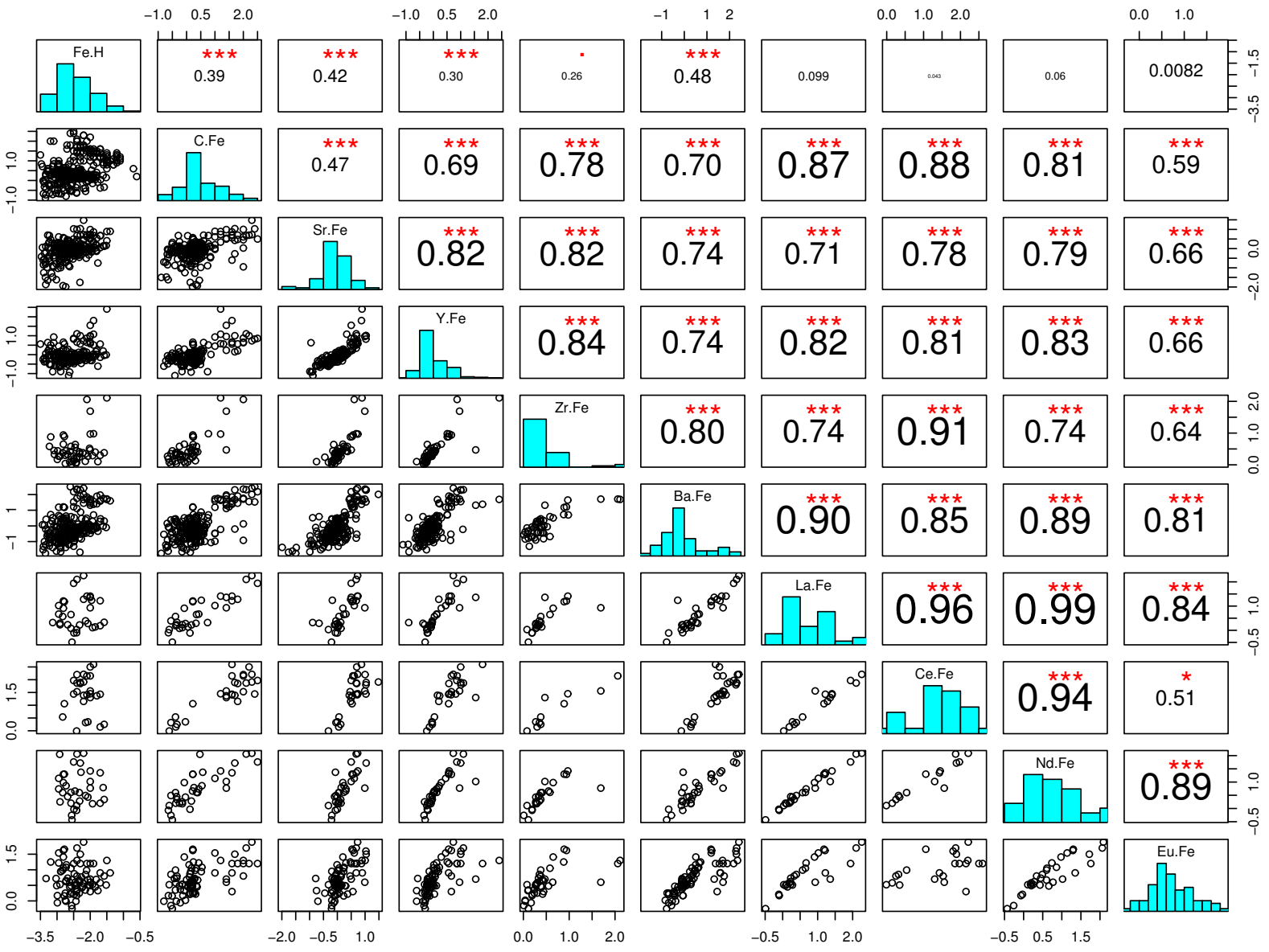

Fig. 4.1 Diagrama de pares para os elementos químicos estudados neste trabalho.

A figura 4.1 (Diagrama de pares) mostra o comportamento geral das abundâncias elementais estudadas. Na diagonal principal da figura encontram-se os histogramas das 
abundâncias em relação ao ferro. Na parte abaixo desta, encontram-se as dispersões relativas a cada par de abundâncias, relativas às legendas presentes na diagonal. Já a parte superior mostra o coeficiente de correlação da dispersão encontrada na parte inferior da figura, diametralmente oposta à diagonal, ou seja, a dispersão entre as abundâncias de dois elementos localizados nas células $A_{i i}{ }^{1}$ e $A_{j j}$ da diagonal principal encontra-se na célula $A_{j i}$, enquanto o coeficiente de correlação encontra-se na célula $A_{i j}$. Também pode ser encontrado junto ao coeficiente de correlação uma medida da qualidade do mesmo, avaliada pelo valor-p do ajuste, ou seja, quanto maior a quantidade de asteriscos vermelhos, melhor é a qualidade do valor da correlação entre as variáveis ${ }^{2}$.

Como foi visto no capítulo 2, os processos de captura de nêutrons necessitam de condições muito particulares e extremas para que ocorram. Portanto, são necessários locais astrofísicos com alta densidade de nêutrons e temperatura. Essas condições ocorrem essencialmente em explosões de Supernova tipo Ia (SNIa), em estrelas de massa intermediária que passam pela fase AGB (para o processo-s), em explosões de Supernova tipo II (SNII), estrelas de nêutrons e eventos AIC (para o processo-r). Sendo assim, o estudo das abundâncias elementais faz-se necessário para verificar, além dos locais de formação, as escalas de tempo envolvidas no enriquecimento químico das estrelas observadas.

Para observar este enriquecimento do meio em função do tempo, utiliza-se, por exemplo, $[\mathrm{X} / \mathrm{Fe}]$ vs. $[\mathrm{Fe} / \mathrm{H}]$. Em $X$ pode-se usar um único elemento para estudar sua evolução, como também por exemplo a soma de elementos $r$ ou $s$, para uma descrição mais geral do processo de sua formação. A metalicidade pode ser interpretada como uma dimensão de tempo, sabendo que objetos com menor conteúdo metálico foram formados de nuvens menos enriquecidas, ou seja, mais antigas. Exemplos deste tipo de estudo podem ser vistos em Barbuy et al. (2005), Barklem et al. (2005), Rossi et al. (2005), Zhang \& Zhao (2005) entre outros.

A presença de elementos r-processados em estrelas muito velhas sugere que seus progenitores tiveram vidas curtas, ou seja, eram estrelas massivas que evoluíram rapidamente, ejetando os produtos e enriquecendo o meio interestelar, local de formação das estrelas que são observadas hoje em dia. Em contrapartida, o local primário para formação dos

\footnotetext{
${ }^{1} X_{a b}$ é a célula da matriz $X$ localizada na linha $a$ e coluna $b$.

${ }^{2}$ Maiores detalhes sobre o valor-p, coeficiente de correlação bem como a matriz completa de correlação entre todas as abundâncias da amostra podem ser vistos no apêndice A.2.1.
} 
elementos $s$ são estrelas de massa baixa e intermediária $\left(\mathrm{M} \sim 0.8-8.0 M_{\odot}\right)$, com longas escalas de tempo de evolução (Cowan \& Sneden 2003). Sendo assim, espera-se que ocorra um "atraso" na formação dos elementos por processo-s em relação aos elementos $r$. Este fato será melhor explorado no capítulo 5 .

\subsection{Abundâncias elementais}

Nesta seção são apresentadas dispersões da forma $[\mathrm{X} / \mathrm{Fe}]$ vs. $[\mathrm{Fe} / \mathrm{H}]$. Na seção 4.2 são mostradas dispersões encontradas entre os elementos formados por captura de nêutrons presentes na tabela 3.3. Na seção 4.3, apresenta-se as relações entre os elementos formados por captura de nêutrons da amostra com o carbono.

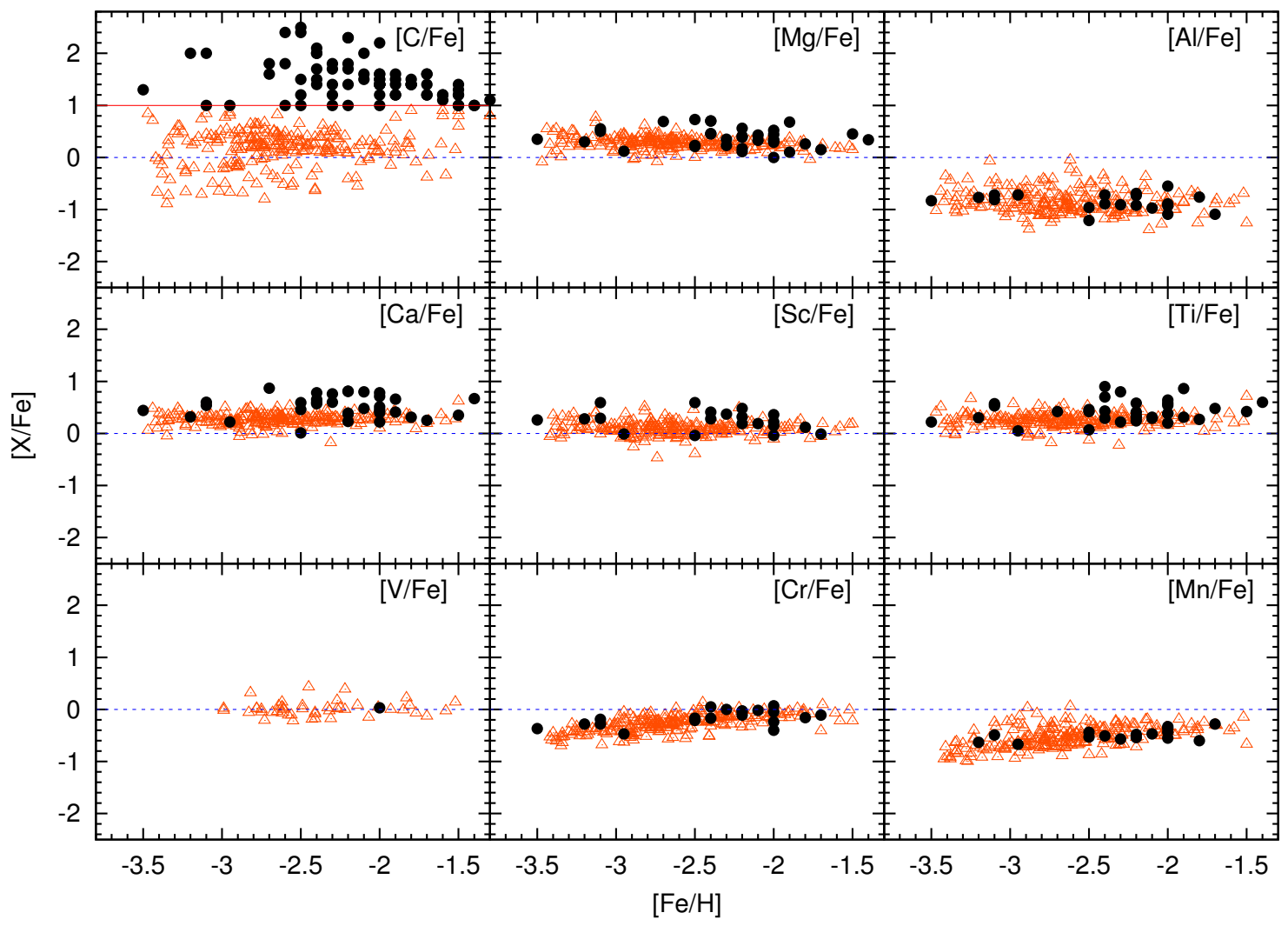

Fig. 4.2 Abundâncias elementais para os elementos com número atômico $6<\mathrm{Z}<25$ presentes na amostra. Os círculos pretos indicam $[\mathrm{C} / \mathrm{Fe}] \geq+1.0$ e os triângulos indicam $[\mathrm{C} / \mathrm{Fe}]<+1.0$.

As figuras 4.2 e 4.3 mostram, respectivamente, o comportamento dos elementos nas faixas $6<\mathrm{Z}<25$ e $27<\mathrm{Z}<63 \mathrm{com}$ a metalicidade. As dispersões relativas aos elementos $\mathrm{Zr}$, 
Ce e Sm foram omitidas por possuírem poucas medidas e não mostrarem nenhum tipo de tendência ou correlação com a metalicidade. Porém, como será visto a seguir, os elementos Zr e Ce serão usados, respectivamente, para descrever a evolução dos elementos do primeiro e segundo picos do processo-s.

Na figura 4.2 pode-se observar o comportamento dos três elementos $\alpha(\mathrm{Mg}, \mathrm{Ca}, \mathrm{Ti})$ em relação à metalicidade, com um espalhamento menor que 1.0 dex. Os elementos $\alpha$ são definidos como elementos (além do carbono e oxigênio) com Z>22 e "múltiplo" de uma partícula $\alpha$, devido à sucessivas adições de um núcleo de hélio (por exemplo $\mathrm{Ne}, \mathrm{Mg}, \mathrm{Si}$, $\mathrm{S}, \mathrm{Ar}, \mathrm{Ca}, \mathrm{Ti})$. A maior parte dos elementos $\alpha$ são formados em SNII e ejetados no meio interestelar. Sendo assim, a razão $[\alpha / \mathrm{Fe}]$ deve ser maior para metalicidades menores. O diagrama padrão que mostra $[\mathrm{O} / \mathrm{Fe}]$ ou $[\alpha / \mathrm{Fe}]$ vs. $[\mathrm{Fe} / \mathrm{H}]$ é conhecido como "Diagrama HR da Evolução Química", dada sua importância na descrição da evolução da Galáxia e do Universo.

Todas as distribuições para os elementos $\alpha$ mostram tendências constantes para metalicidades $[\mathrm{Fe} / \mathrm{H}]<-2.0$. Para valores maiores, podemos notar uma pequena diminuição em $[\alpha / \mathrm{Fe}]$, que pode ser explicado como um aumento na abundância de ferro no meio, ejetado em explosões de SNIa, às quais têm escalas de tempo maiores que as SNII, pois são resultado da evolução de estrelas de massa intermediária. Então, se for possível determinar o ponto no qual $[\alpha / \mathrm{Fe}]$ começa a decrescer, pode-se inferir as idades e faixas de massa das estrelas que sintetizaram estes elementos.

Estudos recentes (como por exemplo, García Pérez et al. 2006) fazem medições de abundâncias de oxigênio afim de mostrar a evolução deste elemento com a metalicidade, para estrelas subgigantes pobres em metal. Utiliza-se o oxigênio por ser o elemento mais abundante no Sol, depois do $\mathrm{H}$ e do He, e sua abundância ser medida utilizando-se três linhas distintas em regiões diferentes do espectro dos objetos. Estes resultados podem ser utilizados para uma futura comparação entre a evolução do oxigênio com a de outros elementos $\alpha$ em função da metalicidade.

Outra classe de elementos com abundâncias determinadas são os elementos do pico do ferro, com números atômicos na faixa $21 \leq Z \leq 30$. Na figura 4.2 , vemos que o espalhamento para alguns dos elementos do pico do ferro (Sc, V, Cr, Mn, Co e Ni) com a metalicidade também não é maior do que 1.0 dex. O estudo detalhado de tendências destes elementos 
com a metalicidade é útil para, por exemplo, pesquisar a origem de aglomerados globulares do Halo Galático que possam ter sido acretados num episódio de merger (ver, por exemplo, Venn et al. 2004 e Sneden 2004).

Dentre todos os elementos da amostra com $Z<30$, o carbono é o único estudado com detalhes. Como visto na seção 2.1, este elemento tem um papel importante nas reações que dão origem aos nêutrons necessários para os processos de captura. Além disso, o estudo das abundâncias de carbono pode contribuir para descrição da evolução de estrelas que passam pela fase AGB e para explicar o padrão de abundância de estrelas muito pobres em metais.

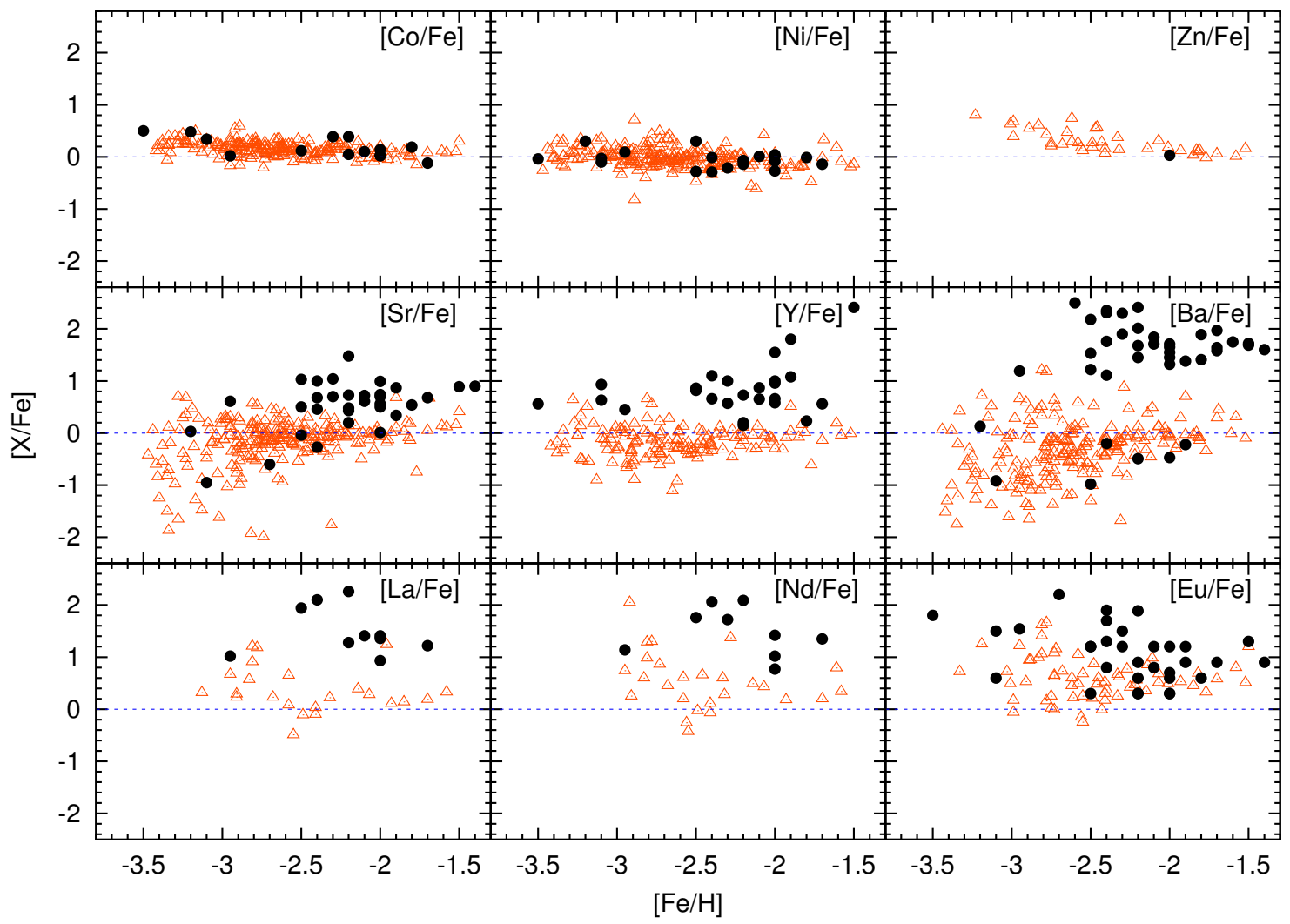

Fig. 4.3 Abundâncias elementais para os elementos com número atômico $27<\mathrm{Z}<63$ presentes na amostra. Os círculos pretos indicam $[\mathrm{C} / \mathrm{Fe}] \geq+1.0$ e os triângulos indicam $[\mathrm{C} / \mathrm{Fe}]<+1.0$.

O painel superior esquerdo da figura 4.2 mostra o comportamento da abundância de C com a metalicidade. Pode-se notar que, para $[\mathrm{Fe} / \mathrm{H}]<-2.0$ existe uma série de objetos com $[\mathrm{C} / \mathrm{Fe}]>+1.0$, definidos por Rossi et al. (2005) como estrelas carbonadas. Na seção 
4.3, estas características são melhor estudadas, bem como são mostradas as relações do C com os outros elementos da amostra.

As dispersões relativas aos elementos formados por captura de nêutrons são mostradas na figura 4.3. Os espalhamentos para os elementos Sr, Y, Ba, La, Nd e Eu são maiores que 2.0 dex para uma grande faixa de metalicidades, em especial para $[\mathrm{Fe} / \mathrm{H}]<-2.5$. O menor espalhamento encontrado é para o elemento Zn ( 99\% formado por processo-r, segundo Arlandini et al. 1999), que está em torno de 0.5 dex e mostra uma anti-correlação linear com a metalicidade. Detalhes sobre cada um dos elementos $r$ e $s$ estudados são mostrados nas seções a seguir.

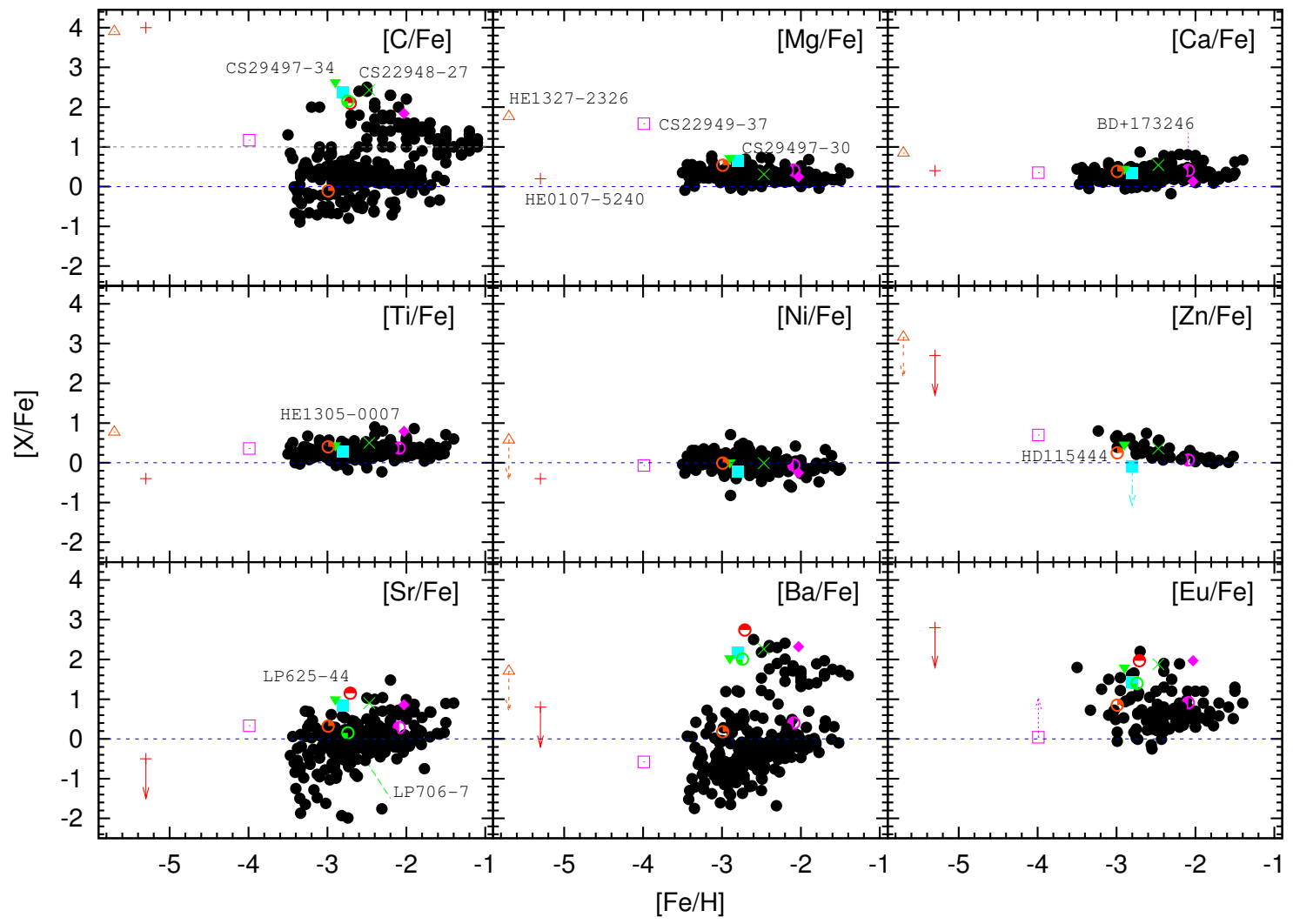

Fig. 4.4 Abundâncias elementais para alguns elementos da amostra e comparação com objetos de outros estudos. As setas indicam limites superiores/inferiores para as abundâncias de alguns elementos. Os símbolos referem-se aos objetos listados na tabela 4.1.

Para fins de comparação e também para tentar identificar possíveis tendências das abundâncias, foram adicionados dados referentes a outros estudos de estrelas pobres em metais retirados da literatura. A figura 4.4 apresenta as abundâncias (ou limites superio- 
res/inferiores) de nove elementos presentes nos objetos da amostra. Os valores de metalicidade, abundâncias dos elementos $\mathrm{Eu}$, Ba e Sr e referências utilizadas encontram-se na tabela 4.1, bem como as subclasses de cada objeto, de acordo com os critérios propostos na tabela 3.1.

\begin{tabular}{|c|c|c|c|c|c|c|c|c|}
\hline Símbolo & Objeto & {$[\mathrm{Fe} / \mathrm{H}]$} & {$[\mathrm{C} / \mathrm{Fe}]$} & {$[\mathrm{Eu} / \mathrm{Fe}]$} & {$[\mathrm{Ba} / \mathrm{Fe}]$} & {$[\mathrm{Sr} / \mathrm{Fe}]$} & Classe & Referência \\
\hline$\triangle$ & HE1327-2326 & -5.70 & +3.90 & - & 1.70 & - & - & Aoki 2006 \\
\hline+ & HE0107-5240 & -5.30 & +4.00 & 2.80 & 0.80 & -0.50 & - & Christlieb 2002 \\
\hline$\bullet$ & CS22949-037 & -3.99 & +1.17 & 0.04 & -0.58 & 0.33 & - & Depagne 2002 \\
\hline () & HD115444 & -2.99 & -0.11 & 0.85 & 0.18 & 0.32 & $\mathrm{r}-\mathrm{I}$ & Westin 2000 \\
\hline - & CS22892-052 & -2.95 & +1.00 & 1.54 & 1.19 & 0.61 & r-II & Sneden 1996 \\
\hline$\nabla$ & CS29497-034 & -2.90 & +2.63 & 1.80 & 2.03 & 1.00 & $r / s$ & Barbuy 2005 \\
\hline$\square$ & CS29497-030 & -2.80 & +2.38 & 1.44 & 2.17 & 0.84 & S-II & Sivarani 2004 \\
\hline$\bullet$ & CS31082-001 & -2.78 & +0.22 & 1.66 & 1.18 & 0.53 & r-II & Hill 2002 \\
\hline () & LP706-7 & -2.74 & +2.15 & 1.40 & 2.01 & 0.15 & s-II & Aoki 2001 \\
\hline () & LP625-44 & -2.71 & +2.10 & 1.97 & 2.74 & 1.15 & s-II & Aoki 2001 \\
\hline$x$ & CS22948-027 & -2.47 & +2.43 & 1.88 & 2.26 & 0.90 & $r / s$ & Barbuy 2005 \\
\hline$\bullet$ & HD221170 & -2.18 & -0.71 & 0.80 & 0.26 & 0.13 & $\mathrm{r}-\mathrm{I}$ & Burris 2000 \\
\hline (อ) & $\mathrm{BD}+17^{\circ} 3246$ & -2.09 & - & 0.91 & 0.40 & 0.29 & r-I & Cowan 2002 \\
\hline$\diamond$ & HE1305+0007 & -2.03 & +1.84 & 1.97 & 2.32 & 0.86 & $r / s$ & Goswami 2006 \\
\hline
\end{tabular}

Tab. 4.1 Objetos utilizados na figura 4.4 para comparação com os dados do HERES. Os objetos CS31082-001 (Hill et al. 2002), CS22892-052 (Sneden et al. 1996 e 2003) e HD221170 (Burris et al. 2000 e Ivans et al. 2006) já fazem parte da amostra e não foram destacados na figura. A coluna classe foi preenchida de acordo com os critérios da tabela 3.1. Os valores em vermelho representam limites superiores/inferiores para as abundâncias.

Pode-se notar que para os elementos $\alpha, \mathrm{Ni}$ e Zn, existem tendências crescentes com a diminuição da metalicidade. Porém, para o Sr, Ba e Eu, embora o espalhamento seja bem maior, pode-se notar uma tendência decrescente de suas abundâncias à medida em que a razão $[\mathrm{Fe} / \mathrm{H}]$ diminui. A hipótese de um meio não homogêneo para baixas metalicidades (ver, por exemplo, Burris et al. 2000; Truran et al. 2002; Barbuy et al. 2005) pode ser uma explicação para este espalhamento, e será melhor explorada no capítulo 5. Também foram 
adicionadas à figura as duas estrelas $U M P^{3}$ encontradas até o momento, com $[\mathrm{Fe} / \mathrm{H}]<-5.0$. Estes dois casos extremos podem trazer evidências sobre a formação da Galáxia e sobre os padrões de abundâncias para as estrelas nesta faixa de metalicidades.

Todas as dispersões levam em conta apenas os objetos com abundâncias determinadas. O fato de um objeto não possuir abundância de um certo elemento pode ser devido ao fato do elemento não estar presente na estrela ou de sua linha espectral ser muito pouco intensa e julgada como parte do ruído de medida ${ }^{4}$. Em ambos os casos a abundância elemental [X/Fe] na base de dados é representada pelo número -9.99 , já que o valor 0.00 representa a abundância solar.

\subsection{Elementos formados por captura de nêutrons}

Os elementos pesados ( $\mathrm{A} \geq 130$, segundo Qian \& Wasserburg 2003) são formados em ambientes com altas densidades e temperaturas. Observa-se um grande espalhamento para estes elementos em baixas metalicidades, e algumas explicações distintas são dadas para o fato.

A figura 4.5 mostra o comportamento de três elementos formados por captura de nêutrons em função da metalicidade. Pode-se observar que, além do aumento do valor de $[\mathrm{Eu} / \mathrm{Fe}]$ com a diminuição da metalicidade, temos um aumento do espalhamento em valores abaixo de $[\mathrm{Fe} / \mathrm{H}] \approx-2.6$. Este fato sugere que a Galáxia não era homogênea no início de sua formação, e que nem todas as estrelas deram origem aos elementos $r$ e ao ferro. Porém, este espalhamento também é consistente com a hipótese de que apenas uma pequena fração das estrelas massivas que formaram Fe também formaram elementos $r$ (Truran et al. 2002).

Uma abordagem alternativa àquela dada por estes últimos autores pode ser encontrada em Qian \& Wasserburg (2003). Neste estudo é sugerido que o espalhamento na relação $[\mathrm{Eu} / \mathrm{Fe}]$ vs. $[\mathrm{Fe} / \mathrm{H}]$ para baixas metalicidades se deve ao fato de os elementos $r$ "pesados"

\footnotetext{
${ }^{3}$ A nomenclatura para estrelas pobres em metais pode ser vista na tabela 1.1.

${ }^{4}$ Para o cálculo das abundâncias (Barklem et al. 2005 e Lucatello - comunicação particular) foi imposto um limite de $3 \sigma$. Se nenhuma linha é detectada neste invervalo, significa que a razão sinal/ruído do espectro é muito baixa para se detectar a linha espectral desejada, neste caso. A abundância só poderia ser determinada se o intervalo de confiança fosse maior ou se o espectro apresentasse maior S/N.
} 
(com massa $\geq 130$ ) serem formados em eventos isolados, como em um colapso induzido por acresção (AIC).

Dois elementos podem ser destacados na figura 4.5: Ba, que como visto na tabela 2.2, é predominantemente formado por processo-s e Eu, por processo-r. A razão [Ba/Fe] decresce com a diminuição da metalicidade. Isto sugere que o bário foi formado numa escala de tempo mais longa, ou seja, por processo-s, associado à evolução de estrelas de massa intermediária que terminam sua vida como SNIa. Já a razão [Eu/Fe] cresce com a diminuição da metalicidade. Este fato pode ser explicado, por exemplo, se as estrelas de População III (primeira geração estelar) forem consideradas massivas e supermassivas $\left(M>10 M_{\odot}\right.$ e $M>100 M_{\odot}$, ver Ballero et al. 2006), as quais ejetariam elementos pesados em explosões de SNII.

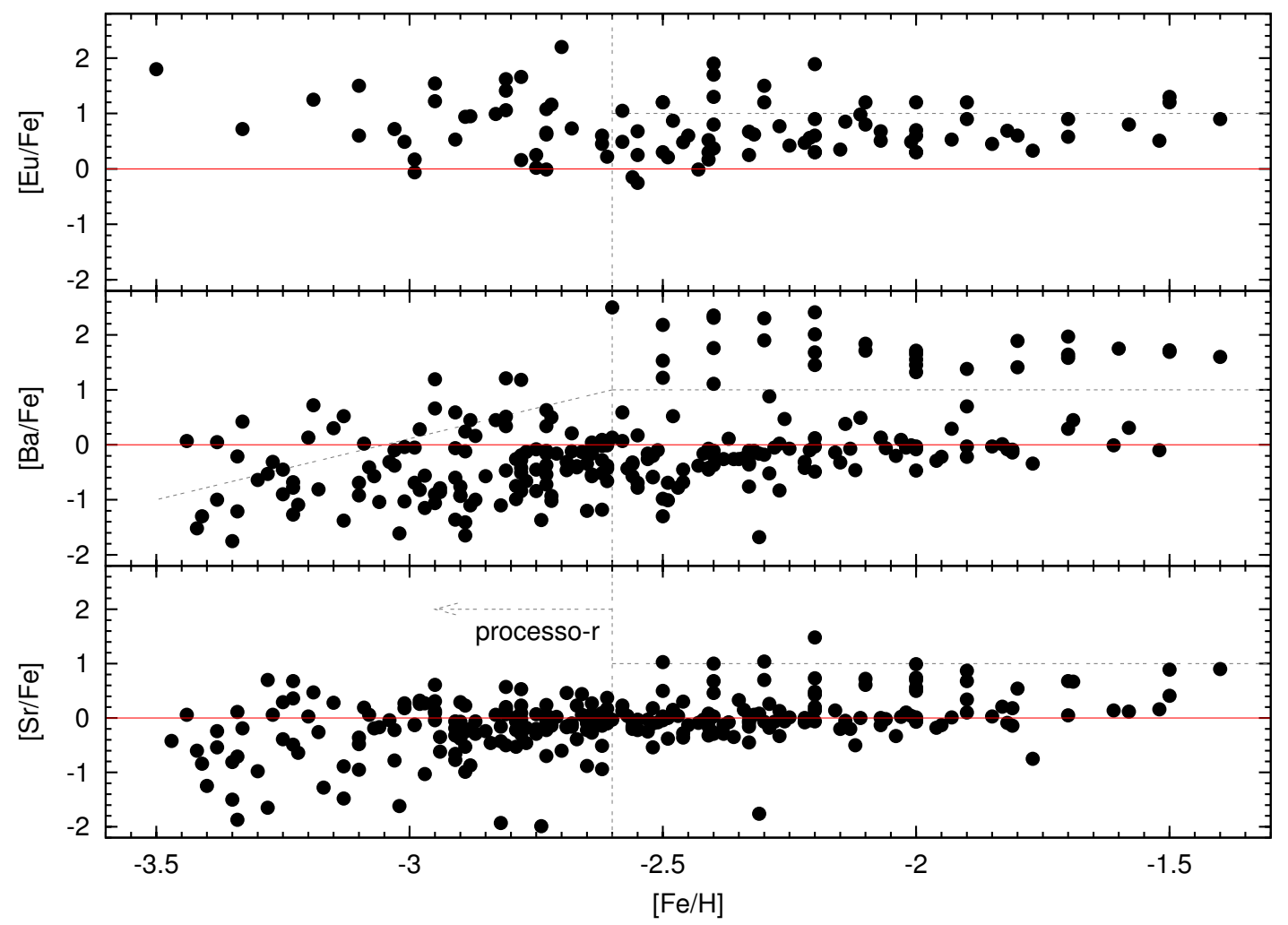

Fig. 4.5 Comportamento das abundâncias em função da metalicidade para os elementos Sr e $\mathrm{Ba}(s)$ e $\mathrm{Eu}(r)$.

O trabalho de Truran et al. (2002) cita outra importante característica que pode ser observada quando se considera a razão $[\mathrm{Eu} / \mathrm{Fe}]$ : para $[\mathrm{Fe} / \mathrm{H}] \simeq-1.0$, os valores de $[\mathrm{Eu} / \mathrm{Fe}]$ 
tendem a diminuir. Isto pode ser reflexo do aumento da produção de Fe, provavelmente pelas Supernovas de tipo Ia, em metalicidades maiores. Já em valores de metalicidade bem baixos, as SNII (de alta massa que evoluem rapidamente) contribuem para a produção de ferro. O início da produção de grande parte do ferro pelas SNIa (com tempos de vida mais longos e massas menores) só ocorre em altas metalicidades, fazendo com que a razão [Eu/Fe] decresça. Porém, para a base de dados do HERES não é possível identificar tal tendência, visto que as metalicidades máximas para os objetos com abundância de Eu determinada são menores que $[\mathrm{Fe} / \mathrm{H}] \sim-1.5$.

Outra tentativa de explicar o comportamento do Eu e do Ba em baixas metalicidades é feita em Cescutti et al. (2006), que utiliza o modelo de evolução química da Galáxia com duplo infall de Chiappini et al. (1997). Neste caso, os resultados mostram que o Ba necessita de uma componente principal formada por processo-s (em estrelas de baixa massa) e outra componente "rápida" (em estrelas com massa entre 10-30 $M_{\odot}$, mesmo ambiente onde a grande maioria do elemento Eu é produzido). Porém, os yields obtidos não conseguem explicar o grande espalhamento a baixas metalicidades, mesmo utilizando um modelo não homogêneo. Para os dados do HERES, encontra-se uma boa correlação com o modelo descrito em Ishimaru et al. (2005), que restringe o intervalo de massas das SNII progenitoras dos elementos $r$ em 8-10M $\odot$. Este modelo mostra um crescimento do espalhamento de $[\mathrm{Eu} / \mathrm{Fe}]$ com a metalicidade até $[\mathrm{Fe} / \mathrm{H}] \sim-3.6$, seguido de uma queda acentuada.

A partir da figura 4.1 pode-se observar que os coeficientes de correlação entre Sr, Ba e Eu com a metalicidade são, respectivamente: $0.42,0.48$ e 0.082 . O valor baixo para o Eu é esperado, e é reflexo do aumento do espalhamento dos dados a partir de $[\mathrm{Fe} / \mathrm{H}] \approx-2.6$. Já os elementos Sr e Ba possuem uma correlação moderada ${ }^{5}$ com a metalicidade ( 0.5) e positiva, o que denota a diminuição dos valores com a queda da metalicidade. Porém, podese observar no painel central da figura 4.5 que o Ba possui dois regimes distintos: 1) parte dos dados se concentra em $[\mathrm{Fe} / \mathrm{H}]>-2.6$ e $[\mathrm{Ba} / \mathrm{Fe}]>1.0$; e 2) os demais objetos encontramse próximos ao valor solar para $[\mathrm{Ba} / \mathrm{Fe}]$ e decrescem, em média, com a diminuição da metalicidade. A figura 4.3 mostra que os objetos destacados em 1) são ricos em carbono, fato que é explorado na seção 4.3.

Além disso, como será mostrado na seção 4.4, as estrelas citadas em 1) possuem a

\footnotetext{
${ }^{5}$ ver intervalos dos coeficientes de correlação no apêndice A.2.1.
} 
razão $[\mathrm{Ba} / \mathrm{Eu}]>0.0$, o que as coloca na classe de objetos $s$ (s-I e s-II). Assim, a partir do painel central da figura 4.5, pode-se inferir um limite para o início do processo-s na Galáxia em $[\mathrm{Fe} / \mathrm{H}] \sim-2.6$. Os demais objetos, principalmente para metalicidades abaixo deste valor, têm sua abundância de Ba formada por processo-r e, quando a componente $s$ é introduzida na Galáxia, ocorre a sobreabundância mostrada na figura. Outros estudos mostram estrelas em baixas metalicidades com assinaturas de processo-s, como Simmerer et al. (2004) $([\mathrm{Fe} / \mathrm{H}]=-2.6)$, Sivarani et al. (2004) $([\mathrm{Fe} / \mathrm{H}]=-2.8)$ e Johnson \& Bolte (2002) $([\mathrm{Fe} / \mathrm{H}]=-3.1)$; porém, as características do processo-s em metalicidades muito baixas ainda são incertas (ver, por exemplo, Beers \& Christlieb (2005) e referências nele contidas).

\subsection{Carbono}

O carbono apresenta grande dispersão para os dados da amostra. Segundo o trabalho de Rossi et al. (2005), espera-se que, para valores de $[\mathrm{C} / \mathrm{Fe}]>+1.0$ (linha vermelha no painel superior esquerdo da figura 4.2) e $[\mathrm{Fe} / \mathrm{H}]<-2.0$, a abundância de carbono cresça com a diminuição da metalicidade. Estes objetos, segundo a classificação de Beers \& Christlieb (2005), são chamados CEMP (Carbon Enhanced Metal Poor).

Uma das explicações para esta sobreabundância de carbono ${ }^{6}$ para metalicidades abaixo de -2.0 é a de que o carbono tenha sido produzido em grande escala em estrelas com massas intermediárias $\left(2.0 \leq M\left(M_{\odot}\right) \leq 8.0\right)$ durante a evolução no AGB. Se estes objetos fossem parte de um sistema binário, em certas condições, esta estrela iria transferir parte de seu conteúdo para sua companheira de baixa massa (e tempo de vida longo), fato que permitiria a detecção deste elemento no presente.

Neste contexto, uma das possíveis explicações para o espalhamento é que nem todas as estrelas são parte de sistemas binários, ou que o enriquecimento pela companheira não ocorre de forma homogênea. Porém, a baixa estatística pode mascarar o crescimento proposto por Rossi et al. (2005). A figura 4.6 mostra o comportamento dos elementos formados por captura de nêutrons em relação à abundância de carbono.

Pode-se notar que, com exceção das abundâncias de Ba e Sr para algumas estrelas, todos os objetos com $[\mathrm{C} / \mathrm{Fe}]>+1.0$ possuem valores acima do valor solar para as abundâncias

\footnotetext{
${ }^{6} \sim 20 \%$ das estrelas com $[\mathrm{Fe} / \mathrm{H}]<-2.0$ apresenta excesso em carbono (Aoki et al. 2007).
} 


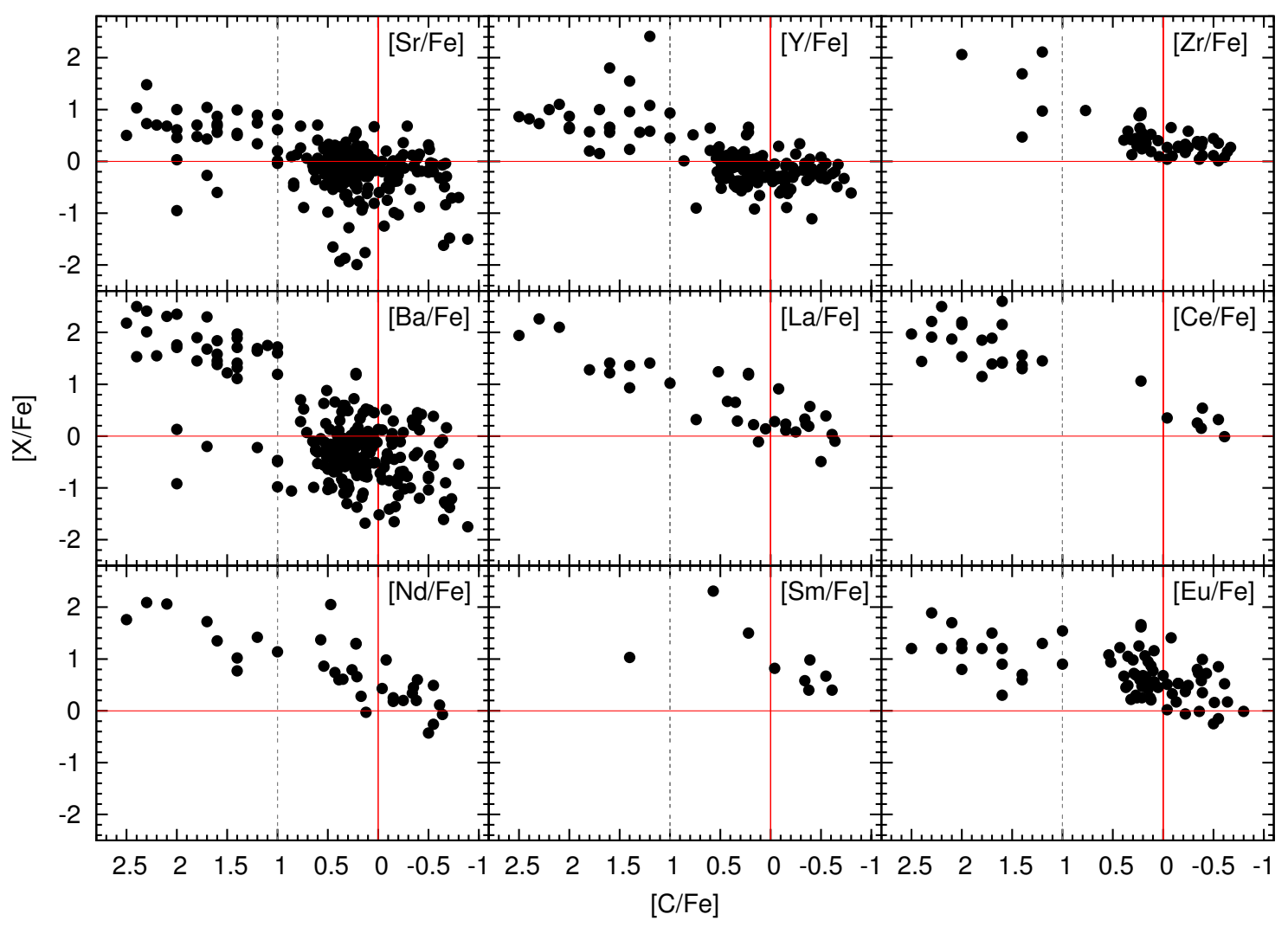

Fig. 4.6 Comportamento dos elementos formados por captura de nêutrons em relação à abundância de carbono. As linhas vermelhas representam a abundância solar para as razões e a linha pontilhada denota o limite para as estrelas CEMP $([\mathrm{C} / \mathrm{Fe}]>+1.0$ - tabela $1.3)$.

dos demais elementos. Da mesma forma, para os elementos Ba e Ce (segundo pico do processo-s $)$, todos os objetos com $[\mathrm{Ba} / \mathrm{Fe}]$ e $[\mathrm{Ce} / \mathrm{Fe}]>1.0$ possuem $[\mathrm{C} / \mathrm{Fe}]>+1.0$, o que não ocorre para os elementos do primeiro pico $s$. Esta distinção na relação das abundâncias de certos elementos com a quantidade de carbono, que também pode ser vista pela análise dos coeficientes de correlação da figura 4.1, é importante para a análise de agrupamento (seção 4.5), pois o carbono pode ser usado como uma dimensão de abundância para separação dos grupos. Também pode-se notar que, para o painel referente à abundância [Ba/Fe], três objetos se encaixam na definição de estrelas CEMP-no (ver tabela 1.3). Estes objetos são sub-abundantes em bário e ricos em carbono, por isso não compartilham o mesmo sítio de formação dos outros objetos presentes no painel.

Segundo Beers \& Christlieb (2005), uma das explicações para o fenômeno do enrique- 
cimento de carbono é a produção interna deste elemento na estrela, ou seja, um enriquecimento intrínseco ao objeto, em estrelas com baixas metalicidades. Esta formação de carbono pode ser inserida no cenário de formação da Galáxia, onde a escassez de elementos pesados pode ter gerado efeitos não usuais de mistura nas estrelas, fazendo com que o carbono formado nas camadas internas fosse trazido à superfície nos episódios de dragagem durante a queima do hélio (Fujimoto et al. 2000; Schlattl et al. 2002; Weiss et al. 2004). Sendo assim, espera-se que tais objetos não façam parte de sistemas binários pois, como será visto no capítulo 5, objetos de baixa massa em sistemas binários sofrem episódios de enriquecimento de elementos pesados vindos da companheira massiva.

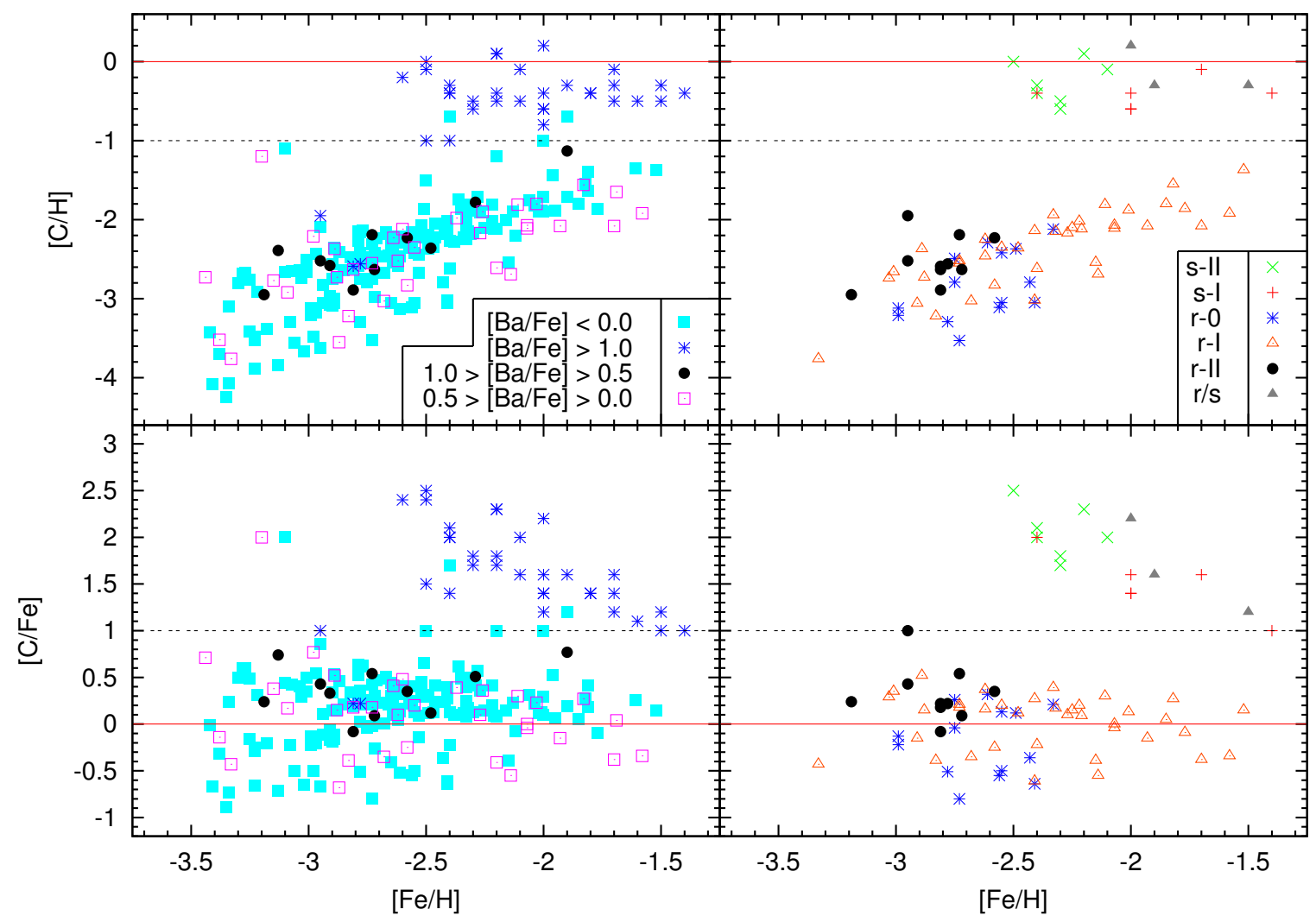

Fig. 4.7 Comportamento das abundâncias de bário e carbono em relação à metalicidade. Também é mostrado, nos paineis da direita, o comportamento das subclasses $r$ e $s$ para os mesmo parâmetros.

As estrelas CEMP-no $([\mathrm{C} / \mathrm{Fe}]>+1.0$ e $[\mathrm{Ba} / \mathrm{Fe}]<0.0)$ também podem ser destacadas na figura 4.7. Nota-se que estes objetos não seguem o comportamento geral das estrelas pobres em Ba, cujas abundâncias $[\mathrm{C} / \mathrm{H}]$ decrescem com a diminuição da metalicidade. 
Além disso, dois objetos podem ser destacados no painel inferior esquerdo da figura, pois possuem $[\mathrm{C} / \mathrm{Fe}] \sim+2.0$ e $[\mathrm{Fe} / \mathrm{H}]<-3.0$. O excesso de carbono em tais objetos não pode ser atribuído ao enriquecimento num sistema binário, pois sua abundância de Ba é baixa, o que reforça a hipótese de existir uma outra fonte para a formação do carbono neste caso.

O comportamento das estrelas enriquecidas em bário para as relações ([C/Fe] e $[\mathrm{C} / \mathrm{H}]$ ) vs. $[\mathrm{Fe} / \mathrm{H}]$ também é mostrado na figura 4.7. É possível notar que a maioria dos objetos com abundâncias de Ba maiores que 1.0 dex concentra-se na parte superior (rica em carbono) para os dois paineis da figura. Este fato reproduz a conclusão descrita em Aoki et al. (2006b), onde os objetos ricos em bário encontram-se no intervalo $-1.0<[\mathrm{C} / \mathrm{H}]<0.0$, com um corte claro em $[\mathrm{C} / \mathrm{H}] \approx 0.0$. Porém, a definição de estrelas ricas em bário segundo o trabalho de Aoki et al. (2006b) inclui o vínculo $[\mathrm{Ba} / \mathrm{Fe}]>0.5$. Para os dados da amostra existe uma melhor separação quando o vínculo $[\mathrm{Ba} / \mathrm{Fe}]>1.0$ é colocado, como visto na figura 4.7. Também é possível notar com clareza a diferença de comportamento entre as classes $r$ e $s$, como visto na seção 4.2. Todos os objetos da classe $s$ e $r / s$ se concentram na parte superior dos diagramas e com maiores valores de metalicidade dos gráficos.

Outra forma de vincular os locais de formação do carbono com os demais elementos analisados é através de razões entre elementos $r$ e $s$. A figura 4.8 mostra o comportamento das razões $[\mathrm{s} / \mathrm{Eu}]$ para os elementos do primeiro pico $s$ (Y e $\mathrm{Sr}$ - paineis superiores) e do segundo pico s (La e Ce - paineis inferiores) em função da abundância de carbono, divididas de acordo com a intensidade da razão [Ba/Eu]. Duas observações importantes podem ser feitas acerca da figura 4.8:

* Todos os objetos $r$ da amostra $([\mathrm{Ba} / \mathrm{Eu}]<0.0)$ possuem $[\mathrm{C} / \mathrm{Fe}] \leq+1.0$ e, além disso, concentram-se próximos à componente $r$ solar para a razão [Ba/Eu], como é esperado, mostrando que os elementos $r$ e carbono não compartilham um mesmo local de formação.

* As razões $[\mathrm{s} / \mathrm{Eu}]$ para o segundo pico $s$ comportam-se de forma análoga à razão $[\mathrm{Ba} / \mathrm{Eu}]$, indicando que estes elementos (Ba, La e Ce) possam ter sido formados no mesmo ambiente astrofísico, o que não ocorre com os elementos do primeiro pico (ver, por exemplo, Qian \& Wasserburg 2003), e para valores dessas razões maiores do que zero (valor solar), todos os objetos da amostra possuem $[\mathrm{C} / \mathrm{Fe}]>+1.0$. Na seção 4.4 são mostradas outras evidências desta distinção entre os elemetos $s$ leves e pesados. 


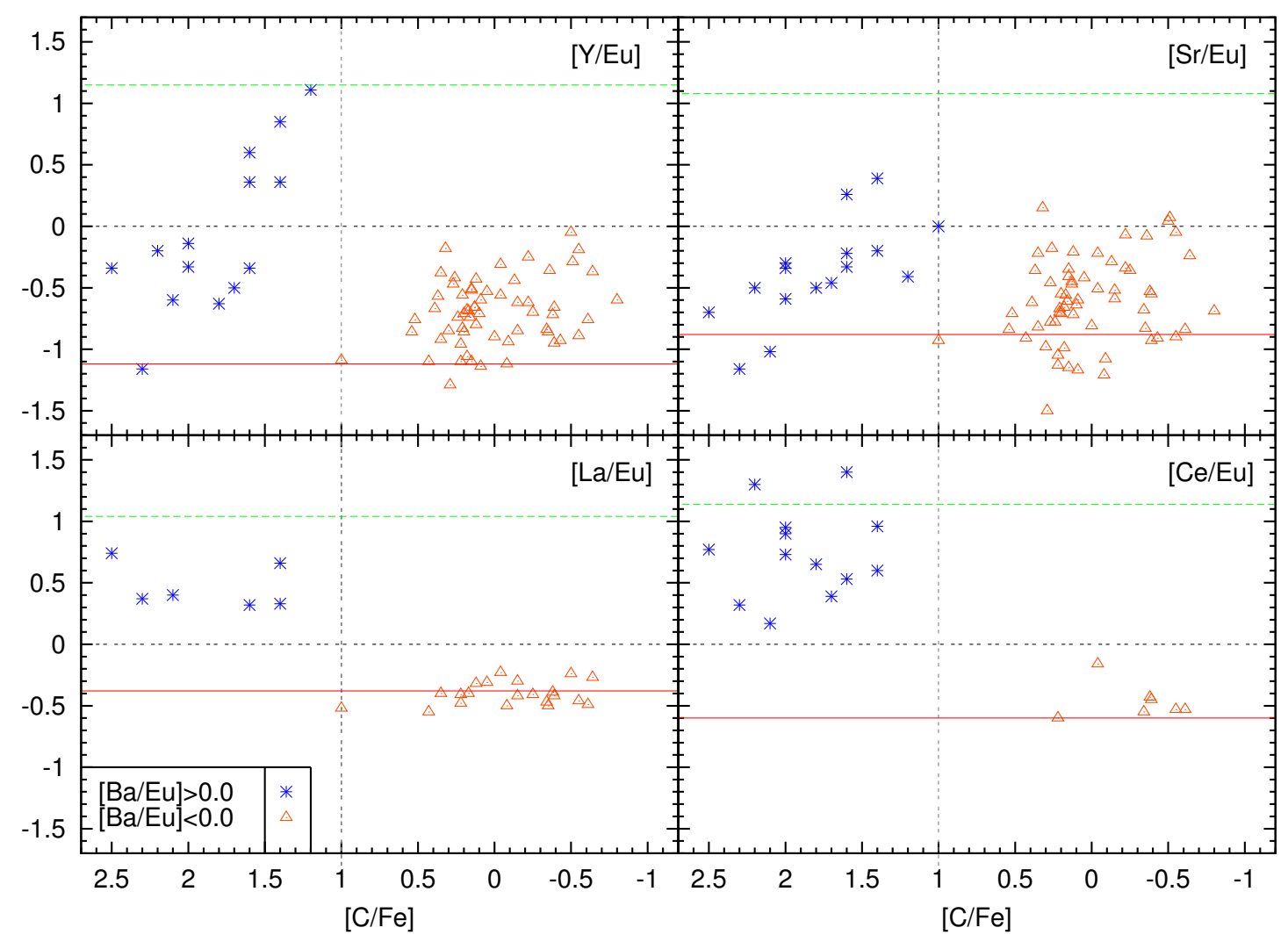

Fig. 4.8 Razões entre elementos $s$ (primeiro e segundo picos) e $r$ (Eu) em função da abundância de carbono. A linha verde representa a componente do processo-s e a linha vermelha representa a componente do processo-r para as razões de elementos mostradas na parte inferior direita de cada gráfico.

\subsection{Enriquecimento químico}

Para inferir a origem dos objetos pobres em metais e analisar com mais detalhes suas abundâncias elementais, pode-se usar razões de elementos formados por processos distintos de captura de nêutrons ou até mesmo elementos formados predominantemente pelo mesmo processo. Fazendo isso, é possível separar os objetos mais (ou menos) enriquecidos por elementos de um determinado processo e analisá-los separadamente. Nesta seção são mostradas algumas razões de abundâncias que possibilitam tais separações e no capítulo 5 são mostrados os padrões de abundâncias para alguns objetos selecionados.

Para comparação com as abundâncias determinadas para os objetos, são calculadas as componentes $r$ e $s$ solares para cada uma das razões apresentadas. Para tanto, são utilizadas as equações 3.10 e 3.11 descritas na seção 3.2. A tabela 4.4 mostra os valores 
calculados para as razões $r$ e $s$ utilizadas nesta seção.

\begin{tabular}{c|cc}
\hline Razão & Fração $r$ & Fração $s$ \\
\hline$[\mathrm{Sr} / \mathrm{Eu}]$ & -0.88 & 1.08 \\
{$[\mathrm{Y} / \mathrm{Eu}]$} & -1.12 & 1.15 \\
{$[\mathrm{Ba} / \mathrm{Eu}]$} & -0.65 & 1.20 \\
{$[\mathrm{La} / \mathrm{Eu}]$} & -0.38 & 1.04 \\
{$[\mathrm{Ce} / \mathrm{Eu}]$} & -0.60 & 1.14 \\
\hline
\end{tabular}

Tab. 4.2 Componentes $r$ e $s$ para as razões de elementos químicos utilizadas nesta seção.

A figura 4.9 mostra a evolução de duas razões $[s / r]$ com a metalicidade. Os paineis da figura mostram uma clara separação entre as estrelas $r($ para $[\mathrm{Ba} / \mathrm{Eu}]<0.0)$ e as estrelas $s$ (para $[\mathrm{Ba} / \mathrm{Eu}]>0.0)$, cujas subclasses estão explicitadas na tabela 3.1. Pode-se notar também que alguns objetos seguem o padrão solar $r$ para esta razão de elementos. O fato do comportamento ser o mesmo para o Ba e o La também sugere que estes compartilham o mesmo local de origem (além de pertencerem ao mesmo pico do processo-s). Pode-se observar que o espalhamento neste caso é menor, porém o La é mais difícil de ser detectado em espectros de baixa resolução e baixa razão S/N. Outra limitação para o uso do La seria que sua fração $s$ é menor do que a do $\mathrm{Ba}(\sim 10 \%)$; portanto, este elemento teria uma maior "contaminação" pelo processo-r.

Porém, estudos recentes (Winckler et al. 2006) mostram medidas mais precisas da abundância solar do La (14 linhas epectrais entre 3713 e 6390A) e de sua seção de choque, parâmetros importantes para descrever a componente principal do processo-s. Além disso, a abundância de La é medida a partir de apenas um isótopo ( $\left.{ }^{139} \mathrm{La}\right)$, sendo que para o Ba são usados 5 isótopos ( ${ }^{134} \mathrm{Ba},{ }^{135} \mathrm{Ba},{ }^{136} \mathrm{Ba},{ }^{137} \mathrm{Ba}$ e $\left.{ }^{138} \mathrm{Ba}\right)$, o que gera mais incertezas nos cálculos, uma vez que devem ser levados em conta parâmetros atômicos (e erros associados) para todos os isótopos.

A figura 4.10 mostra o comportamento das razões $[s / \mathrm{Eu}]$ para os elementos do segundo pico (La e Ce) e os do primeiro pico (Y e Sr) em relação à metalicidade, e discriminados pela razão $[\mathrm{Ba} / \mathrm{Eu}]$. O comportamento dos elementos do segundo pico reproduz o comportamento do Ba, enquanto para os elementos do primeiro pico não existe correlação aparente com o Ba. Este fato pode apoiar a proposição de Qian \& Wasserburg (2003), que 


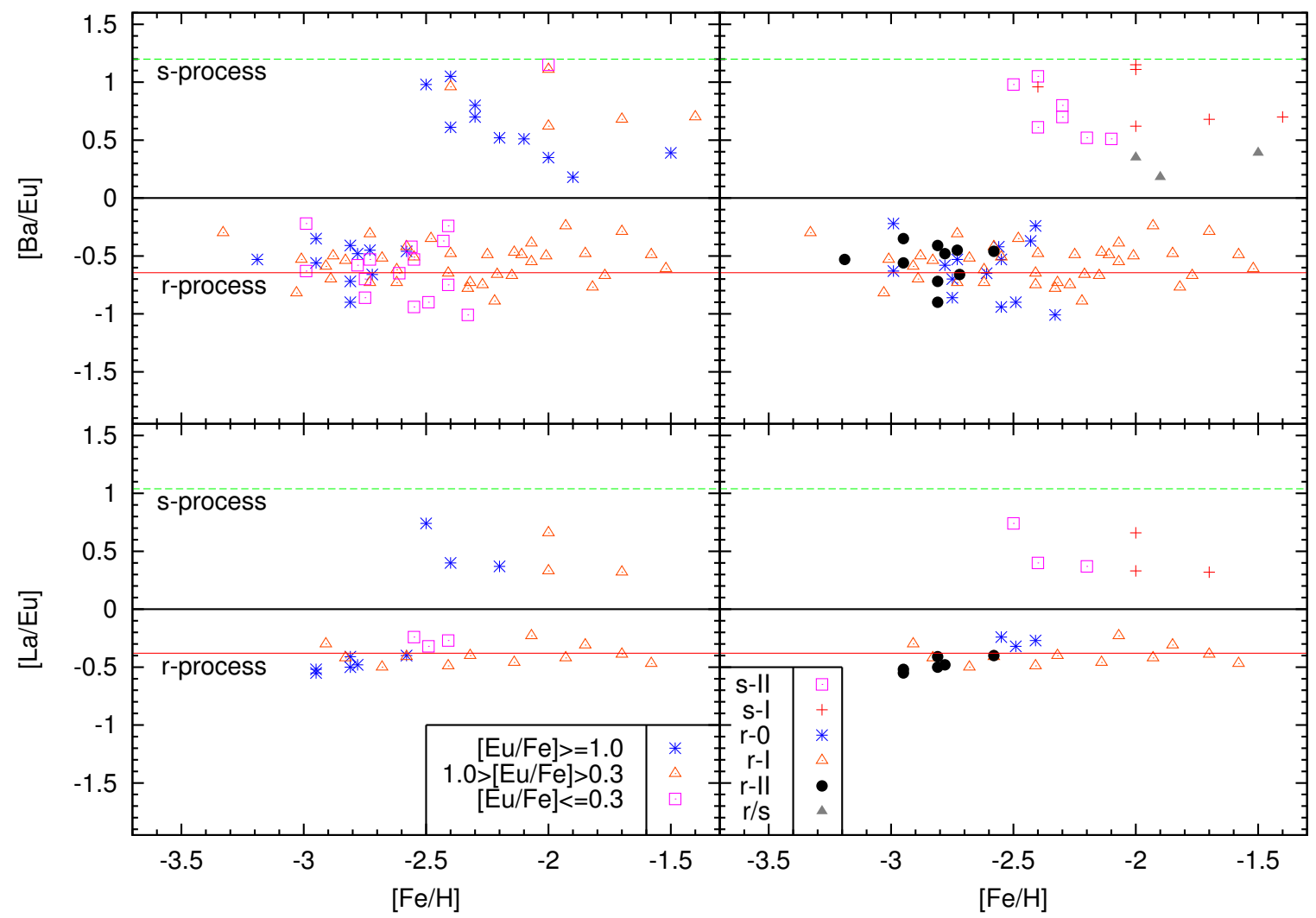

Fig. 4.9 Razões de abundâncias entre elementos $r$ e $s$. A linha verde (tracejada) representa o valor solar para o processo-s puro e a linha vermelha (cheia) o processo-r puro. Os diferentes símbolos discriminam intervalos de abundância do Eu (lado esquerdo) e as subclasses $r$ e $s$ (lado direito).

atribui origens distintas aos elementos dos diferentes picos do processo-s, argumentando que diferentes fluxos de nêutrons seriam necessários para formá-los. A figura 4.10 também mostra o limite proposto para o início da operação do processo-s, que deixa os objetos $s$ na parte mais rica em metais do gráfico.

Também é possível, através da razão entre dois elementos formados pelo mesmo processo, determinar se os mesmos se fomaram em ambientes distintos. Este é o caso dos elementos formados pelo processo-s. Como podemos ver na tabela 3.3, os elementos Sr, Y e Zr pertencem ao primeiro pico (com número de nêutrons $\mathrm{N}=50$ - número mágico) e os elementos $\mathrm{Ba}$, La, Ce e Nd pertencem ao segundo pico (com número de nêutrons N=82 número mágico) do processo-s - ver também figuras 2.1 e 3.4 .

A figura 4.11 mostra as dispersões das razões dos elementos $s$ do primeiro pico Sr e Y 


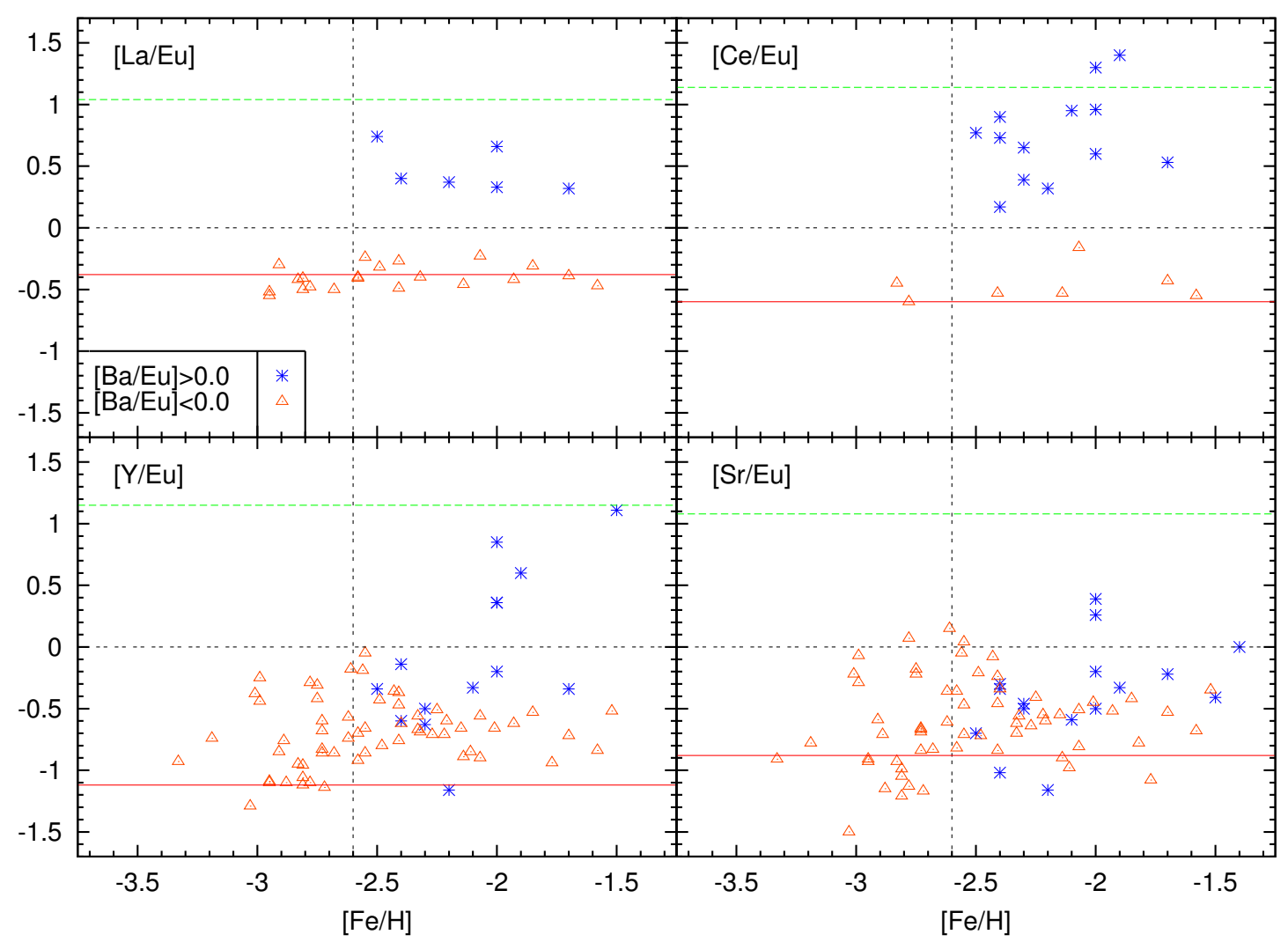

Fig. 4.10 Comparação entre o comportamento dos elementos do primeiro e segundo picos do processo-s com o Eu em relação à metalicidade. Os asteriscos denotam $[\mathrm{Ba} / \mathrm{Eu}]>0.0$ e os triângulos $[\mathrm{Ba} / \mathrm{Eu}] \leq 0.0$. A linha verde (tracejada) representa o padrão solar para o processo-s e a linha vermelha (cheia) o processo-r.

em relação ao Ba, em função da razão $[\mathrm{Ba} / \mathrm{H}]$. Utilizando-se essas variáveis é possível, além de estudar o comportamento dos elementos Sr e Y em relação ao Ba, estudar sua evolução com a abundância de hidrogênio. Os paineis (a) e (b) mostram as separações entre os objetos $r$ e $s$ da amostra. É possível notar novamente que as tendências entre os elementos Sr e Y são semelhantes; e observar também que todos os objetos $s$ da amostra (incluindo os objetos $r / s$ ) encontram-se na região $[\mathrm{Ba} / \mathrm{H}]>-1.0$, e possuem as maiores abundâncias de carbono da amostra (ver painel (c) da figura 4.11).

Além disso, vê-se que o espalhamento para as razões de elementos aumenta para $[\mathrm{Ba} / \mathrm{H}] \lesssim-4.0$, como descrito em François et al. (2006) e, a partir da anticorrelação apresentada entre $[\mathrm{Sr} / \mathrm{Ba}]$ e $[\mathrm{Ba} / \mathrm{H}]$, pode-se inferir a presença de mais de um mecanismo de formação destes elementos, pois acredita-se que uma segunda componente do processo-r 


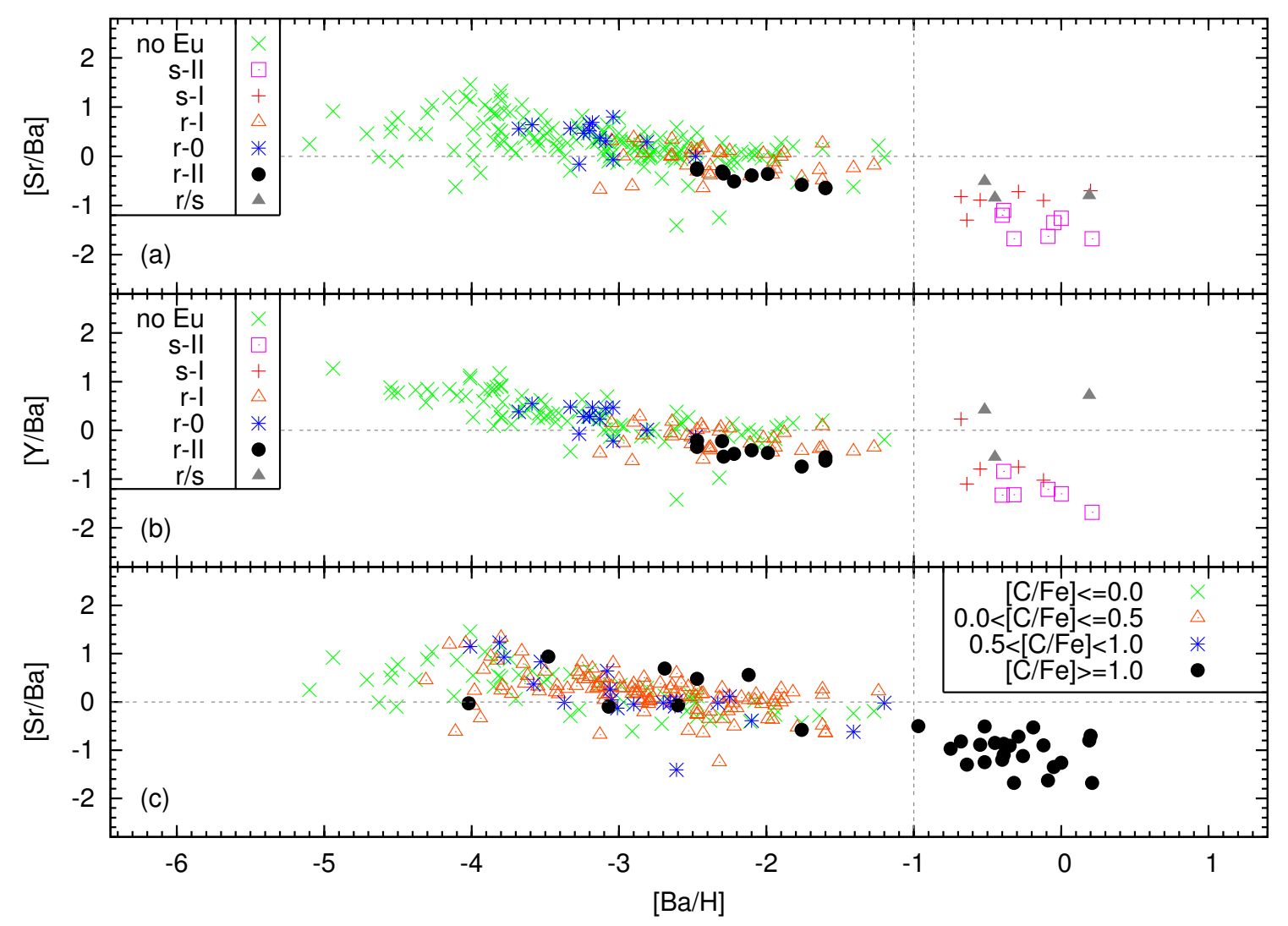

Fig. 4.11 Comportamento das razões $[l s / h s]$ com a abundância de bário $[\mathrm{Ba} / \mathrm{H}]$, em relação às classes $r$ e $s$, e à abundância de carbono.

opere numa faixa de massas distinta das responsáveis pela formação do Eu e Ba para baixas metalicidades (Wanajo \& Ishimaru 2006). A partir dos paineis (a) e (c), pode-se fazer comparações dos objetos do HERES com estrelas de outros estudos. Utilizando-se os dados da tabela 4.1, observa-se que todos os objetos $s$ e $r / s$ também encontram-se na região onde $[\mathrm{Ba} / \mathrm{H}]>-1.0$ e $[\mathrm{Sr} / \mathrm{Ba}]<0.0$. Assim, este tipo de gráfico pode ser visto também como forma de diagnóstico para estrelas onde, por exemplo, não se tenha calculada a abundância de Eu.

Outra forma de estudar as relações entre os elementos do primeiro e segundo picos do processo-s é fazer razões $\left[2^{\circ} \mathrm{s} / 1^{\circ} \mathrm{s}\right]$ e observar seu comportamento com a metalicidade. Para isso, são usados os índices hs (heavy s) e ls (light s), definidos, respectivamente, como as médias dos elementos pesados (segundo pico) e dos elementos leves (primeiro pico). Assim, a razão para os elementos $s$ pode ser definida da forma (adaptado de Norris et al. 1997): 


$$
\left[\frac{h s}{l s}\right]=\left[\frac{h s}{F e}\right]-\left[\frac{l s}{F e}\right]=\left\langle\left[\frac{B a}{F e}\right],\left[\frac{L a}{F e}\right],\left[\frac{C e}{F e}\right],\left[\frac{N d}{F e}\right]\right\rangle-\left\langle\left[\frac{S r}{F e}\right],\left[\frac{Y}{F e}\right],\left[\frac{Z r}{F e}\right]\right\rangle
$$

onde as quantidades entre $<>$ são as médias aritméticas das abundâncias em questão.

A figura 4.12 mostra o comportamento das razões dos elementos $s$ com a metalicidade, bem como o cálculo da média $[h s / l s]$ pela equação 4.1. O comportamento para o elemento Ba é distinto dos outros elementos e também da média, porém é o comportamento esperado segundo Qian \& Wasserburg (2003).

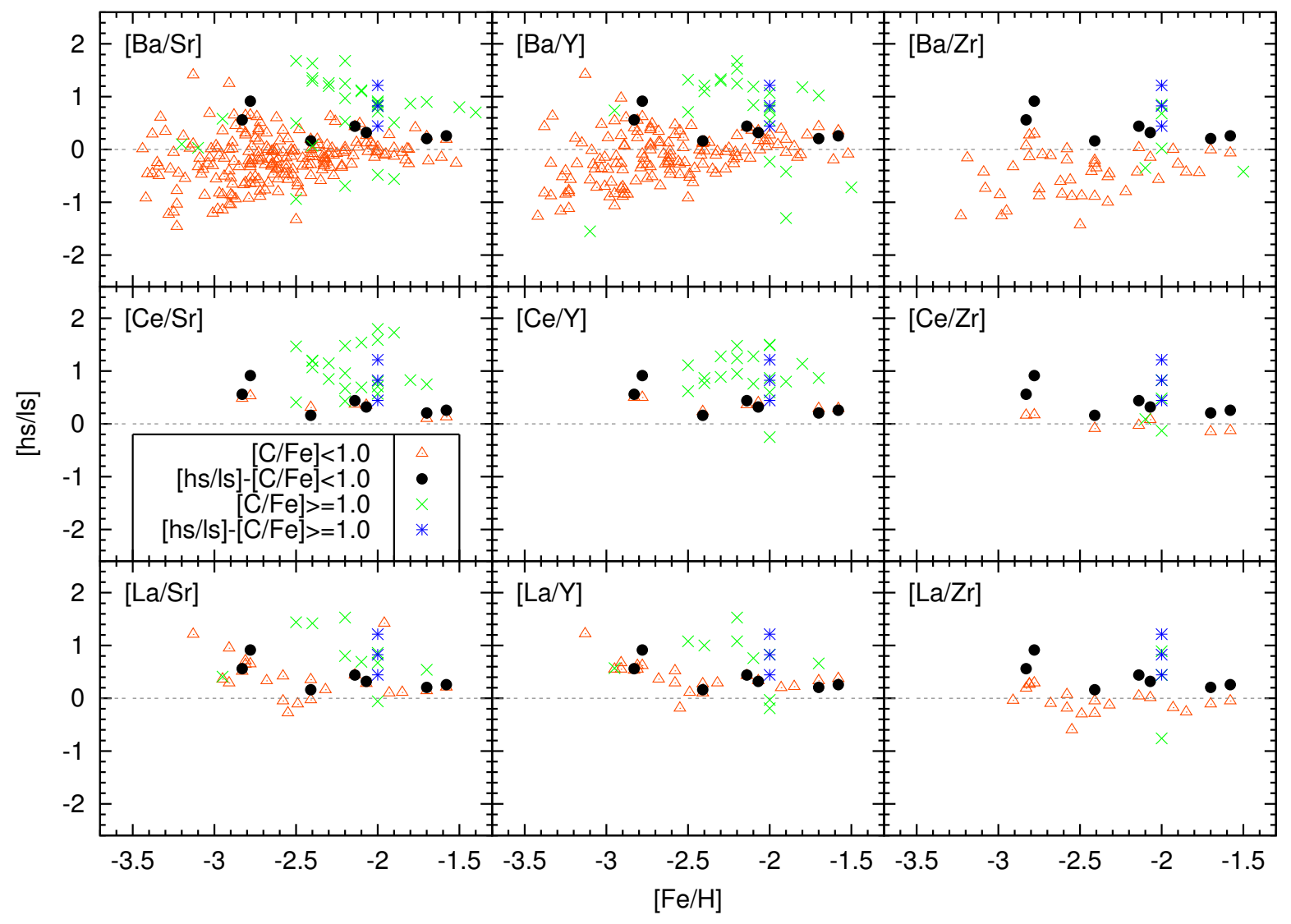

Fig. 4.12 Comportamento de cada componente da razão $[h s / l s]$ com a metalicidade e comparação com a média dos elementos. Foram omitidas as dispersões relativas ao $\mathrm{Nd}$ pois seguem a mesma tendência do elemento La.

Alguns trabalhos (por exemplo Norris et al. 1997, Barbuy et al. 2005) mostram uma tendência crescente desta razão com a metalicidade, como é previsto por alguns modelos teóricos (Busso et al. (2001) discute limitações do modelo). Porém, como pode ser visto 
na figura 4.12, para as razões que envolvem os elementos Ce e La com os elementos do primeiro pico temos poucos objetos, ou seja, o valor médio na verdade descarta todos os objetos com $[\mathrm{Ba} / \mathrm{ls}]<0.0$.

Como visto da seção 4.3, a presença de uma sobreabundância de carbono no objeto pode indicar que o objeto fez parte de um sistema binário, então suas abundâncias não refletem somente a história de sua formação mas também a contaminação por parte de sua companheira já evoluída. Sendo assim, as razões $[h s / l s]$ podem ser afetadas por este parâmetro.

Vemos na figura 4.12 os comportamentos das médias e de cada termo para as estrelas com $[\mathrm{C} / \mathrm{Fe}] \geq+1.0$ e $[\mathrm{C} / \mathrm{Fe}]<+1.0$. A média para as estrelas carbonadas não mostra tendência, pois os objetos possuem a mesma metalicidade, enquanto que os objetos com abundância de carbono mais baixa o comportamento se mostra crescente para a média, o que confirma as hipóteses vistas em Norris et al. (1997) e Barbuy et al. (2005), sendo que o último trabalho é um estudo em alta resolução de duas estrelas muito pobres em metais com alto enriquecimento em carbono. Neste caso, a quantidade de objetos limita a análise, porém é possível inferir que o comportamento dos objetos com diferentes abundâncias de carbono é distinto para as razões $[h s / l s]$.

\subsection{Análise de conglomerados}

Nesta seção é mostrada a análise de conglomerados, realizada com as abundâncias elementais dos dados do HERES, com o intuito de reunir as estrelas em grupos segundo características comuns entre si. A escolha das variáveis de trabalho para cada agrupamento foi feita de acordo com critérios como a variabilidade da abundância de determinado elemento químico (ver histogramas na figura 4.1), número de observações e correlações com as demais variáveis. A medida de dissimilaridade utilizada foi a distância euclidiana e o critério para formação de grupos foi o método de Ward. Mais detalhes sobre a teoria dos métodos algomerativos, critérios de separação de grupos e métodos gráficos utilizados nesta seção podem ser vistos no apêndice A.1 e referências nele contidas. 


\subsection{1 $[\mathrm{Eu} / \mathrm{Fe}][\mathrm{Ba} / \mathrm{Fe}]$}

Um dos agrupamentos realizados neste trabalho utilizou as variáveis $[\mathrm{Ba} / \mathrm{Fe}]$ e $[\mathrm{Eu} / \mathrm{Fe}]$, com um total de 78 objetos. Os objetos cuja abundância de Eu foi determinada apenas como limite superior não foram utilizados nesta análise, uma vez que o método de agrupamento não distingue tais limites dos valores calculados. O dendrograma gerado para o agrupamento dessas variáveis pode ser visto na figura 4.13.

$[\mathrm{Ba} / \mathrm{Fe}][\mathrm{Eu} / \mathrm{Fe}]$

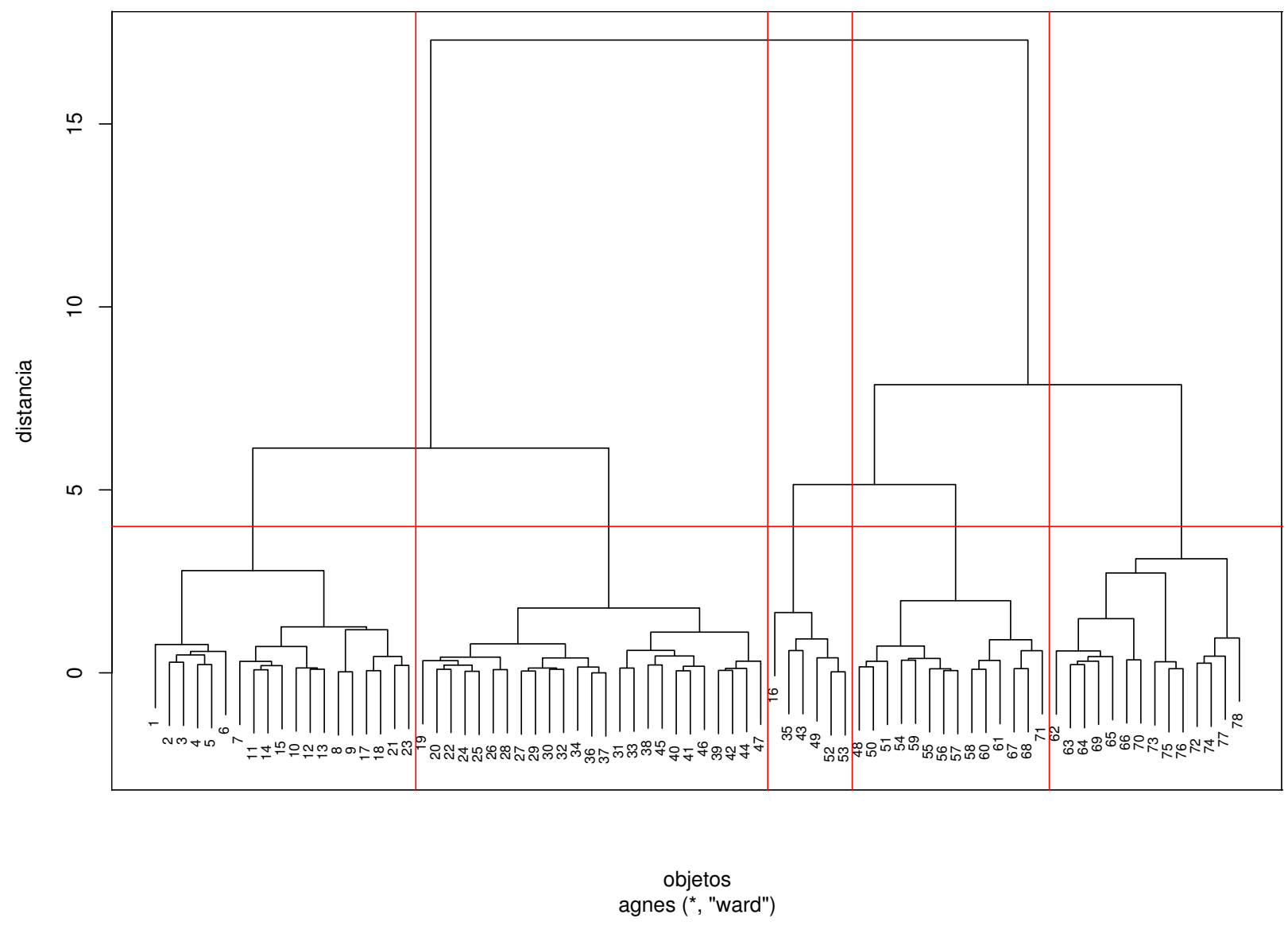

Fig. 4.13 Dendrograma para o agrupamento das variáveis [Eu/Fe] e [Ba/Fe]. As linhas verticais representam os limites dos grupos formados e a linha horizontal representa o número de grupos encontrado segundo o critério da figura 4.14.

O dendrograma ${ }^{7}$ mostrado é uma ferramenta gráfica que auxilia na vizualização da

\footnotetext{
7 ver apêndice A.1.
} 
base de dados, principalmente quando esta possui um número elevado de parâmetros (por exemplo, na seção 4.5.2). O eixo y representa a distância entre um ponto no espaço de $n$ parâmetros e o centro de cada grupo. Quando um novo objeto (e/ou grupo) se encontra dentro desta distância, os objetos se unem e formam um novo grupo. Este processo se inicia com cada objeto sendo um único grupo e termina com todos os objetos num só grupo.

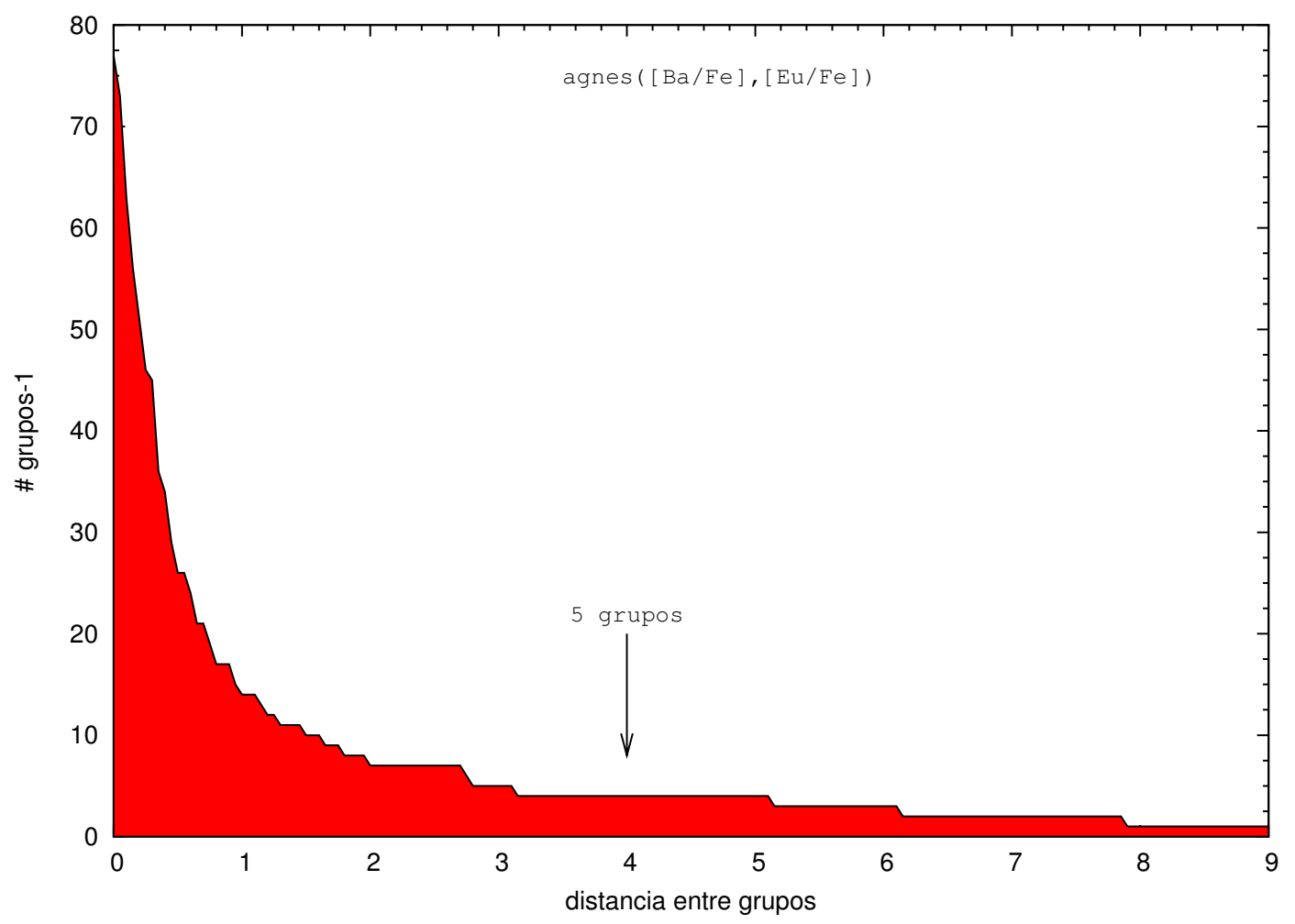

Fig. 4.14 Curva de decaimento de grupos para o agrupamento de [Eu/Fe] e [Ba/Fe].

Uma das dificuldades da análise do dendrograma é a determinação de um critério para o corte horizontal (linha vermelha horizontal da figura 4.13), que determina a quantidade de grupos formados. Tal corte pode ser feito por inspeção visual, que pode gerar um viés quando existe um resultado esperado. Existem critérios matemáticos que determinam o número ótimo de grupos para cada dendrograma (ver Johnson \& Winchern 2002). Neste trabalho foi desenvolvido um método direto para estimar o número de grupos que melhor representa a base de dados, a partir do número de grupos formados em função da distância entre eles. A partir da distância zero (onde cada objeto forma um grupo), são feitas medidas do número de grupos em relação à distância entre eles (com um passo de 0.01dex), que 
fornece o grau de "estabilidade" para um determinado número de grupos. O resultado dessas medidas é mostrado na figura 4.14.

Note-se que, até distâncias de $\sim 3$ dex, o número de grupos diminui rapidamente. O corte é feito para o número de grupos que permanece constante num maior intervalo de distância. Para o agrupamento das variáveis $[\mathrm{Ba} / \mathrm{Fe}]$ e $[\mathrm{Eu} / \mathrm{Fe}]$, o número de grupos encontrado é 5 . Assim, a partir da determinação da quantidade de grupos, pode-se fazer as dispersões entre as variáveis do agrupamento, em forma de gráfico de pares, como mostrado na figura 4.15 .
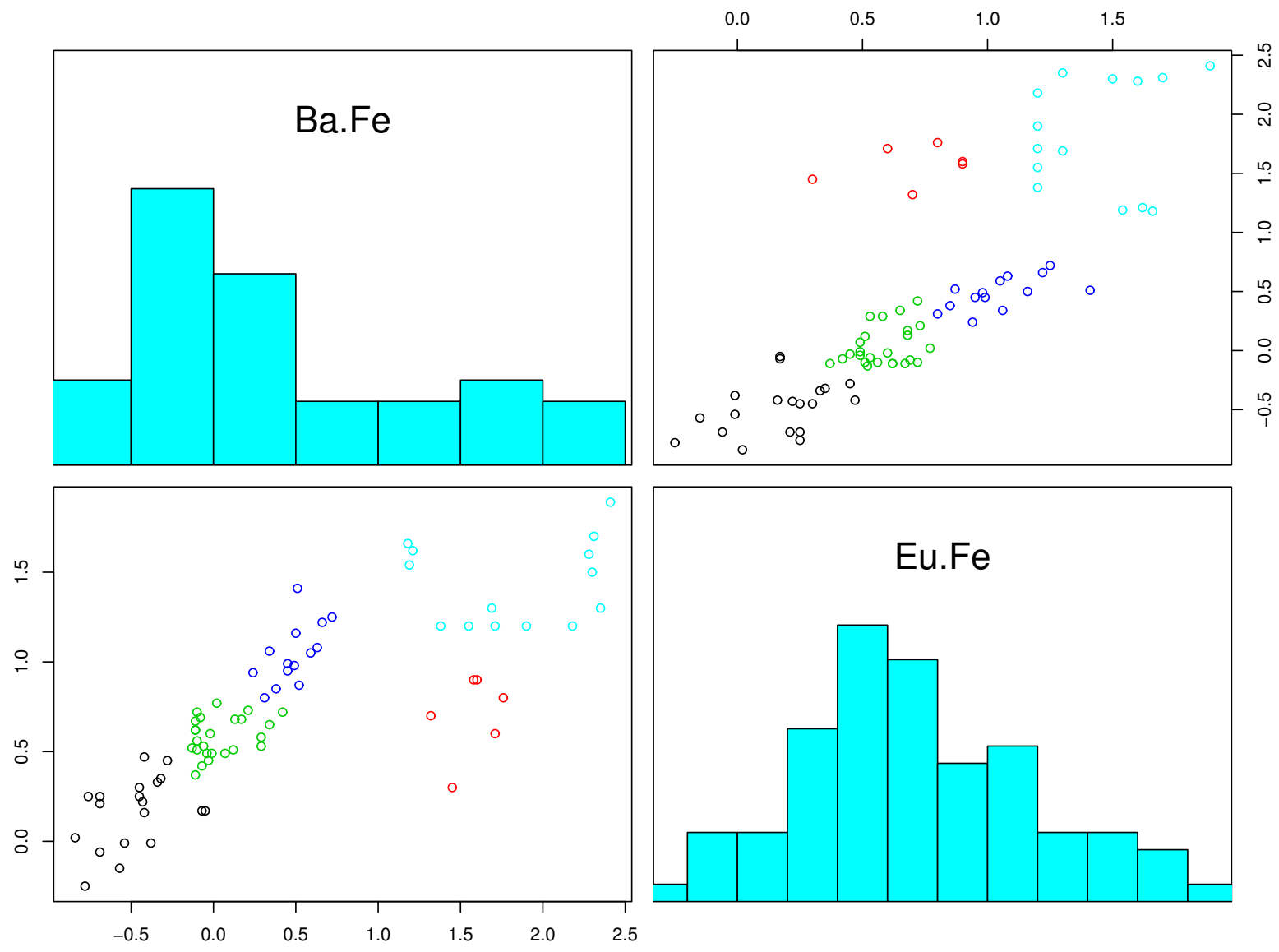

Fig. 4.15 Gráfico de pares para as variáveis do agrupamento da figura 4.13.

Observe-se que, utilizando somente as abundâncias de Ba e Eu, não é possível separar os objetos r-II dos $r / s$ e s-II. Isto ocorre pois, analisando somente essas duas variáveis, os objetos r-II são mais semelhantes (possuem distância menor) aos objetos $r / s$ do que, por 
exemplo, aos r-I. Na classificação ad-hoc de Beers \& Christlieb (2005) também é usado o vínculo $[\mathrm{Ba} / \mathrm{Eu}]$ para classificar os objetos. Este vínculo não pode ser incluído no agrupamento, já que é uma variável resultante da combinação das outras duas variáveis estudadas $([\mathrm{Ba} / \mathrm{Eu}]=[\mathrm{Ba} / \mathrm{Fe}]-[\mathrm{Eu} / \mathrm{Fe}])$. Isso implica na introdução de um termo misto no cálculo da distância euclidiana, o que acarreta na perda da normalização das variáveis e, nessas condições, invalida o método. Portanto, para separar os objetos $r$ e $s$ de forma satisfatória é necessário introduzir novas variáveis no agrupamento, como será mostrado a seguir.

\subsection{2 $[\mathrm{Eu} / \mathrm{Fe}][\mathrm{Ba} / \mathrm{Fe}][\mathrm{C} / \mathrm{Fe}][\mathrm{Sr} / \mathrm{Fe}]$}

A escolha das variáveis para o agrupamento desta seção foi feita com base nas correlações descritas entre as abundâncias elementais no decorrer do capítulo 4. Além do Ba e Eu, foram selecionadas as variáveis [C/Fe] (por suas relações com os objetos $s$ - ver seção 4.3) e [Sr/Fe] (representante do primeiro pico do processo-s - ver seção 4.4). O número de objetos neste caso é 77, limitado pelas determinações das abundâncias de Sr para as estrelas apresentadas na seção 4.5.1. A metalicidade, mesmo introduzindo vínculos entre as variáveis ${ }^{8}$, não pode ser utilizada, pelas mesmas razões citadas na seção 4.5 .1 para a grandeza $[\mathrm{Ba} / \mathrm{Eu}]$. Mesmo assim, pode-se notar na figura 3.1 que os objetos $s$ se encontram numa faixa de metalicidades maior que os objetos $r$ (ver seção 4.2). A figura 4.16 mostra o dendrograma gerado para o agrupamento das quatro variáveis descritas acima.

Pode-se notar que, para este conjunto de variáveis, o número de grupos formados utilizando-se o critério descrito acima também é 5. Porém, os objetos pertencentes a cada grupo não são os mesmos da seção 4.5.1, e o dendrograma se comporta de maneira diferente. Observe-se no dendrograma a formação de dois grandes grupos no intervalo de distâncias entre 10 e 15. Os dois grupos do lado esquerdo (com maior número de objetos) são os equivalentes às subclasses r-0 e r-I. Já os três grupos da direita são, respectivamente (da esquerda para a direita), equivalentes às subclasses s-I, s-II e r-II.

A linha vermelha horizontal determina o número de grupos considerado ótimo para este agrupamento, baseado no critério descrito acima e na figura 4.17. Ainda assim, vemos que se a linha fosse deslocada para cima, as subclasses s-I e s-II se tornariam uma só. Da mesma forma, ao deslocar a linha na direção das menores distâncias, as subclasses r-0 e

\footnotetext{
${ }^{8}$ ver figura 4.5 e discussão na seção 4.2 .
} 


\section{$[\mathrm{Ba} / \mathrm{Fe}][\mathrm{Eu} / \mathrm{Fe}][\mathrm{C} / \mathrm{Fe}][\mathrm{Sr} / \mathrm{Fe}]$}

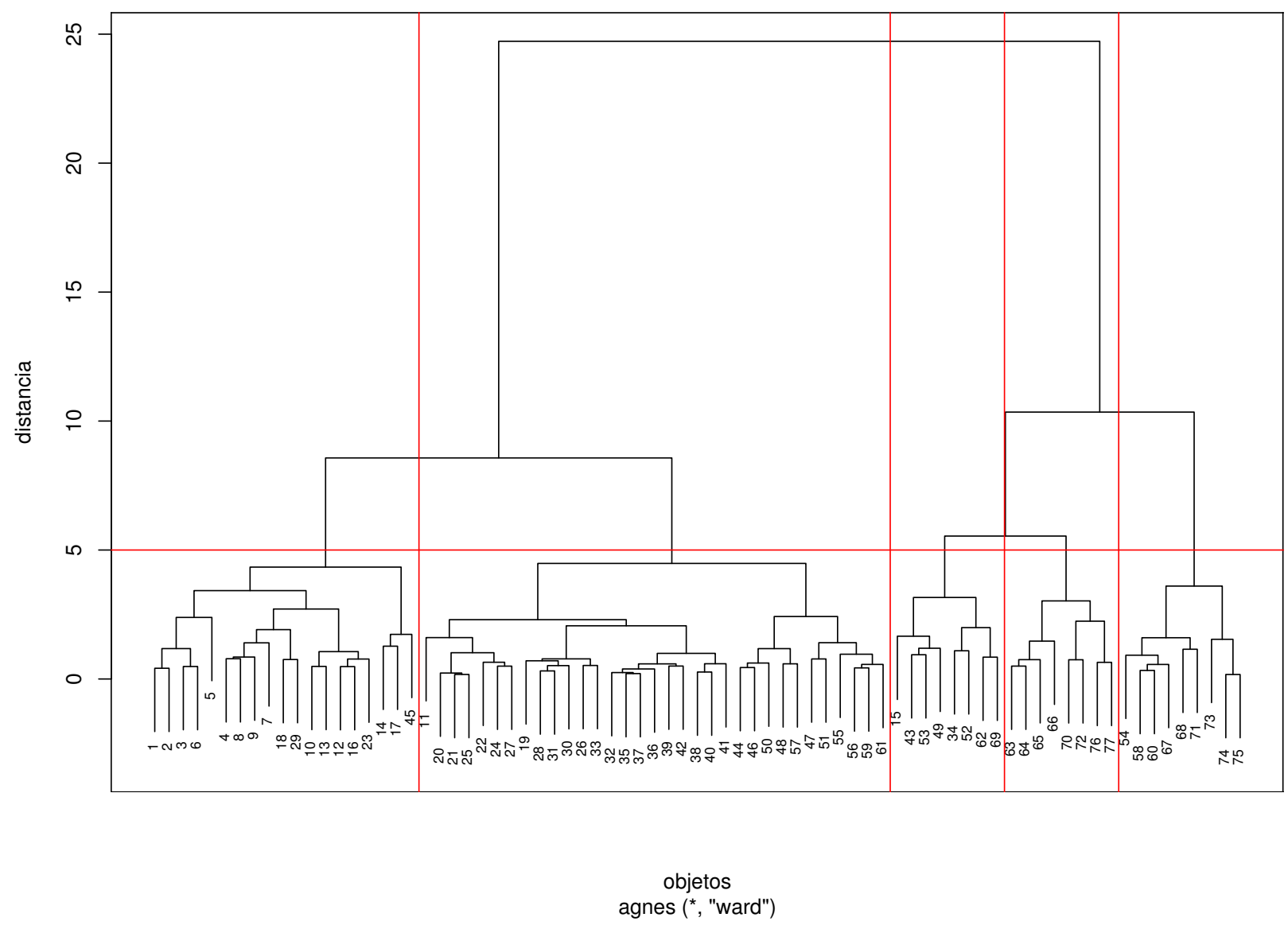

Fig. 4.16 Dendrograma para o agrupamento das variáveis [Eu/Fe], [Ba/Fe], [C/Fe] e [Sr/Fe]. As linhas verticais representam os limites dos grupos formados e a linha horizontal representa o número de grupos encontrado segundo o critério da figura 4.17.

r-I seriam divididas, formando 2 novos grupos. É interessante perceber, na figura 4.1, que os coeficientes de correlação entre as variáveis deste agrupamento têm valores positivos. Assim, como será visto a seguir na figura 4.18, espera-se que um dos grupos formados contenha os maiores valores das variáveis, outro os menores valores e os demais valores intermediários, dependendo da intensidade da correlação entre as variáveis.

A figura 4.17 mostra a curva de decaimento de grupos. O agrupamento apresenta estabilidade também em 7 grupos, mas existe uma transição abrupta entre 7 e 5 grupos (r-0 e r-I, como visto no parágrafo anterior). Sendo assim, o valor 5 mostra-se mais estável.

O gráfico de pares mostrado na figura 4.18 apresenta as combinações em duas dimensões 


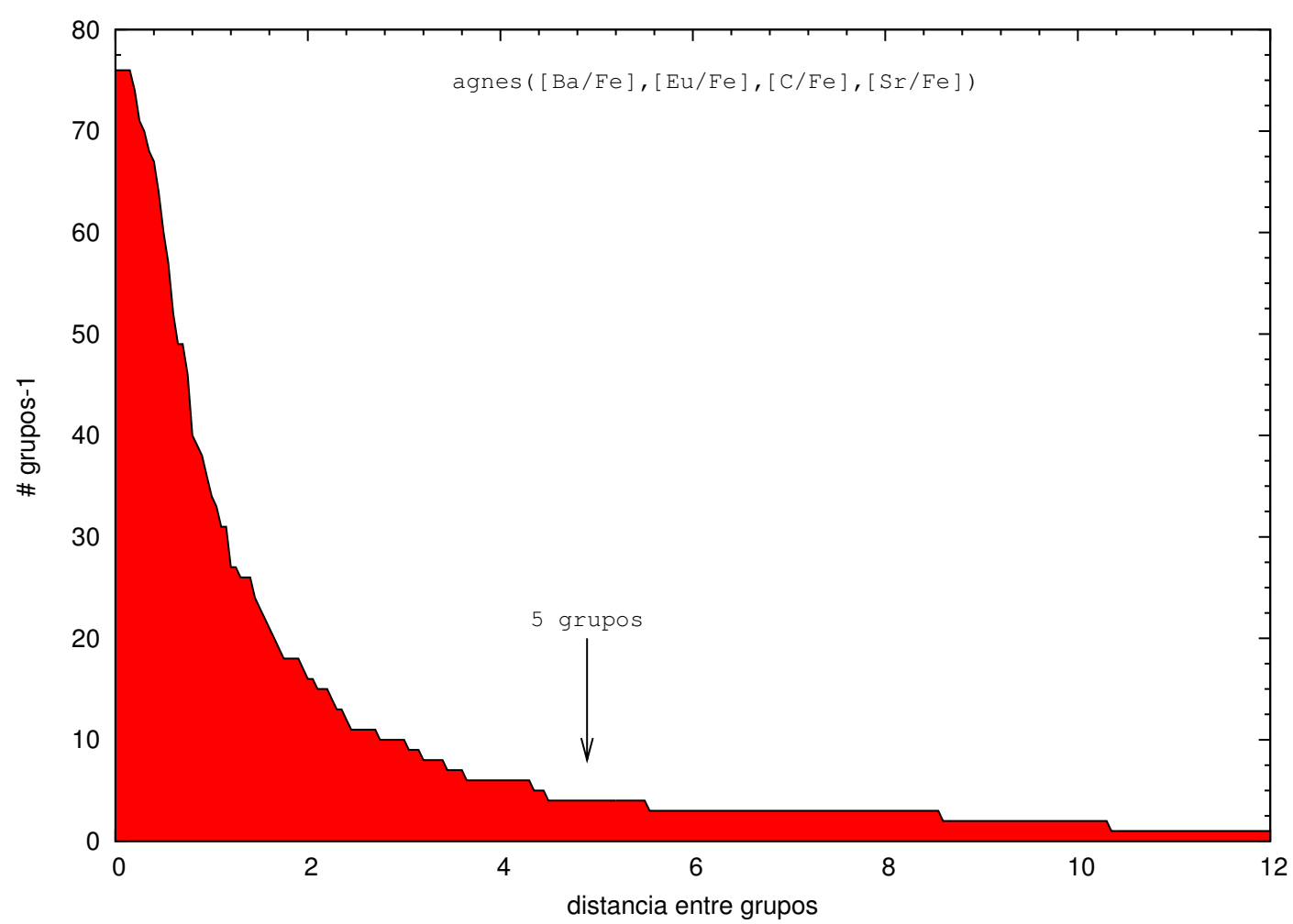

Fig. 4.17 Curva de decaimento de grupos para o agrupamento de [Eu/Fe], [Ba/Fe], [C/Fe] e $[\mathrm{Sr} / \mathrm{Fe}]$.

de todas as variáveis. Os grupos formados neste caso são semelhantes aos descritos na tabela 3.1, com exceção dos objetos $r / s$, que se misturam aos objetos $s$. Isto ocorre devido à proximidade dos valores de abundâncias para os objetos s-I, s-II e $r / s$. Mesmo assim, como será visto no capítulo 5 , os objetos $r / s$ apresentam certas diferenças em relação aos demais objetos da classe $s$, o que justifica a designação deste grupo.

Algumas observações podem ser feitas acerca das dispersões da figura 4.18:

* Para todas as combinações entre as variáveis, os grupos formados pelos objetos r-0 e s-II possuem, respectivamente, os menores e maiores valores de abundâncias;

* O objeto CS22892-052 (Sneden et al. 1996; 2003) é a estrela $r$ com maior abundância de carbono da amostra $([\mathrm{C} / \mathrm{Fe}]=+1.0)$, sendo que os demais objetos $r$ concentram-se em $[\mathrm{C} / \mathrm{Fe}] \leq+0.5$. Observa-se, pelas dispersões relativas ao carbono, que este objeto encontra-se mais próximo aos objetos $s$ do que aos $r$. Porém, a combinação de suas abundâncias o designa como membro do grupo $r$; 


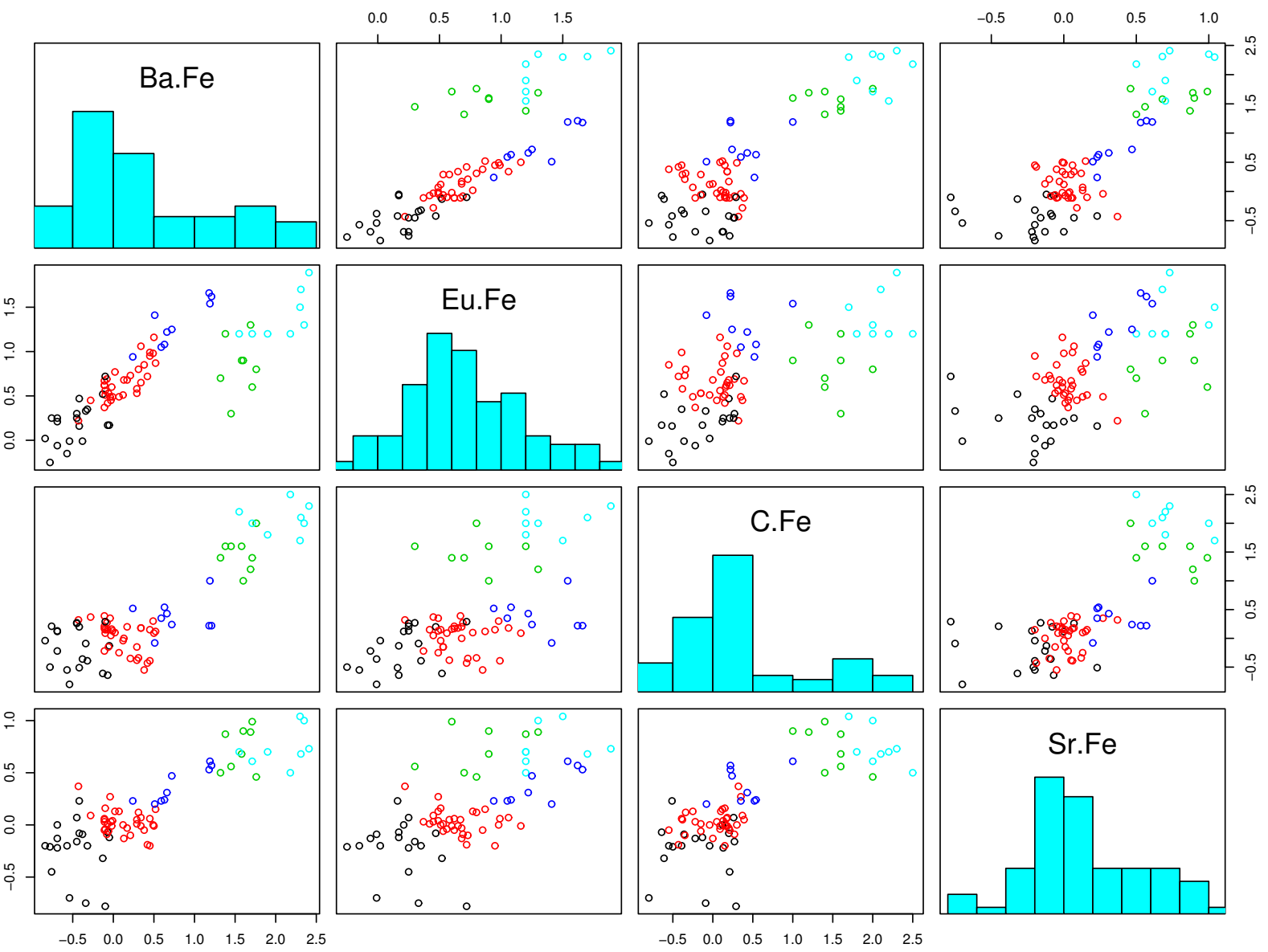

Fig. 4.18 Gráfico de pares para as variáveis do agrupamento da figura 4.16.

* Para combinações como [Eu/Fe] e [Sr/Fe], os objetos r-II com maiores abundâncias de Ba e Eu agrupam-se com os objetos s-II, e os objetos r-I, r-0 e s-I também ficam mais próximos, principalmente para $[\mathrm{Eu} / \mathrm{Fe}]<0.5$;

A tabela 4.3 apresenta um sumário das medidas das variáveis analisadas nesta seção, com os valores mínimos, máximos e médios de cada variável, para cada grupo. O valor médio neste caso não pode ser interpretado como um valor físico, visto que as estrelas não têm influência umas nas outras. Este valor é útil apenas para descrever o comportamento geral do grupo em relação à variável em questão.

Pode-se observar da tabela 4.3 que todos os valores médios para as variáveis [Ba/Fe] e [Eu/Fe] encontram-se dentro dos limites impostos por Beers \& Christlieb (2005) e pela tabela 3.1. Com exceção dos valores para a variável Eu, todos os demais (mínimos, máximos 


\begin{tabular}{c|c|ccccc}
\hline \multicolumn{2}{c|}{} & r-0 & r-I & r-II & s-I & s-II \\
\hline \multicolumn{2}{c}{$\mathrm{n}^{\circ}$ de objetos } & 19 & 33 & 9 & 8 & 8 \\
\hline \multirow{2}{*}[\mathrm{Ba}/\mathrm{Fe}]{} & mínimo & -0.84 & -0.43 & 0.24 & 1.32 & 1.55 \\
& máximo & -0.05 & 0.52 & 1.21 & 1.76 & 2.41 \\
& média & -0.46 & 0.12 & 0.77 & 1.56 & 2.09 \\
\hline \multirow{2}{*}[\mathrm{Eu}/\mathrm{Fe}]{} & mínimo & -0.25 & 0.22 & 0.94 & 0.30 & 1.20 \\
& máximo & 0.72 & 1.16 & 1.66 & 1.30 & 1.89 \\
& média & 0.19 & 0.66 & 1.31 & 0.84 & 1.40 \\
\hline \multirow{2}{*}[\mathrm{Sr}/\mathrm{Fe}]{} & mínimo & -0.78 & -0.20 & 0.20 & 0.46 & 0.50 \\
& máximo & 0.23 & 0.37 & 0.61 & 0.99 & 1.04 \\
& média & -0.23 & 0.03 & 0.38 & 0.73 & 0.75 \\
\hline \multirow{2}{*}[\mathrm{C}/\mathrm{Fe}]{} & mínimo & -0.80 & -0.55 & -0.08 & 1.00 & 1.70 \\
& máximo & 0.29 & 0.39 & 1.00 & 2.00 & 2.50 \\
& média & -0.18 & 0.03 & 0.38 & 1.48 & 2.08 \\
\hline
\end{tabular}

Tab. 4.3 Sumário das abundâncias elementais para os diferentes grupos formados no agrupamento da seção 4.5.2.

e médios) encontram-se em ordem crescente, a partir da subclasse r-0 para a s-II. Como visto na seção 4.5.1, levando em consideração apenas as variáveis Ba e Eu, não seria possível separar os objetos r-II dos s-II, que possuem valores médios para o Eu muito próximos. Então, justifica-se a introdução das variáveis [C/Fe] e [Sr/Fe], que, mesmo possuindo valores médios próximos para as subclasses s-I e s-II, são necessários para distinguir os regimes $s$ e $r$.

Com base na figura 3.1, pode-se construir um diagrama semelhante utilizando-se os novos grupos formados nesta análise de conglomerados. Tal diagrama é mostrado na figura 4.19. Como dito anteriormente, é interessante notar que, no plano $[\mathrm{Eu} / \mathrm{Fe}]$ vs. [Ba/Fe], os três objetos r-II com maiores abundâncias de Ba encontram-se mais próximos dos objetos $s$ do que dos demais de sua subclasse.

Além disso, é mostrada a formação de três grupos para o regime $r$, como previsto pela classificação da tabela 3.1. Nota-se que alguns objetos ultrapassam os limites designados para seus grupos, o que é esperado pois os limites impostos para as abundâncias de Eu 
foram determinados segundo dados observacionais.

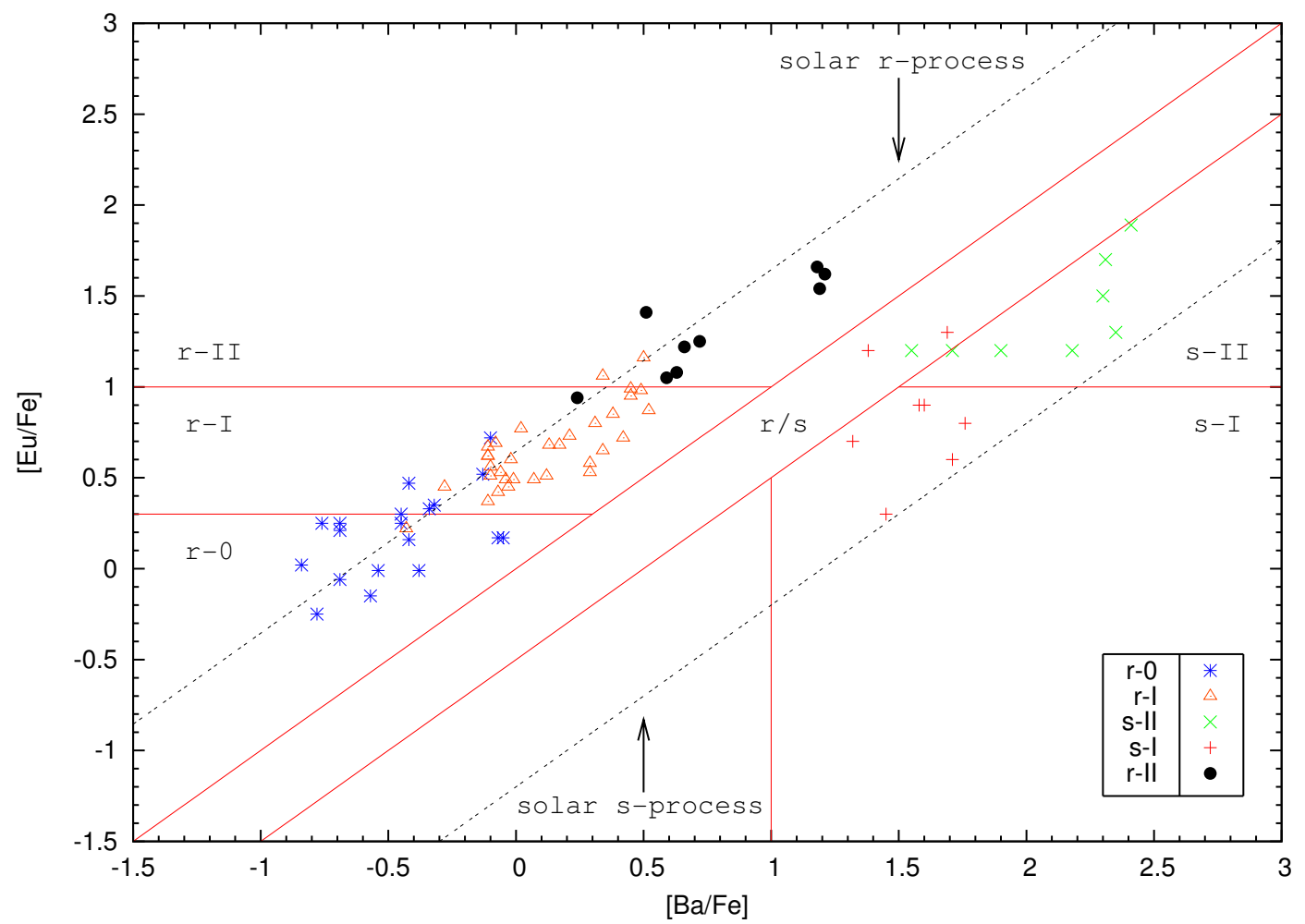

Fig. 4.19 Diagrama semelhante à figura 3.1, para os grupos formados no agrupamento da seção 4.5.2.

É importante ressaltar que os resultados encontrados com o agrupamento das variáveis $\mathrm{Ba}, \mathrm{Eu}, \mathrm{Sr}$ e C (em relação ao ferro) reproduzem a classificação proposta por Beers \& Christlieb (2005) para estrelas pobres em metais com abundâncias determinadas para elementos formados por captura de nêutrons (exceto para a subclasse $r / s$ ), sem o uso do vínculo $[\mathrm{Ba} / \mathrm{Eu}]$. No capítulo 5 todas as subclasses são estudadas separadamente, mostrando os padrões de abundâncias de objetos pertencentes à cada uma delas. 


\section{PADRÕES DE ABUNDÂNCIAS}

Neste capítulo é feita a análise detalhada das subclasses descritas na tabela 3.1. Para tanto, são utilizadas as abundâncias elementais (na forma $\log \epsilon$ ), com suas respectivas incertezas, para os elementos formados por captura de nêutrons Sr, Y, Zr, Ba, La, Ce, Nd, Sm e Eu. A justificativa para a introdução das classes r-0 e s-II na classificação original de Beers \& Christlieb (2005) é dada na seção 4.5.2. A análise foi feita para todos os objetos presentes no agrupamento da seção 4.5.2, porém, dada a semelhança entre os padrões para os objetos de mesma subclasse, são apresentados apenas os objetos com maior número de abundâncias determinadas, bem como aqueles com os valores mínimo e máximo para a metalicidade de cada subclasse.

Para estudar os padrões de abundâncias dos objetos citados acima, é necesssário comparar suas abundâncias com os valores solares. Como as abundâncias utilizadas para tal análise estão na forma apresentada por Grevesse \& Sauval (1998), é preciso fazer a normalização dos valores solares para a escala de valores de cada objeto. Deste modo, é possível

observar as contribuições dos processos $r$ e $s$ para as abundâncias de cada elemento da estrela.

As normalizações feitas para as componentes $r$ e $s$ solares de um elemento $X$ foram calculadas usando:

Componente $r$

$$
\epsilon_{\odot_{X_{n}}}^{r}=\epsilon_{\odot_{X}}^{r} \cdot \frac{\epsilon_{E u_{\star}}^{r}}{\epsilon_{E u_{\odot}}^{r}}=\left(f_{X}^{r} \cdot \epsilon_{\odot_{X}}\right) \cdot \frac{\left(f_{E u}^{r} \cdot \epsilon_{E u_{\star}}\right)}{\left(f_{E u}^{r} \cdot \epsilon_{E u_{\odot}}\right)}=\left(f_{X}^{r} \cdot \epsilon_{\odot_{X}}\right) \cdot \frac{\epsilon_{E u_{\star}}}{\epsilon_{E u_{\odot}}},
$$

Componente s

$$
\epsilon_{\odot_{X}}^{s}=\epsilon_{\odot X}^{s} \cdot \frac{\epsilon_{B a_{\star}}^{s}}{\epsilon_{B a_{\odot}}^{s}}=\left(f_{X}^{s} \cdot \epsilon_{\odot_{X}}\right) \cdot \frac{\left(f_{B a}^{s} \cdot \epsilon_{B a_{\star}}\right)}{\left(f_{B a}^{s} \cdot \epsilon_{B a_{\odot}}\right)}=\left(f_{X}^{s} \cdot \epsilon_{\odot_{X}}\right) \cdot \frac{\epsilon_{B a_{\star}}}{\epsilon_{B a_{\odot}}},
$$

onde os índices superiores representam os processos $s$ e $r$, os inferiores os valores das abundâncias solares e de cada objeto $(\odot$ e $\star$, respectivamente), Eu e Ba são os elementos 
utilizados para normalizar os demais e $f$ representa as frações $r$ e $s$ para cada elemento, que foram retiradas de Arlandini et al. (1999). As abundâncias solares foram retiradas de Grevesse \& Sauval (1998).

\subsection{Estrelas $s$}

Acredita-se que a "componente principal" do processo-s ocorra nos pulsos térmicos de estrelas AGB de massa intermediária ${ }^{1}$. Acredita-se também que a principal fonte de nêutrons dessas estrelas seja a reação ${ }^{13} C(\alpha, \mathrm{n}){ }^{16} O$ (Beers \& Christlieb 2005). Devido a possibilidade de que seja necessário haver como "semente" deste processo um elemento do pico do ferro, não se esperaria que houvesse formação de elementos por processo-s nos primórdios da Galáxia.

Porém, as observações mostram o contrário. Alguns de estudos recentes (como por exemplo Johnson \& Bolte 2002; Simmerer et al. 2004; Sivarani et al. 2004) mostram que estrelas pobres em metais $(\mathrm{com}[\mathrm{Fe} / \mathrm{H}]<-2.6$ para os três estudos) possuem assinaturas fortes de processo-s em suas composições . Porém, este fato não implica que necessariamente exista uma semente do pico do ferro, pois o mecanismo do processo-s em ambientes com pouco conteúdo metálico ainda não é completamente compreendido.

\subsubsection{Objetos $\mathrm{S}-\mathrm{II}$}

A figura 5.1 mostra o comportamento das abundâncias para objetos s-II da amostra. As normalizações para os padrões solares foram calculadas utilizando as equações 5.1 e 5.2. Pode-se notar que os elementos La, Ce, Nd e Sm reproduzem bem o padrão solar para o processo-s, e os elementos Y e Sr reproduzem o padrão solar $r$ dentro de um intervalo de $3 \sigma$.

Um possivel cenário para explicar as abundâncias dos objetos da figura 5.1 é a existência um limite superior para o início da operação da componente principal do processo-s em $[\mathrm{Fe} / \mathrm{H}]=-2.60$, já que o objeto HE0131-3953 reproduz o padrão solar $s$ para os elementos do segundo pico (Ba, La, Ce e $\mathrm{Nd}$ ). Como os elementos do primeiro pico $s$ seguem o padrão solar $r$, pode-se ter uma co-produção destes com os elementos $r$ pesados (A $\geq 130$ - Qian

\footnotetext{
${ }^{1}$ mais detalhes na seção 2.1.2.
} 


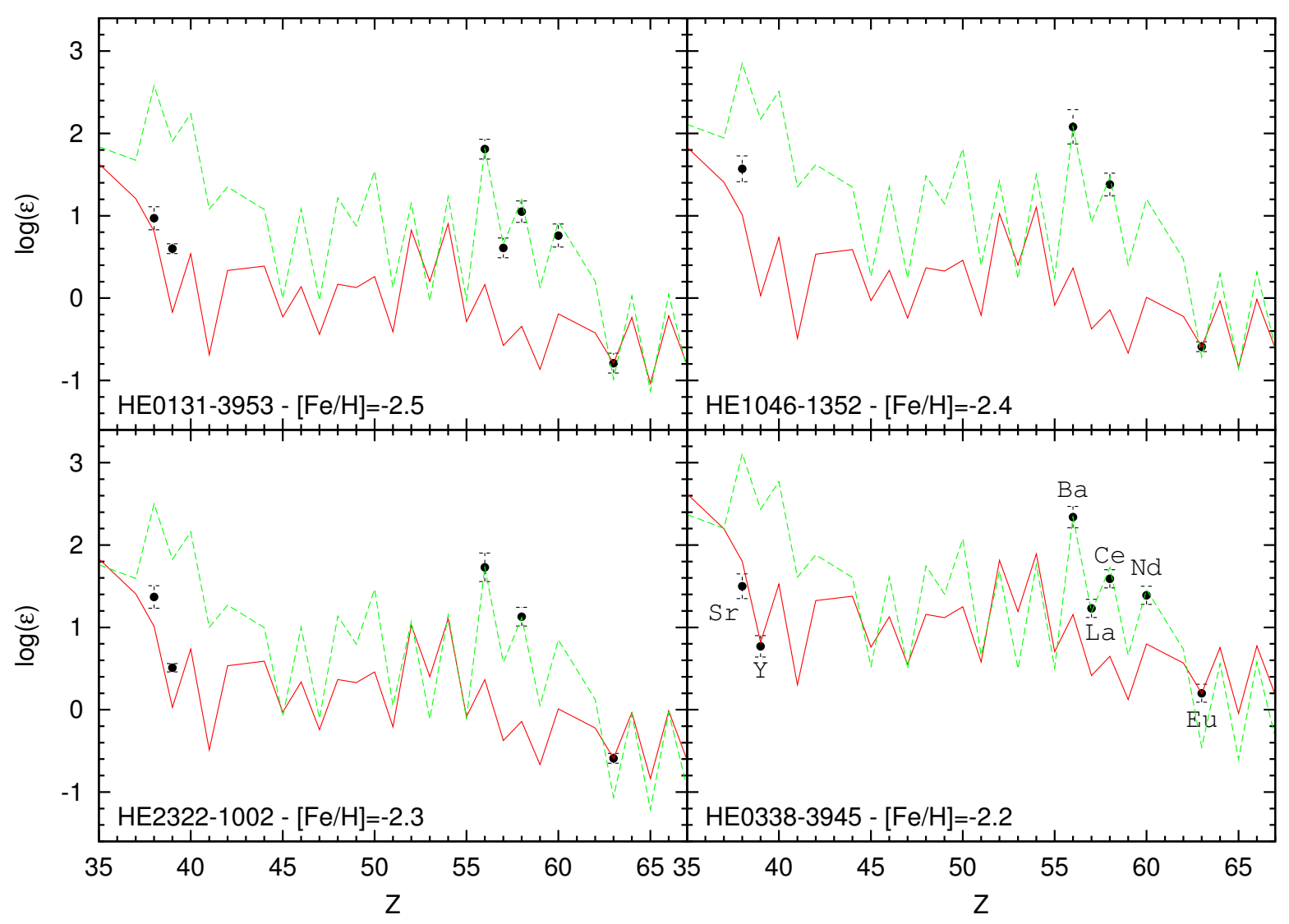

Fig. 5.1 Abundâncias de estrelas s-II da amostra. A linha vermelha (cheia) representa o padrão solar do processo-r normalizado pelo Eu e a linha verde (tracejada) o padrão solar do processo-s normalizado pelo Ba. As frações utilizadas foram retiradas de Arlandini et al. (1999).

\& Wasserburg 2003) em algum momento da evolução da Galáxia e possivelmente antes da introdução da componente $s$ no meio.

Alguns pontos podem ser levantados acerca do cenário proposto acima:

* A componente principal do processo-s para o objeto HE0131-3953 pode ser um efeito local devido a um sistema binário? Se sim, este processo poderia ocorrer antes do processo "global"?

* O fato de observar-se apenas algumas estrelas s-II é, de alguma forma, um efeito de seleção ou sua freqüência no halo Galático é mesmo muito baixa?

* Se a sobreabundância em carbono de HE0131-3953 ([C/Fe $]=+2.50)$ for atribuída ao 
sistema binário, possivelmente os elementos-s foram acretados da companheira mais massiva que já evoluiu.

\subsubsection{Objetos s-I}

As estrelas representativas da subclasse s-I são mostradas na figura 5.2. É possível notar que o comportamento dos elementos do segundo pico é o mesmo dos objetos s-II, seguindo o padrão solar s. Porém, para os elementos Sr, Y e Zr, nota-se um deslocamento em direção ao padrão solar $s$, que evidencia um excesso destes elementos em relação às estrelas s-II.

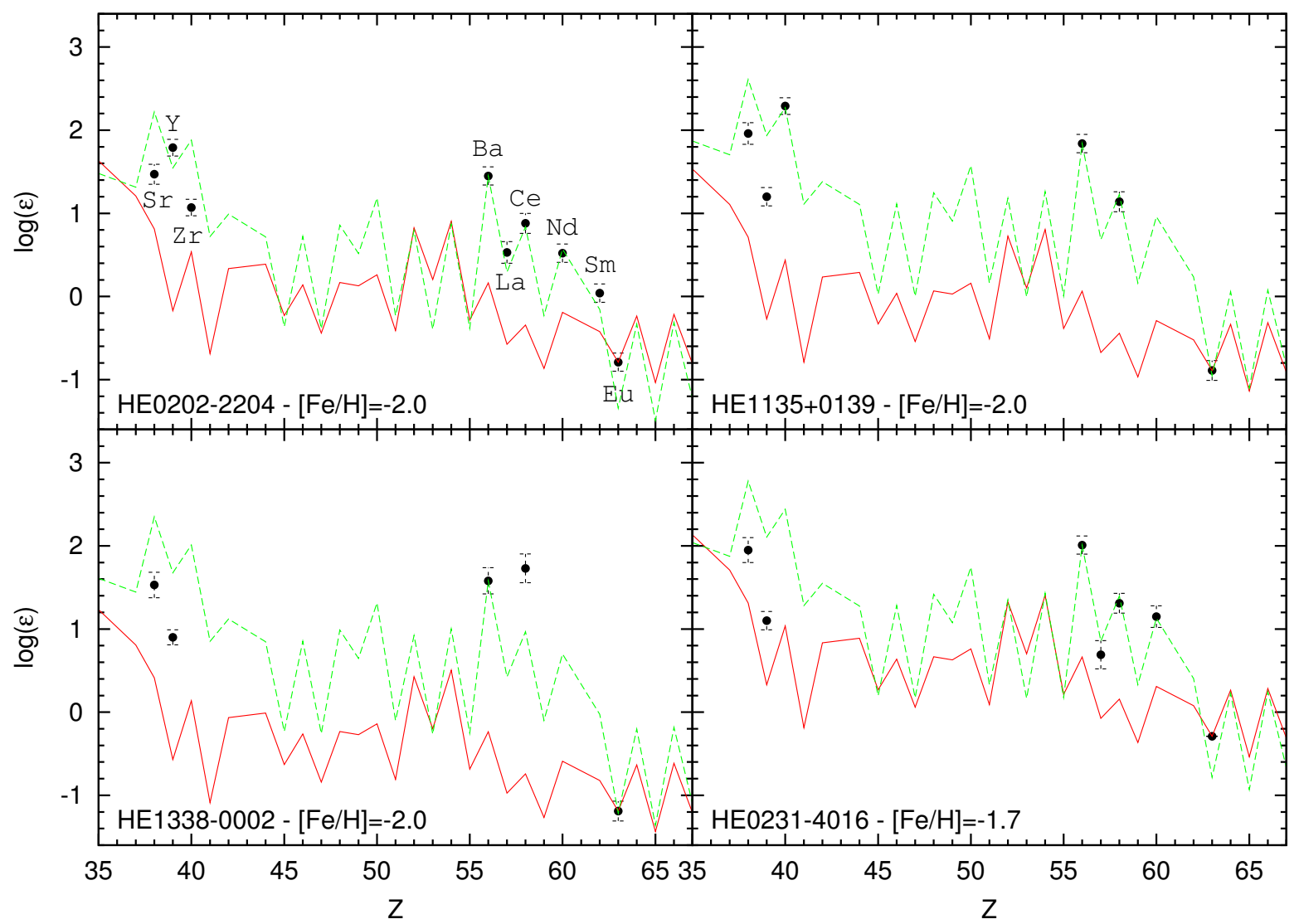

Fig. 5.2 Abundâncias de estrelas s-I da amostra. A linha vermelha (cheia) representa o padrão solar do processo-r normalizado pelo Eu e a linha verde (tracejada) o padrão solar do processo-s normalizado pelo Ba. As frações utilizadas foram retiradas de Arlandini et al. (1999).

Neste contexto, as abundâncias químicas dos objetos s-I (que possuem [Eu/Fe] menores 
que os s-II) podem ser resultado de uma componente secundária do processo-s responsável pela síntese dos elementos do primeiro pico, possivelmente associado à evolução de estrelas com massas intermediárias. Isto pode explicar o fato de haver uma sobreabundância destes elementos para metalicidades maiores, ou seja, pode ter ocorrido um segundo processo de formação de elementos, já que num ambiente com metalicidade maior, espera-se um meio onde mais estrelas tenham evoluído e, conseqüentemente, um meio mais rico em metais.

\subsection{Estrelas $r / s$}

A tabela 3.2 mostra que a subclasse com menor número de objetos, considerando as divisões da tabela 3.1, é a r/s, com 4 estrelas. Os objetos CS22948-027 e CS29497-034 (Barbuy et al. 2005) possuem, respectivamente, $[\mathrm{Ba} / \mathrm{Eu}]=0.4$ e 0.2 e o objeto HE1305+0007 (Goswani et al. 2006) possui $[\mathrm{Ba} / \mathrm{Eu}]=0.3^{2}$, e são alguns exemplos de objetos desta subclasse analisados na literatura. Os padrões de abundâncias das estrelas $r / s$ da amostra podem ser vistos na figura 5.3.

A subclasse $r / s$ pode ser vista, no contexto deste trabalho, como uma "transição" entre os objetos $r$ e $s$; porém, dada a restrição $0.0 \leq[\mathrm{Ba} / \mathrm{Eu}] \leq 0.5$, espera-se que estes objetos guardem características dos objetos $s$, como constatado pela análise de conglomerados (seção 4.5.2). Mesmo assim, existem diferenças entre eles, como por exemplo os de subclasse s-II, cujas abundâncias dos elementos do primeiro pico $s$ reproduzem melhor o padrão solar $r$. Um estudo realizado por Jonsell et al. (2006) analisa um objeto $r / s$ do HERES (HE0338-3945) e propõe uma série de possíveis cenários para a formação do mesmo. Este objeto está presente na figura 5.1, e é classificado como s-II $([\mathrm{Ba} / \mathrm{Eu}]=0.52)$.

No trabalho de Jonsell et al. (2006), a classe $r / s$ é definida com as seguintes restrições: $[\mathrm{Ba} / \mathrm{Eu}]>1.0,[\mathrm{Eu} / \mathrm{Fe}]>1.0$ e $[\mathrm{Ba} / \mathrm{Eu}]>0.0 ;$ e a classe $s$ por: $[\mathrm{Ba} / \mathrm{Eu}]>1.0,[\mathrm{Eu} / \mathrm{Fe}] \leq 1.0$ e $[\mathrm{Ba} / \mathrm{Eu}]>0.0$. Porém, como visto na seção 4.5.2, é possível separar pelo menos duas subclasses para $[\mathrm{Ba} / \mathrm{Eu}]>0.0$. Além disto, pode-se ver pela análise feita neste capítulo que existem diferenças entre objetos que possuam, por exemplo, $[\mathrm{Ba} / \mathrm{Eu}]=0.52(\mathrm{HE} 0338-3945$ - s-II) e $[\mathrm{Ba} / \mathrm{Eu}]=0.18(\mathrm{HE} 1405-0822-r / s)$. Na seção 5.4 são mostradas as principais diferenças entre as classes $r$ e $s$.

Existe, para os objetos da figura 5.3, uma elevada abundância do elemento Ce, que,

\footnotetext{
${ }^{2}$ ver figura 4.4 e tabela 4.1.
} 


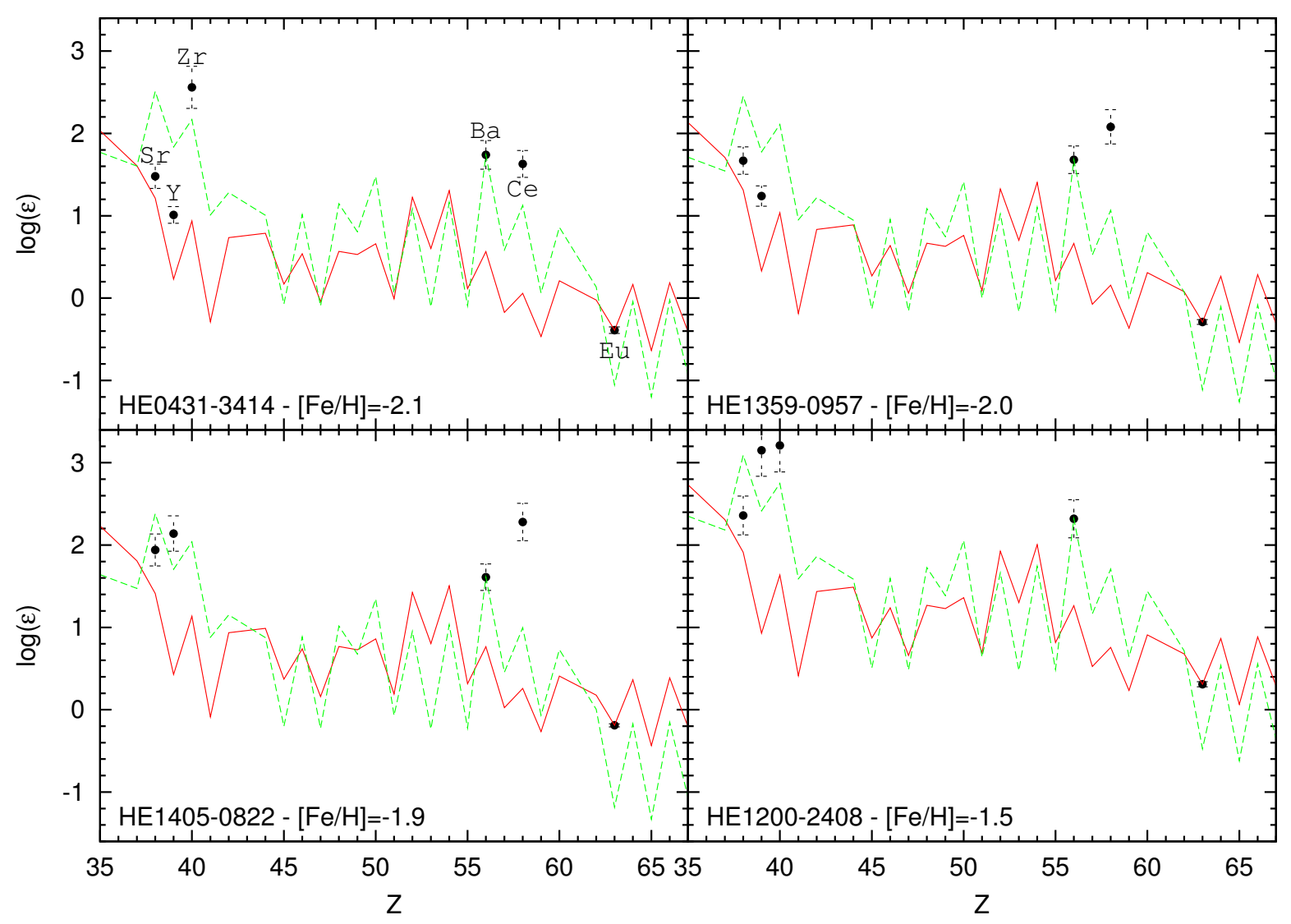

Fig. 5.3 Abundâncias de estrelas $r / s$ da amostra. A linha vermelha (cheia) representa o padrão solar do processo-r normalizado pelo Eu e a linha verde (tracejada) o padrão solar do processo-s normalizado pelo Ba. As frações utilizadas foram retiradas de Arlandini et al. (1999).

para os objetos HE1359-0957 e HE1405-0822, é mais de uma ordem de grandeza maior quando comparada com o valor solar normalizado para o processo-s. Além disto, para o objeto HE1200-2408, as abundâncias de Y e Zr também encontram-se maiores do que seu equivalente solar. Este comportamento não é esperado, visto que o elemento Ce segue o padrão dos demais elementos do segundo pico do processo-s, bem como os elementos do primeiro pico deveriam apresentar comportamento semelhante aos demais objetos da amostra. Esta diferença pode ser atribuída à dificuldade em se determinar abundâncias elementais em objetos com elevada abundância em carbono, com espectros em média/baixa resolução, devido à forte presença da banda $G$ do $C H$ em $4300 \AA$. Observa-se que todos os objetos da figura 5.3 possuem $[\mathrm{C} / \mathrm{Fe}]>+1.2$. 


\subsection{Estrelas $r$}

A afirmação mais importante acerca da ocorrência do processo-r seria, como visto na seção 2.2, a de que só se pode sintetizar elementos por tal processo em ambientes com temperaturas e densidades extremas. Para tanto, alguns cenários são propostos (ver, por exemplo, Cowan \& Sneden 2003 e Qian \& Wasserburg 2003) para tentar reproduzir o padrão de abundâncias encontrado nas estrelas ricas em elementos $r$.

Neste trabalho, adota-se a convenção de que as chamadas "estrelas $r$ " são aquelas onde a condição $[\mathrm{Ba} / \mathrm{Eu}]<0.0$ (ver tabelas 1.2 e 3.1) se aplica, ou seja, onde a contribuição do processo-r é maior que a do processo-s. Na figura 3.1 vemos uma clara separação entre essas estrelas e as estrelas $s$.

A nomenclatura utilizada também pode ser justificada pela figura 4.9. Nela se pode notar que os objetos com $[\mathrm{Ba} / \mathrm{Eu}]<0.0$ se concentram próximos ao valor solar desta razão para o processo-r, tanto para o Ba quanto para o La. Já os demais objetos (com $[\mathrm{Ba} / \mathrm{Eu}]>0.0)$ se encontram entre o valor solar total e a fração do processo-s. Ainda assim, dentre os objetos $r$, temos uma grande faixa de valores para a abundância de Eu e dos demais elementos formados por captura de nêutrons. Por isto torna-se necessária (como visto acima) a introdução de subclasses para tais objetos, que serão explicitadas a seguir.

\subsubsection{Objetos $r-I I$}

Os objetos r-II são, segundo Beers \& Christlieb (2005), fortemente enriquecidos em elementos formados por processo-r. Como visto na tabela 3.1, os critérios para sua classificação são: $[\mathrm{Eu} / \mathrm{Fe}]>1.0$ e $[\mathrm{Ba} / \mathrm{Eu}]<0.0$. Segundo a tabela 3.2, a amostra possui 10 estrelas com essas características.

A figura 5.4 mostra o comportamento das abundâncias dos elementos formados por captura de nêutrons para nove estrelas r-II da amostra comparadas com os padrões solares para os processos s e $r$. O gráfico referente ao objeto CS29491-069 foi omitido por possuir um número menor de abundâncias determinadas e ter comportamento semelhante aos demais. Os objetos CS22892-052 e CS31082-001 já foram estudados, respectivamente, em Sneden et al. (1996; 2003) e Hiil et al. (2002).

As metalicidades dos objetos r-II encontram-se entre $-3.19 \leq[\mathrm{Fe} / \mathrm{H}] \leq-2.58$. Da mesma forma, os objetos r-II presentes na figura 4.4 também possuem metalicidade nesta faixa, 


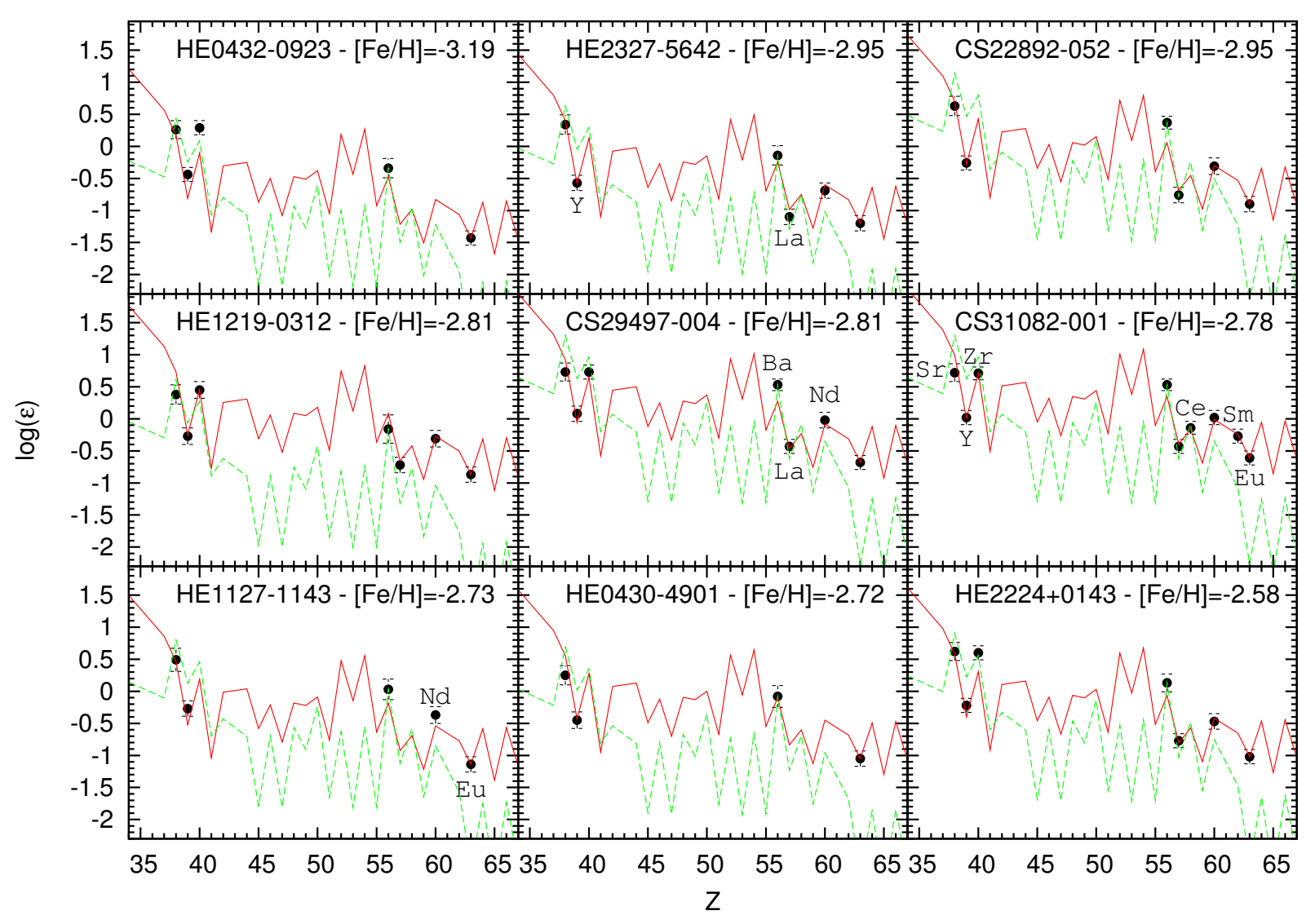

Fig. 5.4 Abundâncias de estrelas r-II da amostra. A linha vermelha (cheia) representa o padrão solar do processo-r normalizado pelo Eu e a linha verde (tracejada) o padrão solar do processo-s normalizado pelo Ba. As frações utilizadas foram retiradas de Arlandini et al. (1999).

fato que apoia a hipótese de que a componente forte do processo-r ocorreu nos primórdios da Galáxia, e está relacionada com eventos explosivos como supernovas de tipo II.

As contribuições relativas ao processo-s nas estrelas r-II podem ser consideradas desprezíveis, pois, como visto na seção 2.1 , o processo-s ocorre no AGB, associado a estrelas de massa mais baixa e sistemas binários (ver também Hill et al. 2002, Burris et al. 2000 e referências neles citadas). Isto pode ser visto nos elementos presentes nas estrelas da figura 5.4 , que reproduzem (num intervalo de até $3 \sigma$ ) o padrão solar do processo-r normalizado pelo Eu. Assim, todos os elementos químicos presentes em estrelas desta subclasse foram formados por processo-r. 


\subsubsection{Objetos $r-I$}

Os objetos r-I apresentam abundância moderada de $\mathrm{Eu}(0.3 \leq[\mathrm{Eu} / \mathrm{Fe}] \leq 1.0)$, além da condição $[\mathrm{Ba} / \mathrm{Eu}]<0.0$ (Beers \& Christlieb 2005). Espera-se que o comportamento das abundâncias elementais para estes objetos seja semelhante ao dos objetos r-II, exceto pelos elementos do primeiro pico do processo-s (Sr, Y e Zr) que, em alguns dos objetos, apresentam desvios em relação ao padrão solar normalizado para o processo-r. Segundo a tabela 3.2 , a base de dados possui 38 objetos nesta subclasse.

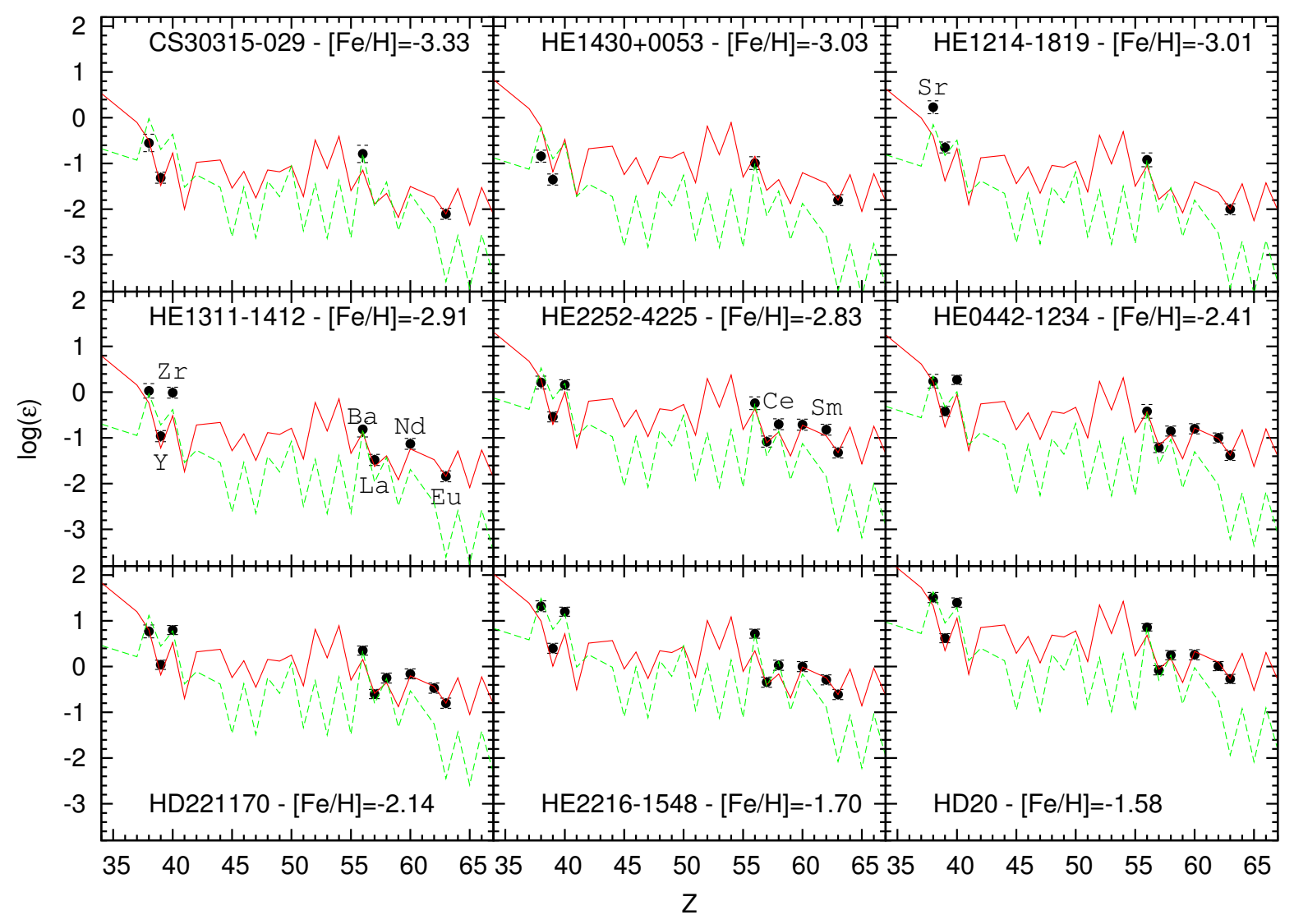

Fig. 5.5 Abundâncias de estrelas r-I da amostra. A linha vermelha (cheia) representa o padrão solar do processo-r normalizado pelo Eu e a linha verde (tracejada) o padrão solar do processo-s normalizado pelo Ba. As frações utilizadas foram retiradas de Arlandini et al. (1999).

A figura 5.5 mostra o comportamento das abundâncias de alguns dos objetos r-I da amostra. O objeto HD221170 também é objeto de estudo em Burris et al. (2000) e Ivans et al. (2006). É importante observar que o comportamento global dos elementos não se altera 
(dentro deste subgrupo) para uma grande faixa de metalicidade $(-3.33 \leq[\mathrm{Fe} / \mathrm{H}] \leq-1.58)$, cuja variabilidade é cerca de 3 vezes maior do que para as estrelas r-II.

Em comparação aos objetos r-II, as estrelas da figura 5.5 mostram comportamento semelhante para os elementos do segundo pico do processo-s, mesmo para metalicidades que diferem em quase duas ordens de grandeza. Já para os elementos do primeiro pico vemos alguns desvios para o Sr e o Zr, que não reproduzem o padrão solar para o processo$\mathrm{r}$ dentro de um intervalo de $3 \sigma$. Nestes objetos, principalmente os com metalicidades maiores, pode haver a presença de mais um episódio de enriquecimento tardio, resultado de explosões de supernovas de tipo Ia, que acrescentaram elementos $s$ (do primeiro pico) à estrela.

\subsubsection{Objetos $r-0$}

A figura 3.1 mostra as diferentes classificações para os objetos da amostra a partir das abundâncias de bário e európio. Além das subclasses definidas no trabalho de Beers \& Christlieb (2005), foi introduzida uma nova classe (r-0) que compreende todos os objetos $\operatorname{com}[\mathrm{Eu} / \mathrm{Fe}]<0.3$ e $[\mathrm{Ba} / \mathrm{Eu}]<0.0$. Na amostra encontra-se um total de 14 objetos com esta classificação, no intervalo de metalicidades $-2.99 \leq[\mathrm{Fe} / \mathrm{H}] \leq-2.33$.

O comportamento das abundâncias elementais dos objetos r-0 pode ser visto na figura 5.6. Objetos com poucas abundâncias determinadas e comportamento semelhante aos demais foram omitidos.

É possível notar que os elementos do primeiro pico do processo-s estão em excesso em relação aos objetos r-II e r-I, e também com relação ao padrão solar $r$ normalizado. Para os objetos onde a abundância de Ba está acima do padrão solar r (HE1314-3036 e HE00512304), os elementos do primeiro pico reproduzem o padrão solar para o processo-s. Este fato demonstra a relação (ainda que não direta) entre os elementos do primeiro e segundo picos do processo-s. Já os demais elementos do segundo pico (La e Nd), quando presentes, seguem o comportamento do Ba, como esperado.

A introdução desta nova subclasse também é importante para descrever padrões de abundância para estrelas que possuem valores menores que os valores solares. Assim, é possível mostrar que, mesmo que os objetos experimentem episódios de enriquecimento em locais distintos, e com intensidades distintas, o padrão de abundância não se altera para 


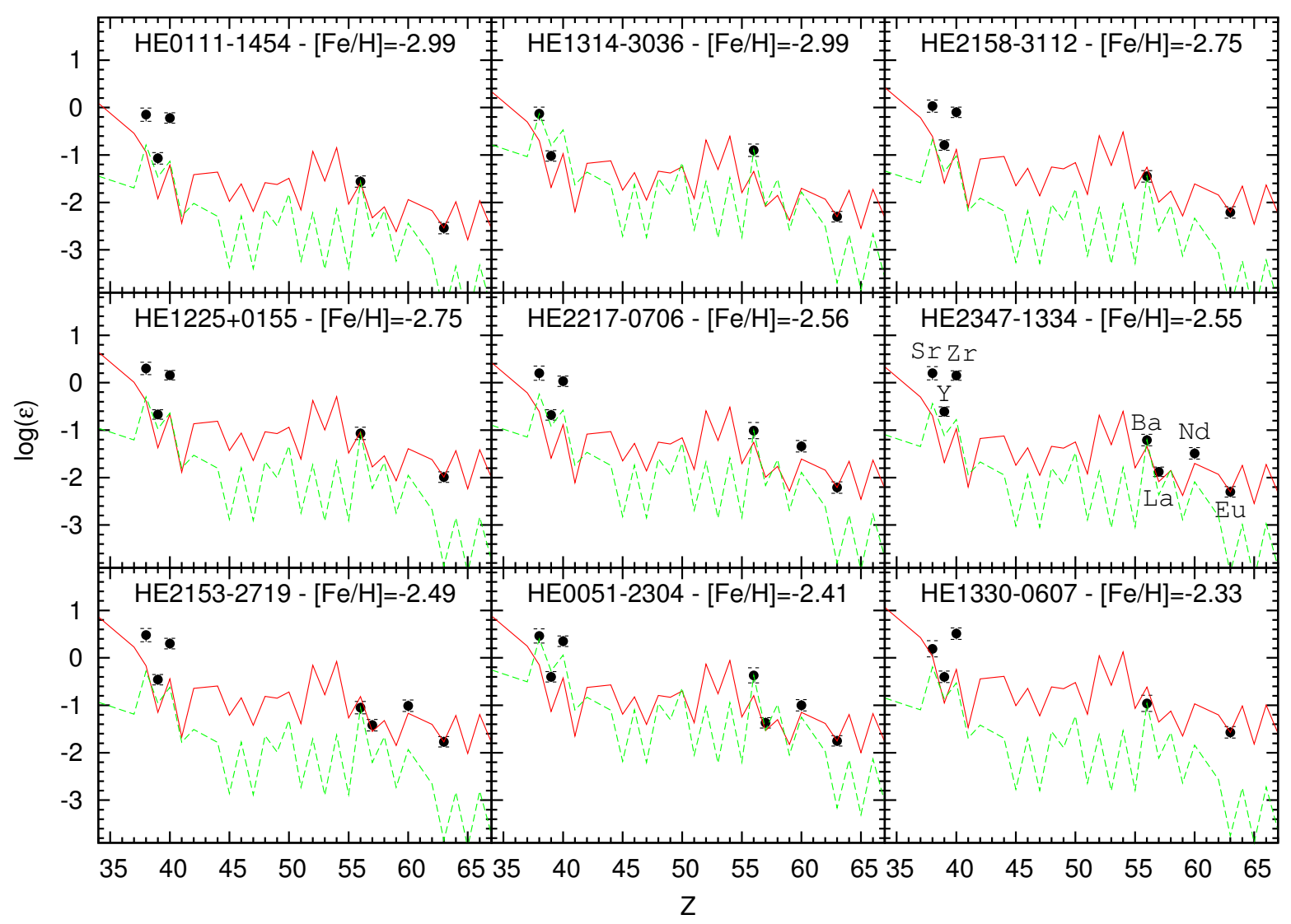

Fig. 5.6 Abundâncias de estrelas r-0 da amostra. A linha vermelha (cheia) representa o padrão solar do processo-r normalizado pelo Eu e a linha verde (tracejada) o padrão solar do processo-s normalizado pelo Ba. As frações utilizadas foram retiradas de Arlandini et al. (1999).

os elementos do segundo pico $s$ e para o Eu. No entanto, pode-se observar o excesso dos elementos Sr, Y e Zr em relação ao padrão solar s, o que novamente mostra evidências de que existe mais de um mecanismo de produção destes elementos.

\subsection{Comparação entre as classes $r$ e $s$}

As seções 5.1, 5.2 e 5.3 descrevem o comportamento das subclasses $r$ e $s$ para os objetos presentes na amostra. Através desta análise é possível observar correlações entre, por exemplo, os elementos do primeiro pico $s$ e o Eu. Também é interessante notar que, mesmo com metalicidades consideravelmente diferentes ${ }^{3}$, as abundâncias (em log $\epsilon$ ) dos

\footnotetext{
${ }^{3}$ até $\sim 2$ ordens de grandeza para os objetos r-I.
} 
objetos pertencentes à uma mesma subclasse se comportam de forma semelhante.

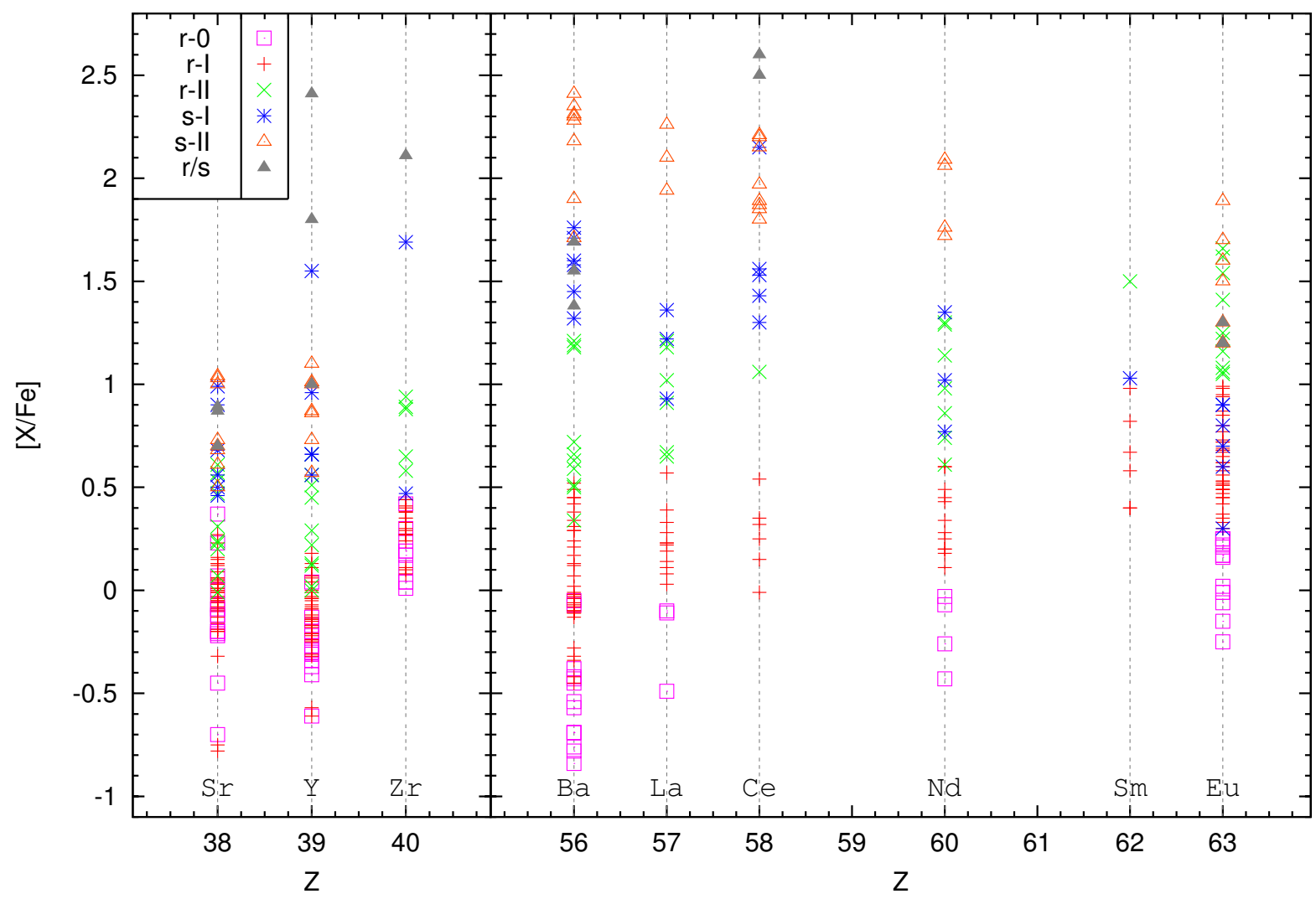

Fig. 5.7 Comportamento das abundâncias (em relação ao ferro) entre as subclasses $r$ e $s$ em função do número atômico.

O próximo passo é comparar as classes $r$ e $s$ entre si, de forma a determinar possíveis correlações e diferenças entre elas. A figura 5.7 mostra o comportamento das abundâncias para os elementos formados por captura de nêutrons para os objetos selecionados pelos critérios da tabela 3.1. É importante notar que, utilizando somente os elementos Ba e Eu não é possível distinguir, por exemplo, os objetos s-I e r-II (ver seção 4.5.1), cujas abundâncias se sobrepõem em sete dos nove elementos. Por isto a inclusão da restrição em [Ba/Eu] faz parte da definição das subclasses feita por Beers \& Christlieb (2005). Entretanto, foi visto que a partir do conjunto das abundâncias de C, Sr, Ba e Eu (seção 4.5.2), a restrição não é necessária para classificar os objetos. Também é importante ressaltar o uso das variáveis na notação de colchetes, que leva em conta a quantidade de ferro do objeto e a compara com o valor solar, visto que os valores absolutos (em log $\epsilon$ ) não 
fornecem o mesmo tipo de informação, como visto na seção 3.2.

O La tem comportamento próximo ao do Ba (ver seção 4.4), o que reforça a hipótese de ambos compartilharem a mesma origem. Além disto, nota-se que os elementos $\mathrm{Nd}$ e $\mathrm{Ce}^{4}$ também seguem as mesmas tendências, porém a determinação de suas abundâncias é mais difícil devido à fraca intensidade das linhas destes elementos presentes no intervalo de comprimento de onda medido.

Outra forma de comparar as classes $r$ e $s$ é através do padrão de suas abundâncias normalizadas em relação a algum elemento de interesse. Assim, tem-se o comportamento de cada subclasse para os nove elementos formados por captura de nêutrons presentes na amostra.

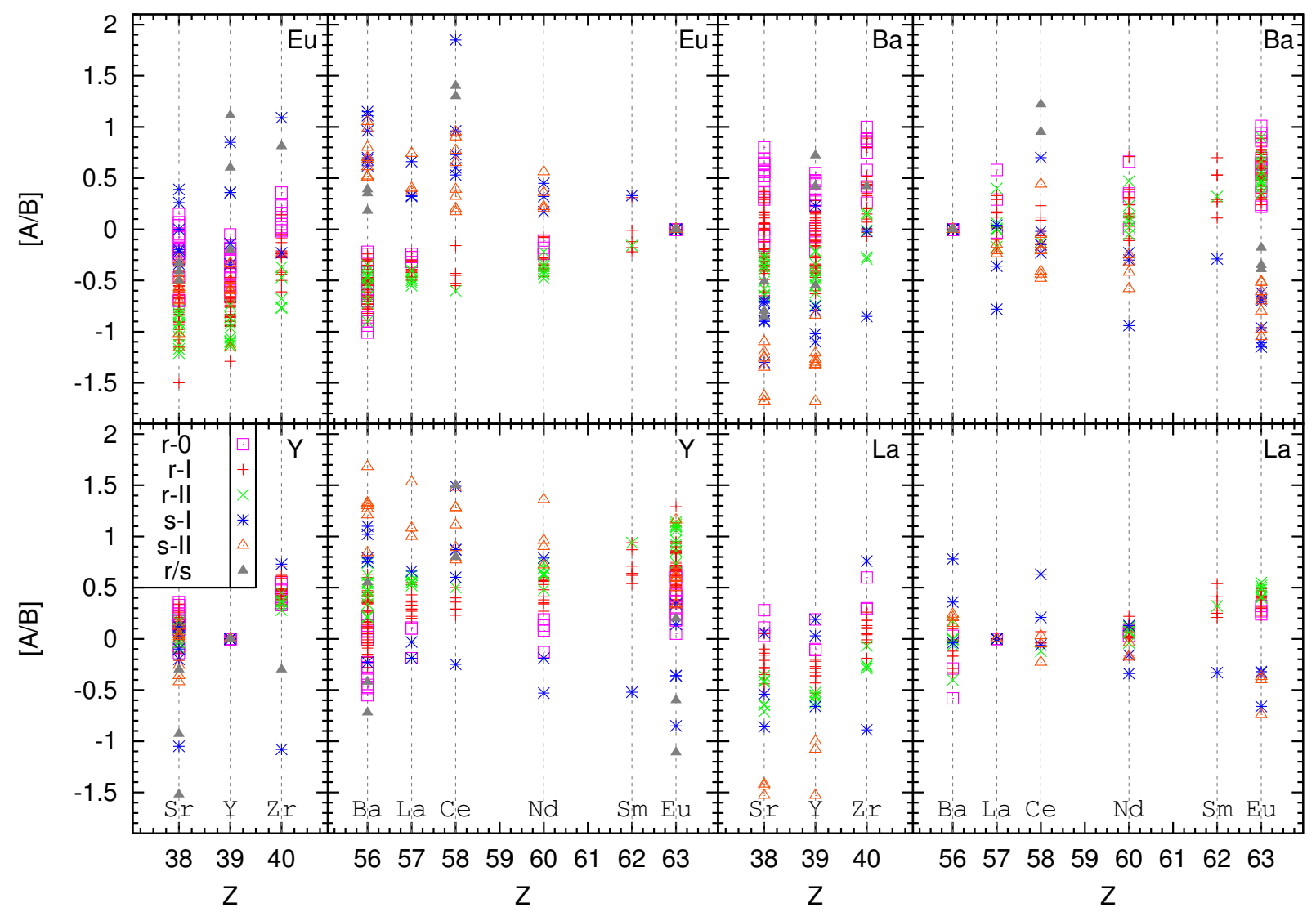

Fig. 5.8 Comportamento das abundâncias normalizadas entre as subclasses $r$ e $s$ sem levar em conta a abundância de ferro.

A figura 5.8 mostra os perfis das abundâncias para seis subclasses (r-II, r-I, r-0, s-II,

\footnotetext{
${ }^{4} \mathrm{O}$ elemento Ce, como visto na seção 5.2 , apresenta comportamento diferente para alguns objetos $r / s$ da amostra.
} 
s-I e $r / s$ ), normalizadas pelo Y (elemento $s$ do primeiro pico), Ba e La (elementos $s$ do segundo pico) e pelo Eu (elemento $r$ ). A normalização adotada neste caso foi:

$$
\left[\frac{A}{B}\right]=\left[\frac{A}{F e}\right]-\left[\frac{B}{F e}\right]
$$

onde $A$ é um dos nove elementos formados por captura de nêutrons, identificados na parte inferior do gráfico, e $B$ é o elemento pelo qual os demais foram normalizados, e que se encontra na parte superior direita de cada painel.

Como se pode ver na figura 5.8, o comportamento das abundâncias entre os subgrupos muda de acordo com a normalização adotada. As principais características de cada uma delas estão listadas abaixo:

* Eu: Para os elementos do segundo pico do processo-s as classes $r$ e $s$ ficam separadas. Isto decorre diretamente da definição pois, neste caso, a normalização fornece [Ba/Eu]. Então, como visto na seção 4.4, pode-se concluir que os demais elementos do segundo pico compartilham a mesma origem do Ba. Já para os elementos do primeiro pico $s$ não existe separação clara, mas pode-se notar, no primeiro painel superior do lado esquerdo da figura 5.8, que os objetos r-II e s-II estão sobrepostos. Este fato desvincula a formação dos elementos do primeiro e segundo pico do processo-s, uma vez que essas subclasses possuem em comum somente a abundância de $\operatorname{Eu}([\mathrm{Eu} / \mathrm{Fe}]>1.0)$.

* Ba: Feita a normalização para o elemento do segundo pico $s$ Ba, nota-se que, para as abundâncias de Sr e Y, a subclasse s-II possui uma abundância mais baixa que as demais, sendo que os objetos s-I misturam-se com a classe $r$. Neste caso, a baixa abundância destes elementos é resultado da alta abundância de Ba. Para o elemento Eu o comportamento também é resultado da definição das classes $r$ e $s$.

* La: Por ser um elemento do segundo pico do processo-s, o comportamento das abundâncias em relação ao La se mostra semelhante ao do Ba, porém com um espalhamento menor.

* Y: A normalização pelo Y fornece, para o Ba e La, a razão $[l s / h s]$ (ver seção 4.4). Neste caso existe separação apenas para os elementos do segundo pico $s$, e novamente as classes s-II e r-II tornam-se indistinguíveis em relação ao Eu. 
Na figura 5.9 são mostrados quatro objetos de diferentes subclasses analisados neste capítulo. O objetivo da figura não é propor uma seqüência evolutiva entre os objetos, mas sim mostrar que as estes provêm de ambientes distintos, mesmo que apresentem algumas semelhanças na distribuição de suas abundâncias. A faixa de metalicidades onde se encontram estes objetos é $-2.81 \leq[\mathrm{Fe} / \mathrm{H}] \leq-2.00$.

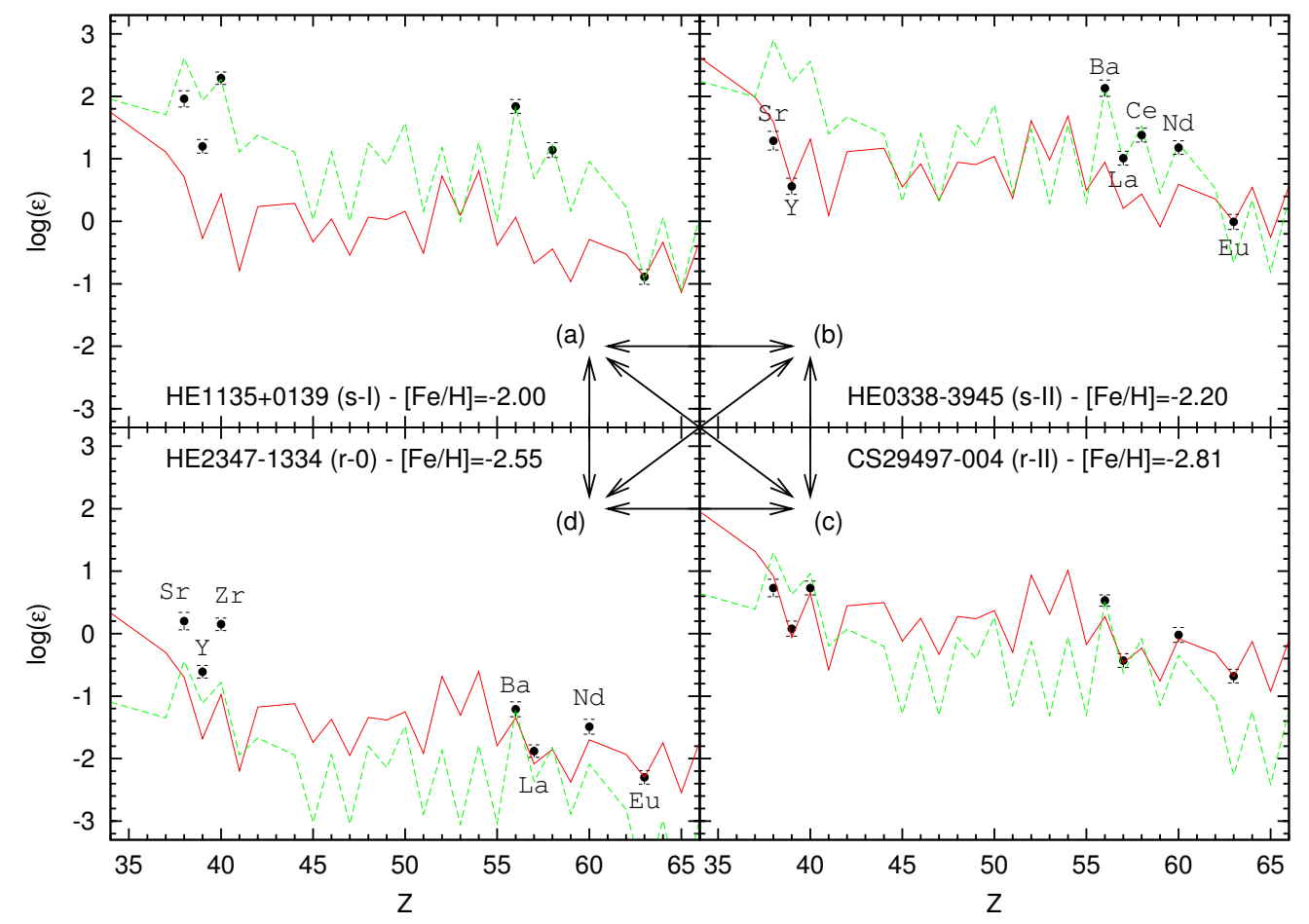

Fig. 5.9 Comparação entre os objetos localizados nos extremos da figura 4.19. A linha vermelha (cheia) representa o padrão solar do processo-r normalizado pelo Eu e a linha verde (tracejada) o padrão solar do processo-s normalizado pelo Ba. As frações utilizadas foram retiradas de Arlandini et al. (1999).

A tabela 5.1 sumariza alguns parâmetros dos objetos da figura 5.9 e, a partir disto, pode-se inferir uma "seqüência", partindo de uma certa subclasse e verificando como suas abundâncias de Sr, Ba e Eu se comportam. Assim, é possível mostrar que, de fato, ocorre uma co-produção de elementos do primeiro pico $s$ e elementos formados por processo-r (ver Qian \& Wasserburg 2003), bem como argumentar que também existe outro mecanismo responsável pela formação de elementos como Sr, Y e Zr, provavelmente associado a supernovas numa faixa de massas diferente da proposta para os elementos mais pesados ${ }^{5}$.

\footnotetext{
${ }^{5} 8.0 \geq M\left(M_{\odot}\right) \geq 10.0$ - ver seção 4.2 .
} 


\begin{tabular}{c|c|cccc|c}
\hline$\star$ & subclasse & {$[\mathrm{Fe} / \mathrm{H}]$} & {$[\mathrm{Ba} / \mathrm{Fe}]$} & {$[\mathrm{Eu} / \mathrm{Fe}]$} & {$[\mathrm{Sr} / \mathrm{Fe}]$} & {$[\mathrm{Ba} / \mathrm{Eu}]$} \\
\hline HE1135+0139 & s-I & -2.00 & 1.71 & 0.60 & 0.99 & 1.11 \\
HE0338-3945 & s-II & -2.20 & 2.41 & 1.89 & 0.73 & 0.52 \\
HE2347-1334 & r-0 & -2.55 & -0.78 & -0.25 & -0.21 & -0.53 \\
CS29497-004 & r-II & -2.81 & 1.21 & 1.62 & 0.57 & -0.41 \\
\hline
\end{tabular}

Tab. 5.1 Abundâncias de Sr, Ba e Eu e metalicidades para as estrelas da figura 5.9.

A partir da figura 5.9 e da tabela 5.1, pode-se chegar às seguintes conclusões:

* $(\mathbf{a}) \longleftrightarrow(\mathbf{b}):$ Ocorre a diminuição de $[\mathrm{Ba} / \mathrm{Eu}]$ e aumento da abundância de Eu e Ba. O Eu aumenta mais de uma ordem de grandeza, e os elementos do primeiro pico se adequam ao padrão solar $r$;

$\star(\mathbf{a}) \longleftrightarrow(\mathbf{c}):$ Aumento da abundância de Eu, diminuição de [Ba/Fe], primeiro pico $s$ reproduz padrão solar $r$ e, dada a metalicidade de -2.81 , espera-se que os elementos do segundo pico sigam o padrão solar $r$, pois o processo-s ainda não deveria operar neste ambiente;

* (a) $\longleftrightarrow(\mathbf{d})$ : Abundância de Ba diminui, razão [Ba/Eu] passa para regime $r$, e ocorre excesso dos elementos do primeiro pico $s$, pois estes não são produzidos no mesmo ambiente do Ba;

* (b) $\longleftrightarrow$ (c): Metalicidade muito baixa para objetos r-II, então espera-se apenas elementos formados por processo-r e, mesmo que a abundância de Eu não varie significativamente, a razão $[\mathrm{Ba} / \mathrm{Fe}]$ diminui em uma ordem de grandeza e objeto passa para regime $r$;

$\star(\mathbf{c}) \longleftrightarrow(\mathbf{d}):[\mathrm{Ba} / \mathrm{Eu}]$ varia apenas 0.1 dex, mas abundâncias diminuem $\sim$ duas ordens de grandeza, deixando elementos do primeiro pico $s$ em excesso. Esta diminuição das abundâncias apoia a idéia de um enriquecimento local para as estrelas pobres em metais, visto que estes dois objetos possuem valores próximos de metalicidade, ou seja, foram formados em épocas próximas, fato que, isoladamente, não justificaria esta diferença nos valores absolutos das abundâncias. 


\section{CONCLUSÕES E PERSPECTIVAS}

\subsection{Conclusões}

Este trabalho fornece uma série de conclusões e perspectivas acerca da análise de uma grande base de dados de estrelas pobres em metais da Galáxia. Esta foi a primeira análise de abundâncias para um grande número de objetos (382 estrelas com metalicidade determinada - $[\mathrm{Fe} / \mathrm{H}]<-1.0)$ de um mesmo survey, que confirma resultados já encontrados na literatura (Barklem et al. 2005) e fornece novas classificações para os objetos peculiares encontrados na amostra, baseadas em métodos estatísticos como a análise de conglomerados. Alguns resultados importantes encontrados são citados a seguir:

* Imposição de limite superior para o início da operação do processo-s na Galáxia $([\mathrm{Fe} / \mathrm{H}] \leq-2.60)$, baseada no comportamento das abundâncias do objeto HE2228$0706([\mathrm{Ba} / \mathrm{Fe}]=2.5$ e $[\mathrm{C} / \mathrm{Fe}]=+2.4)$, que apresenta comportamento semelhante aos objetos $s$. Este limite está de acordo com outros valores encontrados na literatura ${ }^{1}$;

* Aumento do espalhamento das abundâncias de elementos formados por captura de nêutrons para baixas metalicidades $([\mathrm{Fe} / \mathrm{H}]<-2.5)$ sugere um meio interestelar nãohomogêneo nos primórdios da Galáxia, bem como dá suporte ao fato de que os episódios de enriquecimento são locais, afetando apenas o meio próximo ao objeto observado (Cowan \& Sneden 2003);

* Enriquecimento químico distinto para os regimes $r([\mathrm{Ba} / \mathrm{Eu}] \leq 0.0)$ e $s([\mathrm{Ba} / \mathrm{Eu}]>0.0)$. Além disso, mostrou-se que os elementos dos diferentes picos do processo-s não têm relação entre si, em se tratando dos locais de formação;

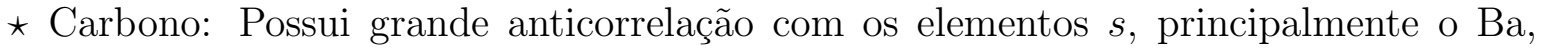
onde se pode notar (ver figura 4.7) que existem dois regimes distintos, sendo que,

\footnotetext{
${ }^{1}$ ver referências citadas na seção 4.2.
} 
para $[\mathrm{C} / \mathrm{H}] \geq-1.0$, os objetos possuem $[\mathrm{Ba} / \mathrm{Fe}]>1.0$, exceto para três estrelas (CEMPno), cuja fonte primária de carbono não é a mesma das demais; e, como descrito em Rossi et al. (2005) e Aoki et al. (2007), as abundâncias de carbono crescem com a diminuição da metalicidade, para $[\mathrm{Fe} / \mathrm{H}]<-2.0$;

* Através das razões $[h s / l s]$ é possível também notar diferenças entre o comportamento de estrelas com diferentes abundâncias de carbono. Porém, mesmo apresentando comportamentos distintos, a baixa estatística disponível para o cálculo da média, usando a equação 4.1, impede que se confirmem tendências com a metalicidade para essa amostra;

* Análise de Conglomerados: A partir de critérios estatísticos, foram escolhidos grupos de variáveis para a análise de agrupamentos. Foram realizadas uma série de análises, mostrando que, ao se utilizar apenas as variáveis $[\mathrm{Ba} / \mathrm{Fe}]$ e $[\mathrm{Eu} / \mathrm{Fe}]$ (seção 4.5.1) não é possível reproduzir as classificações encontradas na literatura para os objetos com abundâncias determinadas de elementos formados por captura de nêutrons (Barklem et al. 2005; Beers \& Christlieb 2005); porém, utilizando as variáveis [Ba/Fe], [Eu/Fe], [Sr/Fe] e [C/Fe] foi possível separar os objetos nos regimes $r$ e $s$, sem o uso do vínculo $[\mathrm{Ba} / \mathrm{Eu}]$, bem como distinguir subclasses (r-0, r-I, r-II, s-I e s-II) dentro destes regimes. A subclasse $r / s$ não foi obtida como resultado dos agrupamentos; porém, foi mantida por apresentar características distintas das demais;

* Análise detalhada dos padrões de abundâncias para todas as subclasses presentes na tabela 3.1, mostrando as principais diferenças e confirmando as hipóteses de diferentes locais de formação para elementos $s$ do primeiro e segundo picos e elementos $r$ (segundo Qian \& Wasserburg 2003), bem como evidências mostradas na seção 5.4 de co-produção dos elementos do primeiro pico $s$ e elementos $r$;

* Introdução de duas subclasses adicionais ao trabalho de Beers \& Christlieb (2005): r-0 e s-II, que auxiliam na classificação dos objetos com presença de elementos formados por captura de nêutrons. A subclasse r-0 leva em conta objetos com razões subsolares para Ba e Eu, sendo que as classificações sugeridas até o presente levam em conta apenas objetos com valores de abundâncias maiores que os solares. Com efeito, 
espera-se haver uma homogeneização da nomenclatura, para facilitar a construção de novas bases de dados e para comparação entre estudos presentes na literatura.

\subsection{Perspectivas}

Uma das perspectivas deste trabalho é extender a análise de grupos naturais para todos os elementos químicos com abundâncias determinadas da amostra (elementos $\alpha$ e do pico do ferro), bem como para suas características cinemáticas (posições e velocidades). Dessa forma, espera-se que seja possível inferir novas características das populações estelares que deram origem a essas estrelas, e possivelmente dar suporte a novos estudos (por exemplo Carollo et al. 2007), que propõe uma divisão do halo Galático em duas componentes distintas (halo interno e halo externo), baseada nas características químio-dinâmicas dos objetos pobres em metais.

A partir dos resultados descritos neste trabalho, espera-se homogeneizar a nomenclatura existente para estrelas pobres em metais com abundâncias determinadas para elementos formados por captura de nêutrons. É importante ressaltar o uso de uma nova ferramenta estatística na análise de dados, que pode ser generalizada para os mais diversos estudos em Astrofísica. Uma ferramenta robusta como a análise de conglomerados mostra-se extremamente útil pois, nos últimos anos, é possível notar um aumento no número de grandes surveys (por exemplo $S D S S, 2 M A S S, H E S$ ), que fornecem dados observacionais para milhões de objetos. Nesse contexto, torna-se importante o domínio de ferramentas que otimizem o tratamento de dados e que possam prestar-se a extrair informações importantes dos mesmos, principalmente em espaços de parâmetros cada vez maiores. 


\section{REFERÊNCIAS BIBLIOGRÁFICAS}

Anscombe, F. J. 1973, American Statistician 27, 17

Aoki, W., Ryan, S. G., Norris, J. E., Beers, T. C., Ando, H., Iwamoto, N., Kajino, T., Mathews, G. J., \& Fujimoto, M. Y. 2001, ApJ 561, 346

Aoki, W., Ryan, S. G., Norris, J. E., Beers, T. C., Ando, H., \& Tsangarides, S. 2002, ApJ 580, 1149

Aoki, W., Frebel, A., Christlieb, N., Norris, J. E., Beers, T. C., Minezaki, T., Barklem, P., Honda, S., Takada-Hidai, M., Asplund, M., Ryan, S. G., Tsangarides, S., Eriksson, K., Steinhauer, A., Deliyannis, C. P., Nomoto, K., Fujimoto, M. Y., Ando, H., Yoshii, Y. \& Kajino, T. 2006, ApJ 639, 897

Aoki, W., Beers, T. C., Christlieb, N., Norris, J. E., Ryan, S. G. \& Tsangarides, S. 2007, ApJ 655, 492

Arlandini, C., Kappeler, F., Wisshak, K., Gallino, R., Lugaro, M., Busso, M., \& Straniero, O. 1999, ApJ 525, 886

Asplund, M., Grevesse, N. \& Sauval, A.J. 2005, ASPC 336, 25

Ballero, S. K., Matteucci, F. \& Chiappini, C. 2006, New Astronomy 11, 306

Barbuy, B., Spite, M., Spite, F., Hill, V., Cayrel, R., Plez, B. \& Petitjean, P. 2005, A\&A 429, 1031

Barklem, P. S., Christlieb, N., Beers, T. C., Hill, V., Bessell, M. S., Holmberg, J., Marsteller, B., Rossi, S., Zickgraf, F.-J. \& Reimers, D. 2005, A\&A 439, 129

Beers, T. C., Preston, G. W. \& Schectman, S. A. 1985, AJ 90, 2089

Beers, T. C., Preston, G. W. \& Schectman, S. A. 1992, AJ 103, 1987 
Beers, T. C. 2000, in Galaxy Evolution - Connecting the Distant Past with the Local Fossil Record, ed. M. Spite (Kluwer:Dordrecht), 105

Beers, T. C. \& Christlieb, N. 2005, ARA\&A 43, 531

Burbidge, E. M., Burbidge, G. R., Fowler, W. A. \& Hoyle, F. 1957, Rev. Mod. Phys. 29,547

Burris D. L., Pilachowski C. A., Armandroff T. E., Sneden C., Cowan, J.J., \& Roe H. 2000, ApJ, 544, 302

Carollo, D., Beers, T. C., Lee, Y. S., Chiba, M., Norris, J. E., Wilhelm, R., Sivarani, T., Marsteller, B., Munn, J. A., Bailer-Jones, C. A. L., Re Fiorentin, P. \& York, D. G. 2007, astro-ph/0706.3005

Cayrel, R., Hill, V., Beers, T. C., Barbuy, B., Spite, M.,Spite, F., Plez, B., Andersen, J., Bonifacio, P., François, P. Molaro, P., Nordstrom, B. \& Primas, F. 2001, Nature 409, 691

Cescutti, G., François, P., Matteucci, F., Cayrel, R. \& Spite, M. 2006, A\&A 448, 557

Chen, Z., Zhang, J., Chen, Y., Cui, W. Y. \& Zhang, B. 2006, astro-ph/0608568

Chiappini, C., Matteucci, M. F. \& Gratton, R. G. 1997, ApJ 477, 765

Christlieb, N., Bessell, M., Beers, T. C., Gustafsson, B., Korn, A., Barklem, P., Karlsson, T., Mizuno-Wiedner, M. \& Rossi, S. 2002, Nature 419, 904

Christlieb, N. 2003, in Rev. Mod. Astron. 16, 191 (astro-ph/0308016)

Christlieb, N., Beers, T. C., Barklem, P. S., Bessell, M. Hill, V., Holmberg, J., Korn, A. J., Marsteller, B., Mashonkina, L., Qian, Y. -Z., Rossi, S., Wasserburg, G. J., Zickgraf, F. -J., Kratz, K. -L, Nordström, B., Pfeiffer, B. \& Rhee, J. 2004, A\&A 416, 1117

Cohen, J. G., Christlieb, N. C., Qian, Y. -Z. \& Wasserburg, G. J. 2003, ApJ 588, 1082

Cowan, J. J., Sneden, C., Burles, S., Ivans, I., Beers, T. C., Truran, J. W.,Lawler, J. E.,Primas, F., Fuller, G. M., Pfeiffer, B. \& Kratz, K. -L. 2002, ApJ 572, 861 
Cowan, J. J., Sneden, C. 2003, in Origin and Evolution of the Elements, Carnigie Observatories Series, vol.4, eds. A. McWilliam \& M.Rauch, Cambridge: Cambridge University Press (astro-ph/0309802)

Depagne, E., Hill, V., Spite, M., Spite, F., Plez, B., Beers, T. C., Barbuy, B., Cayrel, R., Andersen, J., Bonifacio, P., François, P., Nordström, B. \& Primas, F. 2002, A\&A 390, 187

François, P., Hill, V., Spite, M., Spite, F., Plez, B., Beers, T. C., Barbuy, B., Cayrel, R., Andersen, J., Bonifacio, P., Molaro, P., Nordström, B. \& Primas, F. 2003, A\&A 403, 1105

François, P., Depagne, E., Hill, V., Spite, M., Spite, F., Plez, B., Beers, T. C., Barbuy, B., Cayrel, R., Andersen, J., Bonifacio, P., Molaro, P., Nordström, B. \& Primas, F. 2006, A\&A em preparação ("First Stars VIII")

Fujimoto, M. Y., Ikeda, Y. \& Iben, I.Jr. 2000, ApJ 529, L25

García Pérez, A. E., Asplund, M., Primas, F., Nissen, P. E. \& Gustafsson, B. 2006, A\&A 451, 621

Goswami, A., Aoki, W., Beers, T. C., Christlieb, N., Norris, J. E., Ryan, S. G. \& Tsangarides, S. 2006, MNRAS, 372, 343

Grevesse, N. \& Sauval, A.J. 1998, Space Science Reviews 85, 161

Herwig, F. 2005, ARA\&A 43, 435

Hill, V., Plez, B., Cayrel, R., Beers, T. C., Nordstrom, B., Andersen, J., Spite, M., Spite, F., Barbuy, B., Bonifácio, P., Depagne, E., François, P., Molaro, P. \& Primas, F. 2002, A\&A 387, 560

Ivans, I. I., Simmerer, J., Sneden, C., Lawler, J. E., Cowan, J. J., Gallino, R., \& Bisterzo, S. 2006, ApJ 645, 613

Ishimaru, Y., Wanajo, S., Aoki, W., Ryan, S. \& Prantzos, N. 2005, Nuclear Physics A 758, 603 
Jain, A. K., Murty, M. N. \& Flynn, P.J. 1999, ACM Computing Surveys, Vol. 31, n ${ }^{o}$ 3

Johnson, J. A., \& Bolte, M. 2001, ApJ 554, 888

Johnson, J. A., \& Bolte, M. 2002, ApJ 579L, 87

Johnson, R. A. \& Winchern, D. W. Applied Multivariate Statistical Analysis - $5^{a}$ ed. Prentice Hall, 2002

Jonsell, K., Barklem, P. S., Gustafsson, B., Christlieb, N., Hill, V., Beers, T .C. \& Holmberg, J. 2006, A\&A 451, 651

Kappeler, F., Beer, H. \& Wisshak, K. 1989, Rep. Prog. Phys. 52, 945

Karlsson, T. 2006, astro-ph/0602597

Kippenhahn, R. \& Weigert, A. Stellar Structure and Evolution. Springer, 1994.

Lodders, K. 2003, ApJ 591, 1220

McWilliam, A., Preston, G. W., Sneden, C., \& Searle, L. 1995, AJ 109, 2757

Pagel, B. E. J., Nucleosynthesis and Chemical Evolution of Galaxies. Cambridge University Press, 1997

Martínez-Pinedo, G. Kelic, A., Langanke, K., Schmidt, K. -H., Mocelj, D., Fröhlich, C., Thielemann, F. -K., Panov, I., Rauscher, T., Liebendörfer, M., Zinner, T.N., Pfeiffer, B., Buras, R. \& Janka, H. -Th. 2006, in International Symposium on Nuclear Astrophysics, astro-ph/0608490

Nomoto, K., Tominaga, N., Umeda, H., Kobayashi, C. \& Maeda, K. 2006, Nuclear Physics A 777, 424

Norris, J. E., Ryan, S. G. \& Beers, T. C. 1997, ApJ 488, 350

Qian, Y. -Z. \& Wasserbug, G., J. 2003, ApJ 588, 1099

Qian, Y. -Z. 2005, Nuclear Physics A 752, 550 
R Development Core Team 2006, R: A language and environment for statistical computing. R Foundation for Statistical Computing, http://www.R-project.org/

Reimers, D. 1990 The Messenger, 60, 13

Rolfs, C. E. \& Rodney W. S. Cauldrons in the Cosmos. The University of Chicago Press, 1988

Rossi, S., Beers, T. C., Sneden, C., Sevastyanenko, T., Rhee, J. \& Marsteller, B. 2005, AJ 130,2804

Ryan, S., Norris, J. E., \& Beers, T. C. 1996, ApJ 471, 254

Schlattl, H., Cassisi, S., Salaris, M. \& Weiss, A. 2002, A\&A 395, 77

Simmerer, J., Sneden, C., Cowan, J., Woolf, V. \& Lawler, J. 2004, ApJ 617, 1901

Sivarani, T., Bonifacio, P., Molaro, P., Cayrel, R., Spite, M., Spite, F., Plez, B., Andersen, J., Barbuy, B., Beers, T. C., Depagne, E., Hill, V., François, P., Nordström, B. \& Primas, F. 2004, A\&A 413, 1073

Sneden, C., Preston, G. W., McWilliam, A. \& Searle, L. 1994, ApJ 431, L27

Sneden, C., McWilliam, A., Preston, G. W., Cowan, J. J. \& Burris, D. L. 1996, ApJ 467,819

Sneden, C., Cowan, J. J., Lawler, J. E., Ivans, I. I., Burles, S., Beers, T. C., Primas, F., Hill, V., Truran, J. W., Fuller, G. M., Pfeiffer, B. \& Kratz, K. -L. 2003, ApJ 591, 936

Sneden, C. 2004, Mem. S.A.It. 75, 267

Truran, J. W. 1981, A\&A 97, 391

Truran, J. W., Cowan, J. J., Pilachowski, C. A. \& Sneden, C. 2002, PASP 114, 1293

Venn, K. A., Irwin, M., Shetrone, M. D., Tout, C. A., Hill, V. \& Tolstoy, E. 2004, AJ 128,1177

Wanajo, S. \& Ishimaru, Y. 2006, Nuclear Physics A 777, 676 
Ward, J. H. 1963, Journal of the American Statistical Association, Vol. 58, no 301

Wasserburg, G. J., Busso, M., Gallino, R., \& Raiteri, C. M. 1994, ApJ 424, 412

Wasserburg, G. J., Busso, M. \& Gallino, R. 1996, ApJ 466, L109

Weiss, A., Schlattl, H., Salaris, M. \& Cassisi, S. 2004, A\&A 422, 217

Westin, J., Sneden, C., Gustafsson, B. \& Cowan, J. J. 2000, ApJ 530, 783

Winckler, N., Dababneh, S., Heil, M., Käppeler, F., Gallino, R. \& Pignatari, M. 2006, ApJ 647, 685

Wisotzki, L., Köhler, T., Groote, D. \& Reimers, D. 1996, A\&AS 115, 227

Wisotzki, L., Christlieb, N., Bade, N., Beckmann, V., Köhler, T., Vanelle, C. \& Reimers, D. 2000, A\&A 358, 77

Zhang, H. W. \& Zhao, G. 2005, MNRAS 364, 712 


\section{APENNDICE}





\section{A. FERRAMENTAS ESTATÍSTICAS}

\section{A.1 Agrupamento hierárquico}

\section{A.1.1 Introdução}

Agrupamento (Clustering) é uma forma de classificação não supervisionada de padrões (observações, conjunto de dados, vetores) em grupos. O método de agrupamento tem aplicações nas mais diversas áreas do conhecimento, pois pode tratar dados sem conhecimento prévio de sua origem ou de qualquer resultado esperado. Assim, este tipo de análise organiza uma coleção de dados em diferentes grupos baseado em suas similaridades e se presta a formar conglomerados cujos elementos guardem a maior semelhança possível entre si, segundo o número de variáveis desejado.

As principais componentes do agrupamento são:

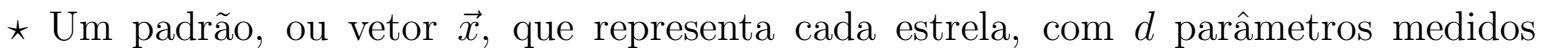
$\left\{x_{1}, x_{2}, \ldots, x_{d}\right\}$

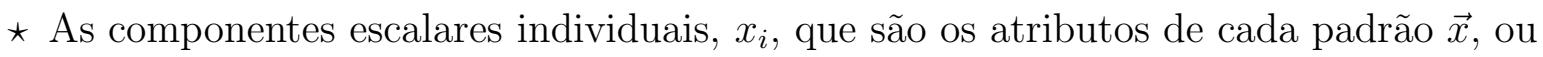
seja, a metalicidade e as abundâncias elementais analisadas na seção 4.5;

* A dimensão $d$ de cada padrão, que representa o número de abundâncias calculadas para cada estrela;

* Uma série de padrões $\left\{x_{1}, x_{2}, \ldots, x_{n}\right\}$, que forma uma matriz de padrões $n \mathrm{x} d$, que é o arquivo de entrada para executar o agrupamento;

* Critério de parecença entre os padrões (distância euclidiana - ver seção A.1.2) e;

* Método de separação dos grupos (Método de Ward - ver seção A.1.2).

Existem dois grandes tipos de agrupamento de dados: os Hierárquicos (aglomerativos) e os Particionais (divisivos). No agrupamento hierárquico, a condição inicial é a de que 
cada padrão (estrela) forme um grupo ( $n$ grupos) e, a partir das medidas de distância e método de separação, os objetos se aglomeram em $n-1, n-2 \ldots$, até que reste apenas um grupo que contém todos os padrões. Já os agrupamentos particionais agem de forma inversa: a condição inicial é um grupo contendo todos os $n$ padrões e a condição final são $n$ grupos com um padrão cada. Neste trabalho foi utilizado a forma aglomerativa para a análise.

A seguir é mostrado um algorítmo simples que ilustra a parte computacional do agrupamento:

01. O número de grupos é igual ao número de padrões. São calculadas as distâncias em $d$ dimensões entre todos os pares possíveis;

02. Utilizando o método de agrupamento, um dos pares forma um novo grupo, restanto agora $n-1$ grupos;

03. As distâncias são atualizadas e uma nova comparação é feita;

04. Os passos 02 e 03 são repetidos até que reste apenas um grupo contendo todos os padrões.

A figura A.1 mostra um exemplo de agrupamento aglomerativo em duas dimensões. O painel esquerdo mostra a dispersão dos dados em relação às duas variáveis a serem analisadas e o painel direito mostra o diagrama de árvore (dendrograma) gerado pelo agrupamento. O dendrograma é construído a partir do algoritmo mostrado acima, e ilustra como se distribuem os objetos em relação aos seus grupos. A partir do dendrograma, podese ter uma idéia da forma como os padrões se agrupam, e então determinar o local onde será feito um "corte" no dendrograma, afim de determinar um número de grupos razoável, de acordo com os resultados da análise, como mostrado na seção 4.5.

\section{A.1.2 Critério de parecença e método de Ward}

Uma das componentes necessárias para realizar os agrupamentos é o tipo da métrica e da medida de distância, que determinará quão similar serão os elementos. Isto influencia não só a formação dos grupos, mas também sua forma, visto que o comportamento das 


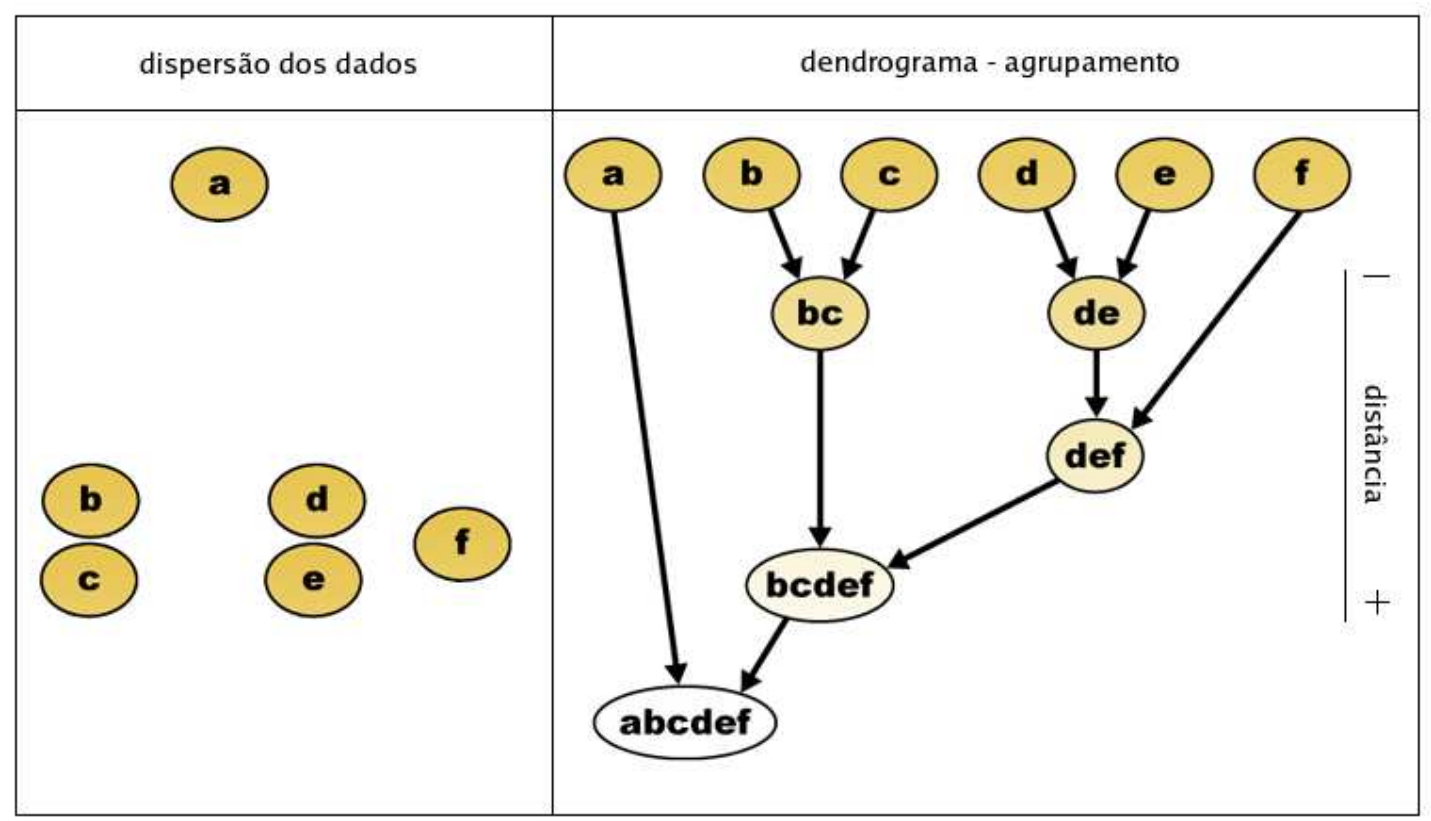

Fig. A.1 Exemplo de agrupamento hierárquico em duas dimensões. A figura do lado esquerdo mostra a dispersão dos dados e do lado direito é mostrado o dendrograma do agrupamento. Figura adaptada de http://en.wikipedia.org/.

distâncias não é sempre o mesmo (ver Jain et al. 1999 para uma revisão sobre determinação de distâncias). Para os agrupamentos da seção A.1.2 a métrica utilizada foi a euclidiana.

A distância Euclidiana funciona como medida de dissimilaridade, pois considera que quanto maior a distância obtida, mais diferentes são as estrelas em relação às variáveis consideradas. Outro fato importante para a escolha da métrica se deve ao fato de que as variáveis que foram utilizadas no agrupamento estão normalizadas ${ }^{1}$.

Define-se a distância euclidiana entre dois pontos $P=\left(p_{1}, p_{2}, \ldots, p_{n}\right)$ e $Q=\left(q_{1}, q_{2}, \ldots, q_{n}\right)$, num espaço de $n$ dimensões, como:

$$
d_{p q}=\sqrt{\left(p_{1}-q_{1}\right)^{2}+\left(p_{2}-q_{2}\right)^{2}+\ldots+\left(p_{n}-q_{n}\right)^{2}}=\sqrt{\sum_{i=1}^{n}\left(p_{i}-q_{i}\right)^{2}}
$$

onde $d_{p q}$ pode ser, por exemplo, a distância entre a estrela $p$ e o centróide do seu grupo $q$, em relação a $n$ variáveis. De maneira análoga, pode-se determinar distâncias euclidianas entre estrelas, centróides de grupos ou até mesmo distâncias médias.

\footnotetext{
${ }^{1}$ utilizando a notação [A/B], onde os valores são normalizados pelo equivalente solar (ver discussão sobre abundâncias na seção 3.2).
} 
Para realizar a separação dos grupos foi utilizado o método de Ward, que tende a formar grupos mais homogêneos, pois utiliza o método ESS (Error Sum of Squares - Ward 1963) para agrupar os objetos. Esta relação funcional mostra qual é a "perda de informação" que ocorre para cada combinação do agrupamento, e sua forma é dada a seguir:

$$
E S S=\sum_{i=1}^{n} x_{i}^{2}-\frac{1}{n}\left(\sum_{i=1}^{n} x_{i}\right)^{2}
$$

onde $x_{i}$ é o valor da distância entre os objetos. Em seguida, é feita a comparação entre as combinações e a formação de um novo grupo é dada pelo ponto mínimo da função objetivo.

\section{A.2 Probabilidades e correlações}

\section{A.2.1 Coeficiente de correlação}

É possível medir o grau de correlação entre duas variáveis medidas $X$ e $Y$ utilizandose o coeficiente de correlação de Pearson. Supõe-se um número $n$ de medidas das duas variáveis, e que ambas se comportem de acordo com uma distribuição normal. A correlação de Pearson indica a "força" de uma relação linear $(y=a \cdot x+b)$ entre as variáveis, porém, deve-se tomar precauções quanto à sua validade, pois diferentes distribuições de medidas podem gerar coeficientes de correlação semelhantes.

A figura A.2 ilustra este fato, onde, para os quatro conjuntos de dados, os valores médios de $x$ e $y$ são os mesmos, bem como a equação para os ajustes lineares e o coeficiente de correlação de Pearson. Portanto, faz-se necessário o uso de um critério que julgue a qualidade dos coeficientes calculados. Neste trabalho o critério utilizado foi o valor- $p$ (seção A.2.2). No entanto, mesmo utilizando o teste de qualidade, deve-se lembrar que a correlação não implica que as variáveis partilhem uma relação causal. O uso deste coeficiente se presta a auxiliar no início de uma análise exploratória de dados, mostrando eventuais tendências que podem ser posteriormente exploradas.

Assim, o coeficiente de correlação pode ser escrito como:

$$
r_{x y}=\frac{\sum\left(x_{i}-\bar{x}\right)\left(y_{i}-\bar{y}\right)}{(n-1) s_{x} \cdot s_{y}}
$$

onde $s_{x}$ e $s_{y}$ representam, respectivamente, as raízes quadradas das variâncias de $x$ e $y$, que podem ser escritas da forma: 


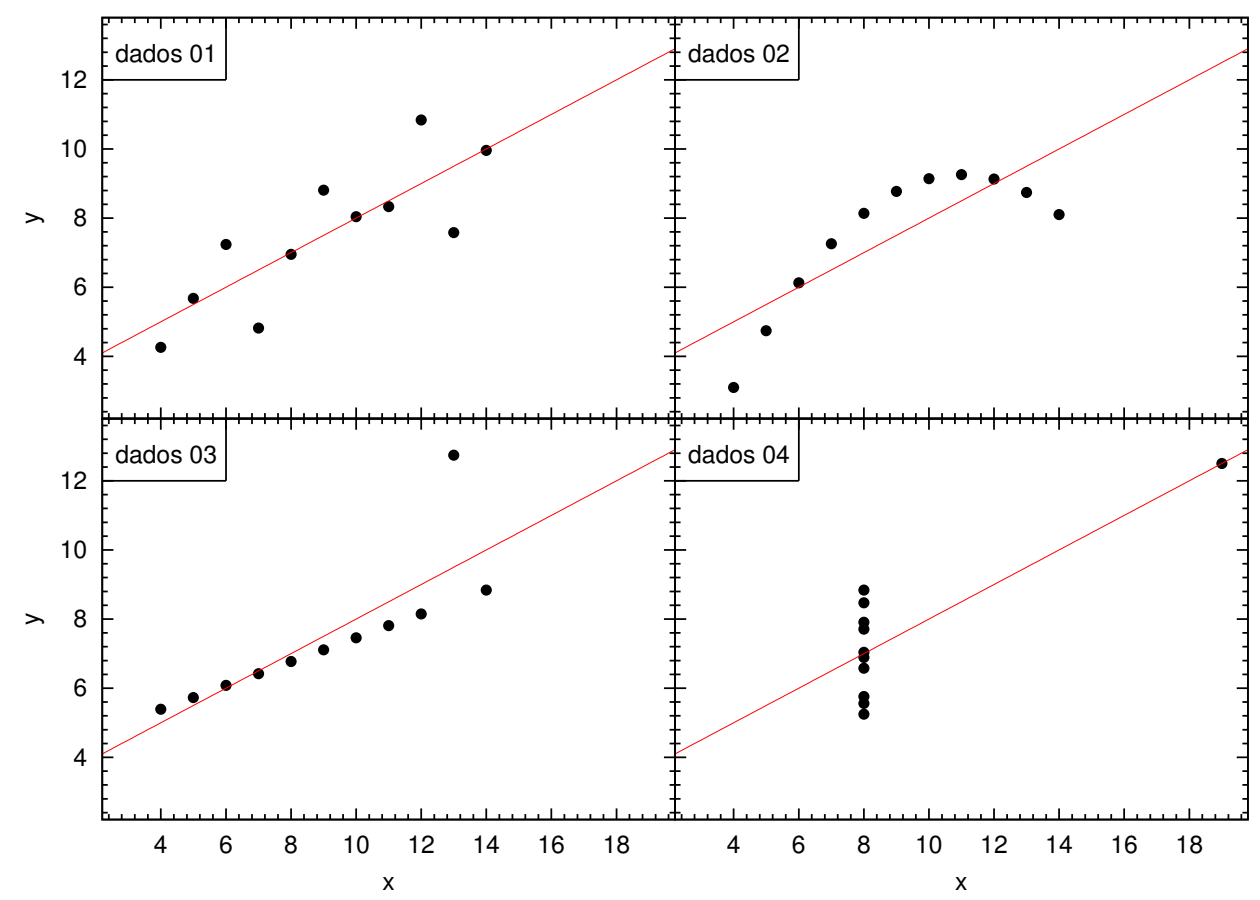

Fig. A.2 Quatro conjuntos de dados distintos podem fornecer os mesmos valores médios, ajustes lineares $(y=3.0+0.5 x)$ e coeficientes de correlação (0.82) (Anscombe 1973).

$$
s_{x}=\sqrt{\frac{1}{N-1} \sum_{i=1}^{N}\left(x_{i}-\bar{x}\right)^{2}} \text { e } s_{y}=\sqrt{\frac{1}{N-1} \sum_{i=1}^{N}\left(y_{i}-\bar{y}\right)^{2}},
$$

onde $\left\{x_{1}, x_{2}, \ldots, x_{N}\right\}$ e $\left\{y_{1}, y_{2}, \ldots, y_{N}\right\}$ são as variáveis medidas, e $\bar{x}$ e $\bar{y}$ são os valores médios. Feitas as devidas substituições das equações A.4 em A.3 tem-se:

$$
r_{x y}=\frac{n \sum x_{i} y_{i}-\sum x_{i} \sum y_{i}}{\sqrt{n \sum x_{i}^{2}-\left(\sum x_{i}\right)^{2}} \sqrt{n \sum y_{i}^{2}-\left(\sum y_{i}\right)^{2}}} .
$$

A equação A.5 admite valores no intervalo [-1:1], sendo que quanto mais distante de zero é o valor do coeficiente, maior é a correlação entre as variáveis de interesse. A tabela A.1 mostra os coeficientes de correlação entre todas as abundâncias elementais presentes na amostra. O esquema de cores se presta a facilitar a identificação dos coeficientes de maior valor em módulo, os quais indicam variáveis que possuem maior correlação entre si. Nota-se que o conjunto dos elementos formados por captura de nêutrons e o carbono possuem os coeficientes de maior valor. 
Table A.1. Matriz de Correlação para as abundâncias elementais. O esquema de cores

refere-se aos seguintes intervalos: $|r| \geq 0.8,0.6 \leq|r|<0.8,0.5 \leq|r|<0.6$ e $|r|<0.5$

\begin{tabular}{|c|c|c|c|c|c|c|c|c|c|c|c|c|c|c|c|c|c|c|c|c|c|c|}
\hline$[\mathrm{X} / \mathrm{Fe}]$ & {$[\mathrm{Fe} / \mathrm{H}]$} & $\mathrm{C}$ & $\mathrm{Mg}$ & $\mathrm{Al}$ & $\mathrm{Ca}$ & $\mathrm{Sc}$ & $\mathrm{Ti}$ & $\mathrm{V}$ & $\mathrm{Cr}$ & $\mathrm{Mn}$ & $\mathrm{Co}$ & $\mathrm{Ni}$ & $\mathrm{Zn}$ & $\mathrm{Sr}$ & $\mathrm{Y}$ & $\mathrm{Zr}$ & $\mathrm{Ba}$ & $\mathrm{La}$ & $\mathrm{Ce}$ & $\mathrm{Nd}$ & $\mathrm{Sm}$ & $\mathrm{Eu}$ \\
\hline$[\mathrm{Fe} / \mathrm{H}]$ & 1.00 & & & & & & & & & & & & & & & & & & & & & \\
\hline $\mathrm{C}$ & 0.39 & 1.00 & & & & & & & & & & & & & & & & & & & & \\
\hline $\mathrm{Mg}$ & -0.16 & 0.27 & 1.00 & & & & & & & & & & & & & & & & & & & \\
\hline $\mathrm{Al}$ & -0.15 & -0.17 & 0.45 & 1.00 & & & & & & & & & & & & & & & & & & \\
\hline $\mathrm{Ca}$ & 0.22 & 0.63 & 0.57 & 0.08 & 1.00 & & & & & & & & & & & & & & & & & \\
\hline $\mathrm{Sc}$ & -0.05 & 0.39 & 0.51 & 0.27 & 0.56 & 1.00 & & & & & & & & & & & & & & & & \\
\hline $\mathrm{Ti}$ & 0.19 & 0.52 & 0.45 & 0.00 & 0.67 & 0.61 & 1.00 & & & & & & & & & & & & & & & \\
\hline $\mathrm{V}$ & 0.08 & 0.51 & 0.14 & -0.15 & 0.45 & 0.49 & 0.47 & 1.00 & & & & & & & & & & & & & & \\
\hline $\mathrm{Cr}$ & 0.66 & 0.41 & -0.05 & -0.12 & 0.30 & 0.13 & 0.35 & 0.62 & 1.00 & & & & & & & & & & & & & \\
\hline $\mathrm{Mn}$ & 0.51 & -0.01 & -0.21 & 0.10 & -0.18 & -0.09 & -0.06 & -0.02 & 0.44 & 1.00 & & & & & & & & & & & & \\
\hline $\mathrm{Co}$ & -0.39 & 0.31 & 0.27 & 0.07 & 0.19 & 0.43 & 0.38 & 0.60 & -0.10 & -0.11 & 1.00 & & & & & & & & & & & \\
\hline $\mathrm{Ni}$ & -0.29 & -0.09 & 0.10 & 0.13 & -0.16 & 0.11 & 0.03 & -0.05 & -0.19 & 0.07 & 0.42 & 1.00 & & & & & & & & & & \\
\hline $\mathrm{Zn}$ & -0.75 & -0.03 & -0.05 & -0.31 & -0.46 & -0.23 & 0.22 & 0.17 & 0.00 & 0.21 & 0.48 & 0.59 & 1.00 & & & & & & & & & \\
\hline $\mathrm{Sr}$ & 0.42 & 0.47 & 0.15 & -0.05 & 0.47 & 0.09 & 0.45 & 0.01 & 0.30 & 0.09 & -0.01 & -0.08 & -0.15 & 1.00 & & & & & & & & \\
\hline Y & 0.30 & 0.69 & 0.28 & -0.07 & 0.62 & 0.38 & 0.60 & 0.19 & 0.22 & -0.06 & 0.12 & -0.01 & -0.30 & 0.82 & 1.00 & & & & & & & \\
\hline $\mathrm{Zr}$ & 0.26 & 0.78 & 0.31 & -0.44 & 0.66 & 0.23 & 0.60 & 0.42 & 0.16 & -0.12 & 0.35 & 0.15 & 0.30 & 0.82 & 0.84 & 1.00 & & & & & & \\
\hline $\mathrm{Ba}$ & 0.48 & 0.70 & 0.24 & 0.05 & 0.60 & 0.32 & 0.47 & 0.12 & 0.33 & 0.08 & 0.00 & -0.12 & -0.54 & 0.74 & 0.74 & 0.80 & 1.00 & & & & & \\
\hline $\mathrm{La}$ & 0.10 & 0.87 & -0.01 & -0.47 & 0.57 & 0.40 & 0.59 & 0.60 & 0.46 & -0.20 & 0.10 & -0.15 & 0.11 & 0.71 & 0.82 & 0.74 & 0.90 & 1.00 & & & & \\
\hline $\mathrm{Ce}$ & -0.04 & 0.88 & 0.31 & -0.48 & 0.71 & 0.52 & 0.59 & 0.52 & 0.63 & -0.56 & 0.19 & -0.48 & 0.04 & 0.78 & 0.81 & 0.91 & 0.85 & 0.96 & 1.00 & & & \\
\hline $\mathrm{Nd}$ & -0.06 & 0.81 & 0.07 & -0.56 & 0.54 & 0.51 & 0.59 & 0.63 & 0.44 & -0.22 & 0.54 & -0.19 & 0.32 & 0.79 & 0.83 & 0.74 & 0.89 & 0.99 & 0.94 & 1.00 & & \\
\hline $\mathrm{Sm}$ & -0.41 & 0.57 & 0.11 & -0.62 & 0.60 & -0.09 & 0.79 & 0.38 & 0.47 & -0.68 & 0.25 & -0.20 & 0.53 & 0.26 & 0.60 & 0.88 & 0.13 & 0.84 & 0.85 & 0.92 & 1.00 & \\
\hline $\mathrm{Eu}$ & 0.01 & 0.59 & 0.13 & -0.37 & 0.40 & 0.29 & 0.46 & 0.38 & 0.10 & -0.31 & 0.37 & 0.01 & -0.13 & 0.66 & 0.66 & 0.64 & 0.81 & 0.84 & 0.51 & 0.89 & 0.82 & 1.00 \\
\hline
\end{tabular}




\section{A.2.2 Valor- $p$}

O valor- $p$, utilizado em testes de hipóteses, é a probabilidade de que uma dada amostra ou conjunto de dados possa ter sido extraída de uma população sendo testada, admitindo que a hipótese nula ${ }^{2}$ seja verdadeira. Em termos práticos, é um número que reflete a probabilidade de que um certo resultado estatístico ocorra por chance, e não por manipulação de dados.

No decorrer deste trabalho, o valor- $p$ foi utilizado para medir a qualidade dos coeficientes de correlação (detalhes na seção A.2.1) entre a metalicidade, abundância de carbono e abundância dos elementos formados por captura de nêutrons (ver figura 4.1). O esquema de símbolos utilizado no gráfico é mostrado na tabela A.2:

\begin{tabular}{cc}
\hline \hline Símbolo & valor $-p$ \\
\hline$* * *$ & $0.1<p \leq 1.0$ \\
$* *$ & $0.05<p \leq 0.1$ \\
$*$ & $0.01<p \leq 0.5$ \\
$\cdot$ & $0.001<p \leq 0.01$ \\
& $0.0<p \leq 0.001$ \\
\hline
\end{tabular}

Tab. A.2 Esquema de símbolos para o valor- $p$ dos coeficientes de correlação.

\footnotetext{
${ }^{2}$ Hipótese que é presumida verdadeira até que testes estatísticos indiquem o contrário. Em alguns casos pode ser representada pelo valor médio.
} 